VAGNER ALBQUERQUE DE LIMA

\title{
USO DAS TÉCNICAS HCT E TDR NO MONITORAMENTO DO PROCESSO DE CONSOLIDAÇÃO EM RESERVATÓRIOS DE BARRAGENS DE REJEITOS
}

Dissertação de Mestrado apresentada à Escola de Engenharia de São Carlos, da Universidade de São Paulo, como parte integrante dos requisitos para a obtenção do Título de Mestre em Geotecnia.

Área de Concentração: Geotecnia Orientador: Prof. Dr. Edmundo Rogério Esquivel 

FOLHA DE JULGAMENTO

Candidato: Engenheiro VAGNER ALBUQUERQUE DE LIMA.

Dissertação defendida e julgada em 25/09/2009 perante a Comissão Julgadora:
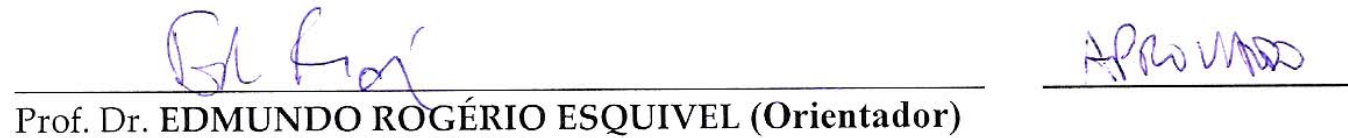

(Escola de Engenharia de São Carlos/USP)
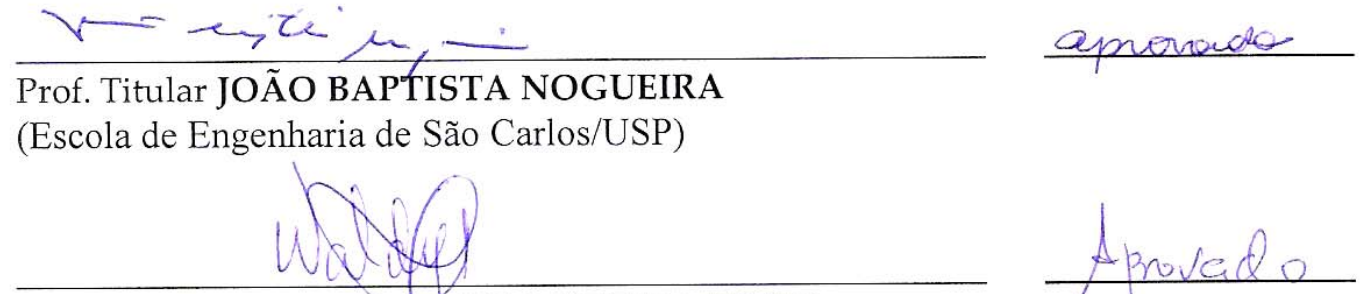

Prof. Dr. WALDYR LOPES DE OLIVEIRA FILHO

(Universidade Federal de Ouro Preto/UFOP)

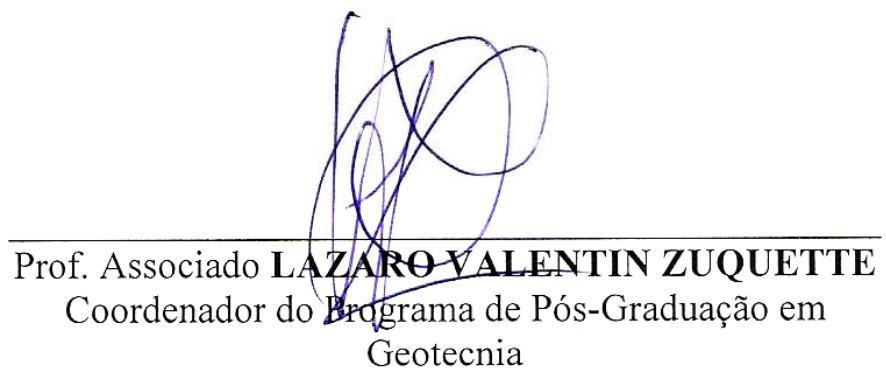

Geotecnia

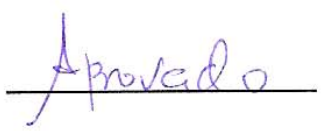
rof. Associado LAZARO

Coordenador do Brotgrama de Pós-Graduação em

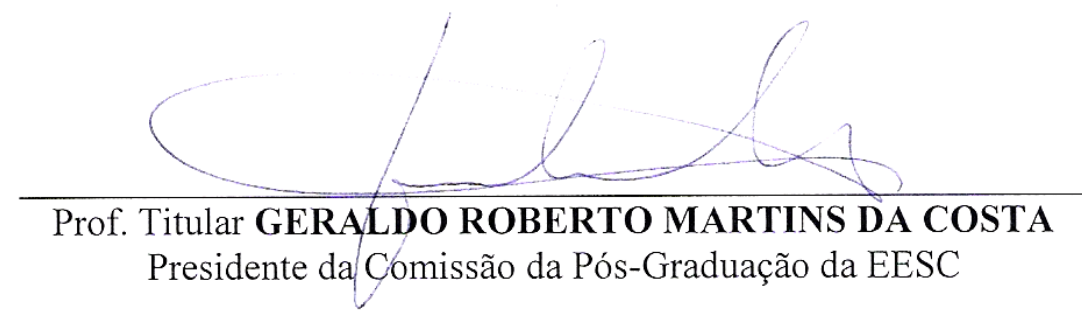





\section{Dedicatória}

\section{À DEUS PRIMEIRAMENTE, POR TER ME DADO ESSA VIDA MARAVILHOSA.}

Ao meu pai Alcir Santos de Lima e minha mãe Francisca Albuquerque de Lima pelo amor incondicional, confiança $e$ eternos exemplos e ensinamentos. Devo tudo o que sou a vocês. Muito obrigado por tudo. Obrigado por sempre estarem presente na minha vida. Amo vocês.

A minha irmã, Larissa Albuquerque de Lima, pelo amor, apoio e proteção que sempre teve comigo desde os tempos de escola. Você sempre será minha proteção

Aos meus avós Maximiniano Santos de Lima (in memorian) $e$ Maria Santos de Lima por toda a participação na minha vida. Vocês são responsáveis pelo cidadão que me tornei.

Aos meus tios Severino Alexandrino Santos de Lima e Edmilson Santos de Lima, por terem me dado tão boa influência nessa carreira que optei. A vocês dedico o profissional que sou.

Às minhas tias Maria Cleide de Lima (in memorian)e Rogéria Maria Santos de Lima vocês tiveram participação decisiva para o bom andamento do meu mestrado. Muito obrigado por todo o incentivo.

Ao professor, mestre e amigo Edgard Ramalho Dantas por ter me iniciado na pesquisa acadêmica. Ao senhor devo todos os frutos obtidos nesta vida acadêmica. Tenho o senhor como exemplo de vida e agradeço a Deus por ter te colocado na minha trajetória de vida. Você sempre será o meu mestre. 



\section{Agradecimentos}

Ao Professor Edmundo Rogério Esquivel, pela orientação, participação sempre presente em todas as etapas da pesquisa e por ter me proporcionado este tema de pesquisa que me abriu tantas portas maravilhosas.

Aos Professores do Departamento de Geotecnia da Escola de Engenharia de São Carlos, que tanto contribuíram para a minha evolução nesta área.

Aos amigos e símbolos de espelhamento Osvaldo de Freitas Neto e Fagner França, que tanto contribuíram com o meu mestrado, incentivando, dando conselhos e auxiliando nos momentos mais difíceis do mestrado.

Aos meus amigos da turma de mestrado Aline, Sergio, Kelly, Daniela Cenci, Daniela Ide, Juliana, Wilson, Leonardo e Elaine por toda a convivência durante o mestrado.

Aos técnicos e amigos: Oscar Neto, José Luiz e o Sr. Antônio, que tanto me ajudaram na parte experimental da pesquisa. Devo toda a minha parte experimental a vocês, muito obrigado.

A CNPq pela bolsa de estudo fornecida durante todo o período do mestrado.

A empresa MJundu, na pessoa do Geólogo Noedir Nava por te dado todo o apoio na realização dos ensaios nas dependências da empresa. Agradeço também ao técnico em mineração Evando Couto pelo acompanhamento durante todas as visitas a Mineração Jundu.

Ao professor Glauco Tulio Pessa Fabbri, pelo fornecimento do programa que realizou a comunicação entre o aquisitor de dados e o computador. Quero lembrar do bolsista de iniciação cientifica Carlos Eduardo que realizou as modificações necessárias no programa garantindo assim o correto funcionamento da automatização do sistema.

A Pimenta de Ávila Consultoria por ter me acolhido tão bem durante a fase final do meu mestrado, dando todo o apoio possível para a conclusão deste mestrado. 

"Os dias prósperos não vêm por acaso; nascem de muita fadiga e persistência”. 

LIMA, V. A. Uso das técnicas HCT e TDR no monitoramento do processo de consolidação em reservatórios de barragens de rejeitos. 2009. 145f. Dissertação de Mestrado - Departamento de Geotecnia, Escola de Engenharia de São Carlos, Universidade de São Paulo.

A indústria de mineração gera uma vasta quantidade de rejeitos que são comumente depositados em reservatórios ou lagoas de contenção. Para dimensionar adequadamente estas construções, quando o rejeito é altamente compressível, é necessário estudar as características de consolidação deste material através de técnicas que contemplem grandes deformações. Este trabalho teve como objetivo implantar a técnica HCT (Hydraulic Consolidation Test) nos laboratórios do Departamento de Geotecnia da EESC-USP e consolidar a utilização da técnica TDR (Time Domain Reflectometry). Também teve como objetivo avaliar o processo de consolidação de rejeitos argilosos contidos em uma barragem com o uso de técnicas de laboratório (HCT) e de campo (TDR). Nos ensaios de laboratório foi utilizada a técnica HCT, enquanto que em campo foi utilizada a técnica TDR. Em laboratório, realizaram-se ensaios com amostras coletadas na região do vertedouro e do canal de lançamento de rejeitos. Foram realizadas diversas análises com estas amostras utilizando a técnica HCT, tendo como resultado uma pequena variação nos parâmetros de consolidação obtidos. Através destes parâmetros foi calculada a curva de compressibilidade de laboratório. A técnica TDR fez uso de uma sonda desenvolvida especialmente para este fim, sendo realizada uma calibração previa em laboratório com o material da barragem. A técnica TDR apresentou, de forma instantânea, a estimativa do teor de umidade para as sondagens realizadas na barragem de rejeitos. Com os resultados da técnica TDR, os índices de vazios foram calculados por correlações e, por fim, calculadas as tensões efetivas atuantes em cada profundidade estudada, gerando uma curva de compressibilidade de campo. Pode-se então comparar as curvas de compressibilidade de laboratório e campo obtendo-se uma grande proximidade entre os valores. Conclui-se que ambas as técnicas são validas para avaliação do processo de consolidação de materiais moles em barragens de rejeitos.

Palavras Chave: Rejeitos, Consolidação, HCT e TDR 

Abstract

LIMA, V. A. Monitoring of consolidation process in deposits of tailings dam by TDR and HCT techniques. 2009. 145f. Dissertação de Mestrado - Departamento de Geotecnia, Escola de Engenharia de São Carlos, Universidade de São Paulo.

The mining industry generates a large amount of tailing, which is usually placed in tailing dams. To properly design these constructions, when the tailing is highly compressible, it is necessary to study the consolidation characteristics of this material by means of techniques that consider large deformations. This study aimed to establish the technique HCT (Hydraulic Consolidation Test) in the laboratories of the Department of Geotechnical Engineering, EESC-USP and consolidate the use of the technique TDR (Time Domain Reflectometry). This research work also aimed to evaluate the process of consolidation of clayey tailings through laboratory and field tests. For laboratory tests it was used the Hydraulic Consolidation Test (HCT) whereas field tests used the Time Domain Reflectrometry (TDR) technique. The laboratory tests were carried out with samples collected in the spillway and next to the discharge spigot. Several analyses were performed using the HCT technique. The analysis results showed very little variations in the consolidation parameter values. The compressibility curve was determined using these consolidation parameters. The TDR tests were carried out using a probe specifically designed for this purpose. Laboratory calibration was performed with samples collected in the dam. One advantage of the TDR technique is to provide in real time estimates of the soil water content. With the water content profiles provided by the TDR technique, void ratio and effective stress profiles were determined using correlations obtained in laboratory, enabling to find a field compressibility curve. Then, the laboratory and field compressibility curves were compared, showing them very close to each other. It was concluded that both techniques are valid for evaluating the process of consolidation of soft materials in tailings dams.

Keywords: Tailing, Consolidation, HCT and TDR. 



\section{Lista de Figuras}

Figura 2.1 - Evolução no tempo das atividades relativas a barragens de rejeitos (modificado -

Gordon,1998)

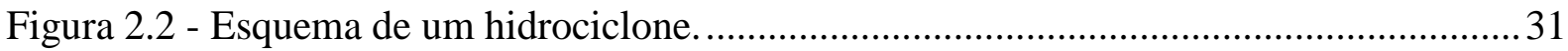

Figura 2.3 - Método construtivo de montante (modificado - Vick 1983). ............................... 33

Figura 2.4 - Método construtivo de jusante (modificado - Vick 1983).................................... 35

Figura 2.5 - Método construtivo de Linha de Centro (modificado - Vick 1983)..................... 37

Figura 2.6 - Comparação de volumes para os três tipos de barragens: (a) método de montante,

(b) método de Jusante e (c) método de linha de centro (modificado - Vick 1983).... 39

Figura 2.7 - Sistemas de coordenadas: (a) Sistema de coordenada lagrangeana no instante $t=0$;

(b) sistema de coordenada euleriana no instante $t$; (c) sistema de coordenada material

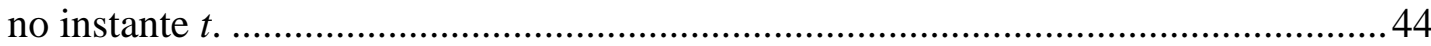

Figura 2.8 - Equilíbrio de um elemento de solo. ................................................................... 46

Figura 2.9 - Componentes constituintes de um equipamento que utiliza a técnica TDR

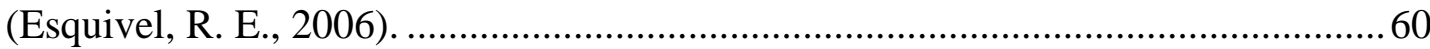

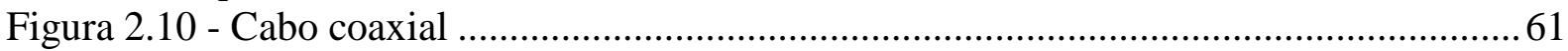

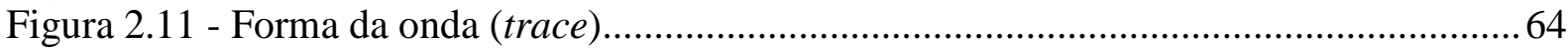

Figura 2.12 - Método das tangentes (Klemunes Jr., 1998) ...................................................66

Figura 2.13 - Principais equipamentos TDR comerciais: 1502C (a), TRIME-FM (b), TRASE

System I (c), TDR100 (d) (Jones et al., 2002). ...........................................................66

Figura 2.14 - Diferentes configurações de sondas (Jones et al., 2002). .................................67

Figura 3.1 - Local de coleta das amostras: (a) mapa geológico do local de lançamento do rejeito na lagoa; (b) e (c) detalhes da coleta da amostra do vertedouro; (d) e (e) detalhes da coleta no local no lançamento dos rejeitos (espigotamento)....................72

Figura 3.2 - Esquema geral do equipamento para a realização do Ensaio HCT ....................... 81

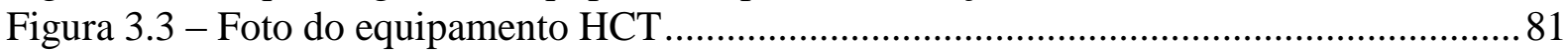

Figura 3.4 - Câmara de Adensamento: (a) Célula triaxial modificada, (b) Sulcos na face da base da célula da amostra e (c) Itens que vão no topo da amostra: papel filtro, pedra

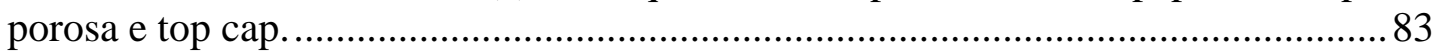

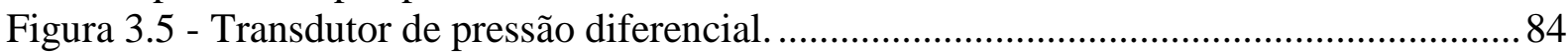

Figura 3.6 - Interface de Pressão : (a) Foto da Interface e (b) Esquema da Interface.............. 85

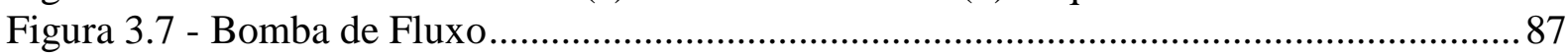

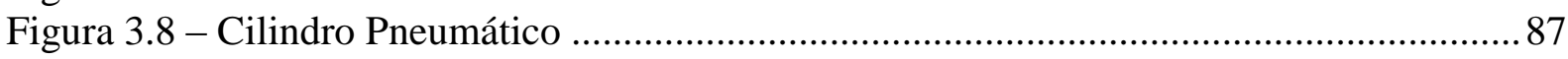

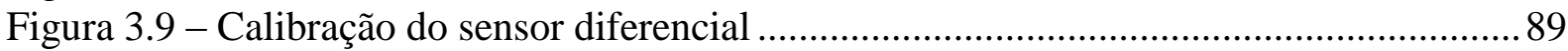

Figura 3.10 - Procedimento de determinação do $e_{00}$ : (a) amostra adensando por peso próprio, (b) retirada da lamina superficial com pipeta, (c) retirada lamina superficial com auxílio da bomba de fluxo e (d) coleta de amostras para determinação do teor de umidade.

Figura 3.11 - Preparação da amostra na câmara de consolidação: (a) colocação da amostra com auxílio de um funil, (b) colocação da pedra porosa e do Top Cap com auxílio de fios de nylon e (c) amostra pronta para o fechamento da câmara triaxial..................96

Figura 3.12 - Procedimento falho de colocação da sobrecarga em material sem resistência vindo diretamente da planta de beneficiamento (a) e (b) colocação da sobrecarga sem amortecimento inicial da carga e (c) ao tocar a amostra o conjunto pedra porosa e Top Cap inclinam. 
Figura 3.13 - Esquema do testador de cabos da marca Tektronix ${ }^{\circledR} 1502 \mathrm{C}$. ........................... 98

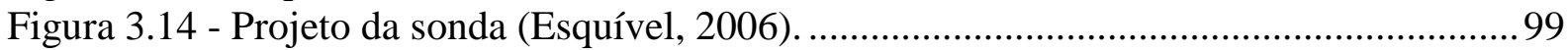

Figura 3.15 - Detalhes construtivos da sonda (Esquível, 2006)............................................99

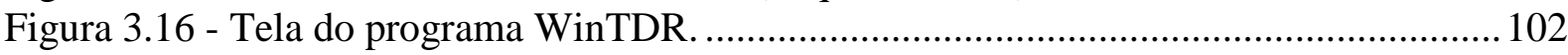

Figura 3.17 - Etapas da Calibração: (a) Coleta das amostras próximo ao vertedouro da lagoa, (b) adição gradativa de água, (c) homogeneização do material, (e) determinação do teor de umidade gravimétrico, Peso do conjunto e (f) leitura da Constante dielétrica aparente. 104

Figura 3.18 - Detalhe do ensaio de Campo: (a) Equipamentos utilizados em campo, (b) Planta baixa do vertedouro e (c) Corte do vertedouro....................................................... 106

Figura 4.1 - Curva granulométrica das amostras de rejeitos. ............................................. 110

Figura 4.2 - Etapa de consolidação hidráulica (amostra vertedouro)...................................112

Figura 4.3 - Etapa de consolidação hidráulica (amostra espigotamento). ............................. 113

Figura 4.4 - Ensaio de condutividade hidráulica por carregamentos incrementais

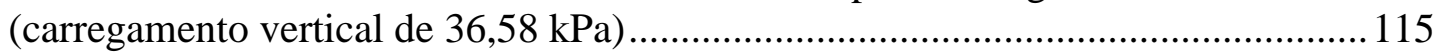

Figura 4.5 - Ensaio de condutividade hidráulica por carregamentos incrementais

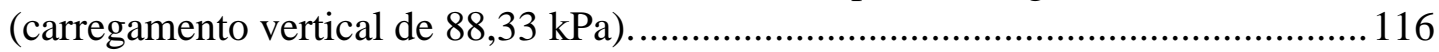

Figura 4.6 - Ensaio de condutividade hidráulica por carregamentos incrementais (carregamento vertical de 18,05 kPa) ............................................................. 117

Figura 4.7 - Ensaio de condutividade hidráulica por carregamentos incrementais

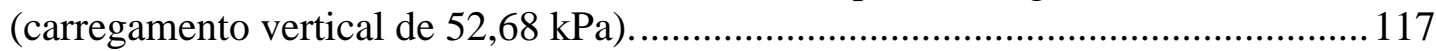

Figura 4.8 - Curvas de compressibilidade (amostra vertedouro) ....................................... 122

Figura 4.9 - Curvas de condutividade hidráulica (amostra vertedouro) ................................ 123

Figura 4.10 - Curvas de compressibilidade (amostra espigotamento) ................................... 124

Figura 4.11 - Curvas de condutividade hidráulica (amostra espigotamento) ......................... 125

Figura 4.12 - Curva de Calibração da Sonda TDR com o rejeito.........................................126

Figura 4.13 - Valores de teores de umidade estimados pela técnica TDR. .......................... 128

Figura 4.14 - Comparação dos resultados obtidos em laboratório e campo........................... 130

Figura 4.14 - Comparação entre os teores e umidade gravimétrico e estimado pela técnica

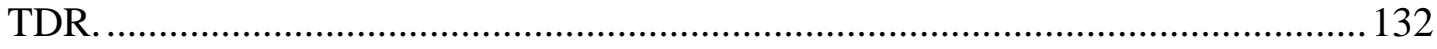




\section{Lista de Tabelas}

Tabela 4.1 - Resultados dos ensaios de caracterização.

Tabela 4.2 - Resultados experimentais da etapa de consolidação hidráulica (amostra vertedouro)

Tabela 4.3 - Resultados dos ensaios de condutividade hidráulica.

Tabela 4.4 - Combinações para as análises de determinação dos parâmetros constitutivos. .119

Tabela 4.5 - Dados de entrada para o programa SICTA

Tabela 4.6 - Parâmetros constitutivos determinados a partir das análises.

Tabela 4.7 - Parâmetros constitutivos determinados a partir das análises.

Tabela 4.8 - Resultados das sondagens.

Tabela 4.9 - Resultados das sondagens.

Tabela 4.10 - Verificação da técnica TDR em campo 



\section{Lista de Símbolos}

- $\varepsilon$-Constante dielétrica do meio

- $\varepsilon_{a r}-$ Constante dielétrica do ar

- $\varepsilon_{\mathrm{s}}$ - Constante dielétrica das partículas solidas do solo

- $\varepsilon_{\mathrm{w}}$ - Constante dielétrica da água

- $\xi$ - Coordenada euleriana

- $\sigma$ - Tensão total

- $\sigma^{\prime}$ - Tensão efetiva

- $\sigma^{\prime} b-$ Tensão efetiva na base da amostra

- $\sigma_{L}^{\prime}$ - Tensões efetivas verticais incrementais para a etapa de condutividade hidráulica

- $\rho$ - Massa específica do solo

- $\rho_{d}$ - Massa especifica seca do solo

- $\rho_{s}$ - Massa específica dos sólidos

- $\rho_{w}$ - Massa específica da fase fluida

- $\gamma_{s}$ - Peso específico dos sólidos

- $\gamma_{\text {Sat }}$ - Peso específico saturado

- $\gamma_{w}$ - Peso específico da água

- $\Theta$ - Teor de umidade volumétrica

- $\Delta P_{L}$ - Diferença de pressão entre o topo e a base para a etapa de condutividade hidráulica

- $\Delta P_{S}$ - Diferença de pressão entre o topo e a base para a etapa de consolidação

- $a$ - Coordenada lagrangeana

- $A, B, Z, C$ e $D$ - Coeficientes empíricos determinados experimentalmente 
- $A_{s}$ - Área da seção transversal da amostra

- $C$ - Velocidade da luz no vácuo $\left(3 \times 10^{8} \mathrm{~m} / \mathrm{s}\right)$

- Cc - Indíce de compressão

- $C_{m}$ - Constante de calibração do testador de cabos

- $C_{v}$ - Coeficiente de variação

- $e$-Índice de vazios

- $e_{0}$ - Índice de vazios inicial

- $e_{00}$ - Índice para tensão efetiva nula

- $e_{L}$ - Índice de vazios para a etapa de condutividade hidráulica

- EP - Erro padrão

- $H_{L}$ - Altura da amostra para para a etapa de condutividade hidráulica

- $H$ - Altura da amostra

- $H_{f}$ - Altura final do corpo de prova

- $H_{\mathrm{o}}$ - Altura inicial do corpo de prova

- Hs - Altura dos sólidos

- $I_{P}$ - Índice de plasticidade

- $k$ - condutividade hidráulica

- $K a$ - Constante dielétrica aparente medida pelo testador de cabos

- $k_{L}$ - Coeficiente de condutividade hidráulica para a etapa de condutividade hidráulica

- $L$ - Comprimento

- $L_{a}$ - Comprimento aparente da sonda

- $n$ - Número de amostras

- $n$ - Porosidade do sistema

- $q$ - Vazão através da amostra 
- $t$ - tempo

- $u$ - Poro pressão

- $u_{e}$ - Excesso de poro pressão

- $u_{s}$ - Poropressão estática

- $u_{w}$ - Poropressão

- $\bar{v}_{s}$ - Velocidade aparente da fase sólida

- $\bar{v}_{w}$ - Velocidade aparente do fluido

- $v$ - Velocidade de propagação do pulso

- $V_{m}$ - Volume total do elemento

- $V_{p}$ - Relação entre a velocidade real de propagação do pulso e a velocidade da luz

- $V_{p}$ - Velocidade do pulso

- $V_{s}$ - Volume de sólidos

- $V_{v}$ - Volume de vazios

- $V_{w}$ - Volume da fase fluida

- $W_{d}$ - Peso seco da amostra

- $W_{m}$ - Peso total do elemento

- $W_{s}$ - Peso dos sólidos

- $W_{w}$ - Peso do fluído

- $w$ - Teor de umidade gravimétrico

- $w_{L}, w_{P}$ - Limites de liquidez e de plasticidade

- $w_{T D R}-$ Teor de umidade estimado pela técnica TDR

- $z$ - coordenada material 

2.1 Métodos de disposição de rejeitos.

2.1.1 Métodos de separação das frações do rejeito ...................................................................... 31

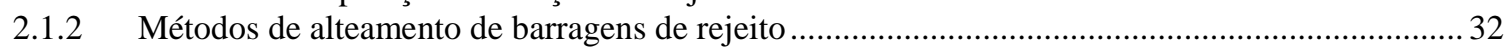

2.1.3 Comparação do volume utilizado nos métodos de alteamentos de barragens de rejeito.................38

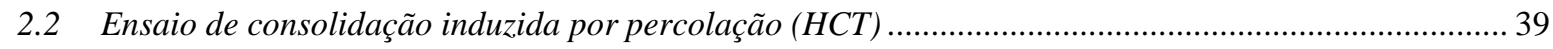

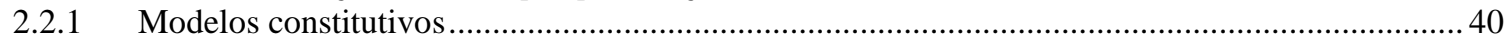

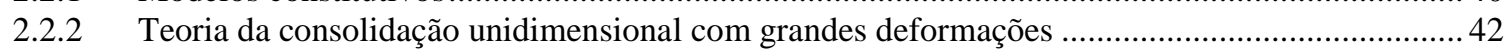

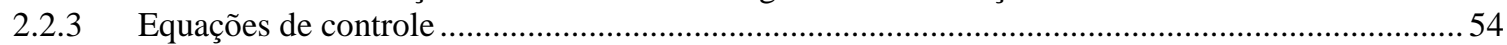

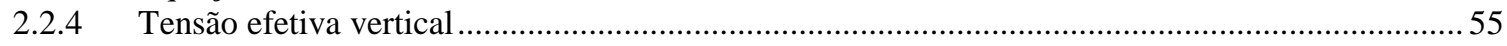

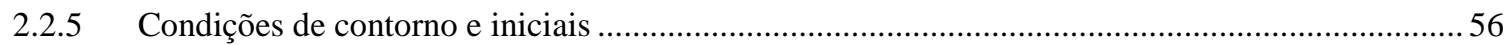

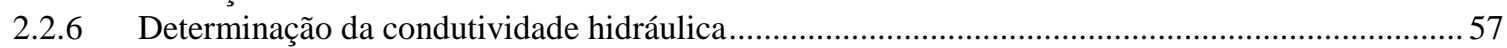

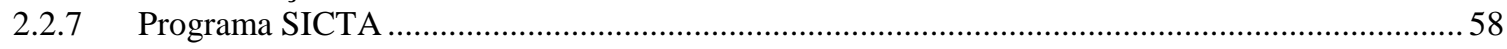

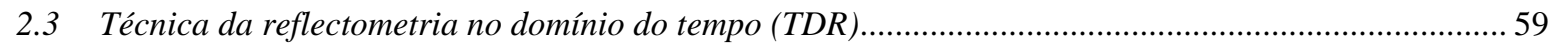

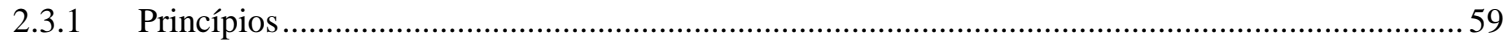

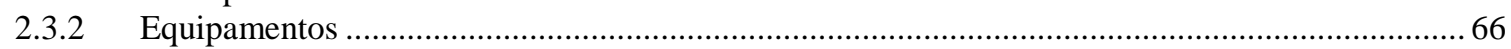

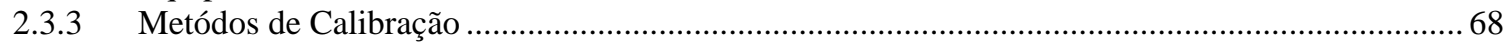

2.3.4 Fatores que afetam a determinação da constante dielétrica aparente .......................................69

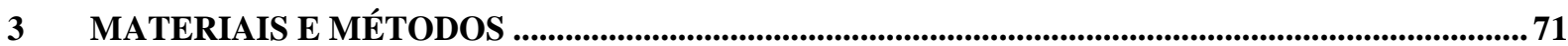

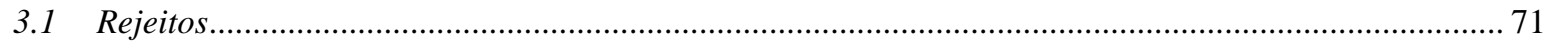

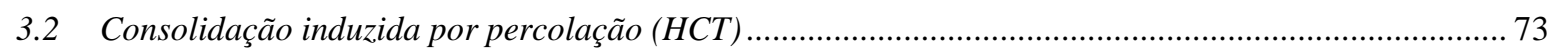

3.2.1 Base do procedimento para a determinação dos parâmetros de consolidação ............................. 73

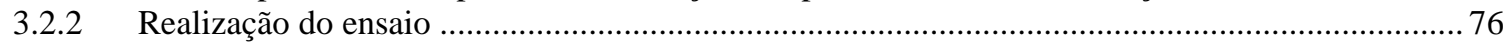

3.2.3 Determinação dos parâmetros constitutivos do processo de consolidação.................................. 77

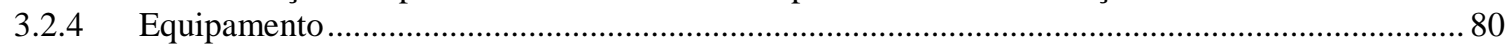

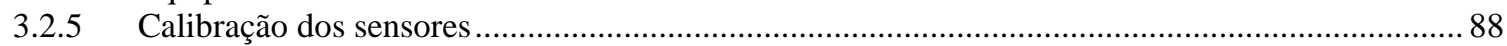

3.2.6 Recomendações operacionais do equipamento que realiza o ensaio HCT ...............................90

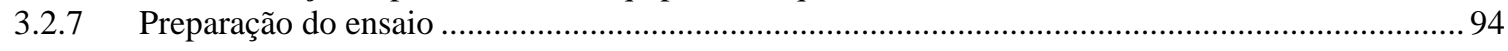

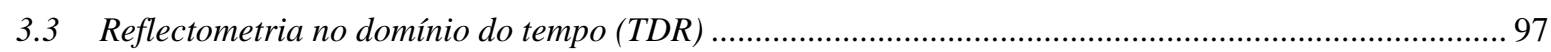

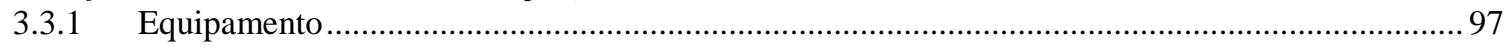

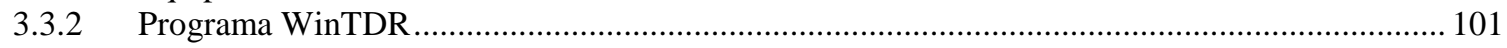

3.3.3 Calibração da sonda helicoidal em laboratório ................................................................... 102

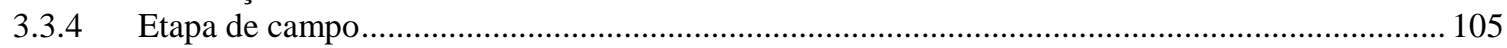

3.3.5 Relações entre índices de vazios e tensões efetivas determinadas utilizando-se a técnica TDR. 106

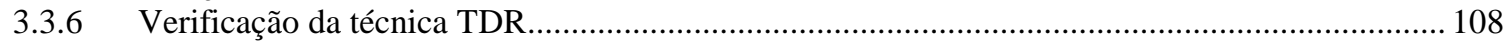

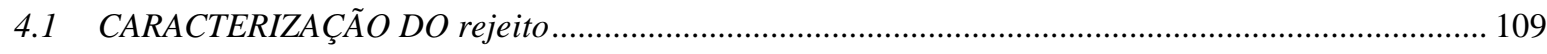

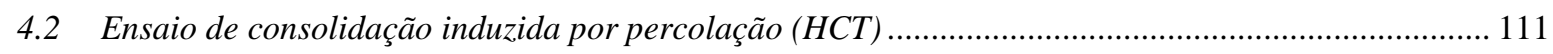

4.2.1 Consolidação induzida por percolação .............................................................................. 111

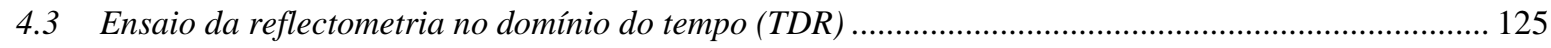




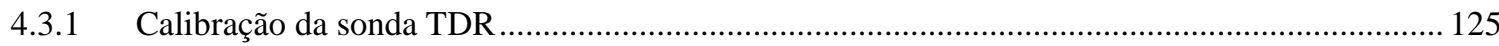

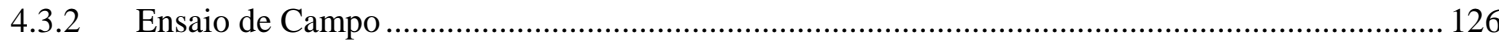

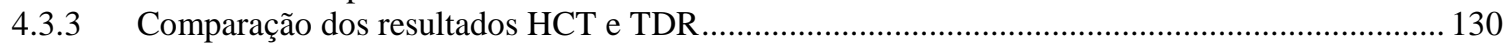

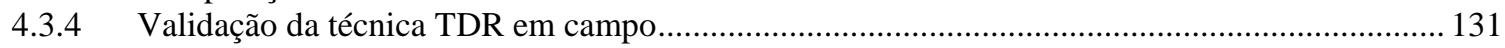

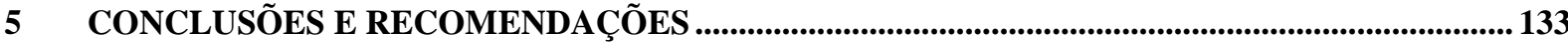

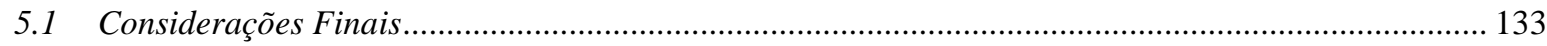

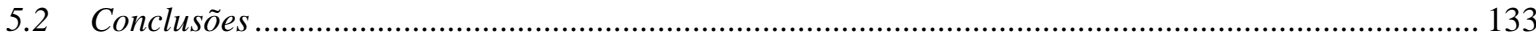

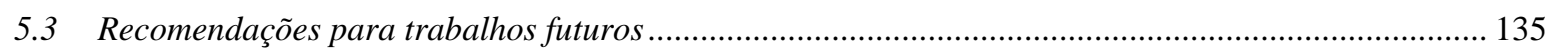

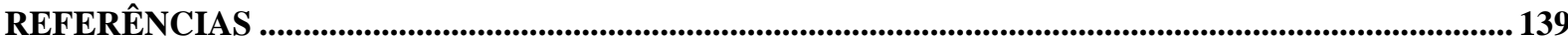




\section{INTRODUÇÃO}

Os rejeitos produzidos pela indústria da mineração ganham cada vez mais importância pelo seu elevado volume de produção. Estes rejeitos geralmente são dispostos em sistemas de armazenamento (e.g. diques, cavas e barragens), cujo perfeito funcionamento é fundamental para a continua realização das atividades de mineração. Dessa forma, os reservatórios necessitam de um adequado dimensionamento. Adicionalmente, se o rejeito produzido for de textura argilosa, este dimensionamento dependerá da previsão da consolidação deste material. Com o tempo, está consolidação liberará mais espaço útil na barragem, para novos lançamentos de rejeito.

Para a previsão de consolidação dos rejeitos, a teoria clássica de Terzaghi ou a teoria de deformações finitas utilizam-se de parâmetros que são determinados em laboratório. Contudo técnicas expeditas podem ser usadas para determinar tais parâmetros e inferir o comportamento de consolidação do rejeito. Atualmente estão sendo pesquisadas técnicas de campo rápidas e que apresentem resultados imediatos.

A teoria clássica de Terzaghi não é adequada para a previsão do processo de consolidação de solos altamente compressíveis. Nestes solos são esperados grandes deslocamentos em relação à espessura inicial da camada em análise. A teoria de Terzaghi admite as seguintes hipóteses: pequenas deformações, relação linear entre índice de vazios e tensão efetiva e coeficiente de condutividade hidráulica constante. Estas hipóteses são extremamente restritivas uma vez que a teoria de Terzaghi foi criada para prever o 
comportamento de materiais onde ocorrem apenas pequenas deformações, como é o caso de fundações de edifícios. Portanto, para o caso de solos altamente compressíveis, é essencial que a teoria de consolidação unidimensional não linear para grandes deformações seja usada. A análise do processo de consolidação deve ser realizada por teorias que contemplem deformações finitas tais como a de Mikasa (1963) e a de Gibson et al. (1967). Pane e Schiffman (1981) demonstraram que estas teorias são equivalentes. A única diferença entre elas é que a teoria de Mikasa utiliza coordenadas lagrangeanas e a teoria de Gibson é expressa em termos de coordenadas materiais.

As principais vantagens das teorias de deformações finitas para o estudo da consolidação de solos altamente compressíveis são: não ter restrições quanto às deformações do material, permitir a consideração de coeficientes de condutividade hidráulica variáveis e considerar uma relação linear ou não linear entre índice de vazios e tensão efetiva. As teorias citadas requerem o conhecimento dos parâmetros de consolidação, os quais podem ser determinados, entre outros processos, através do ensaio de consolidação induzida por forças de percolação, também conhecido como Hydraulic Consolidation Test (HCT), proposto inicialmente por Imai (1979). Com esses parâmetros de consolidação pode-se determinar as curva de compressibilidade e a curva de condutividade hidráulica do rejeito. Embora este ensaio laboratorial seja confiável, a consideração da variabilidade dos materiais existentes num único reservatório de rejeitos exigiria a realização de uma grande quantidade de ensaios laboratoriais, tornando o procedimento demorado e altamente antieconômico.

Uma das maneiras de verificar o processo de consolidação é através da determinação de perfis de índices de vazios e de poro pressões em diferentes pontos da barragem de rejeitos. Uma forma expedita para realizar tal procedimento seria através da determinação de perfis de teores de umidade obtidos com uma ferramenta apropriada para tal fim. Uma destas ferramentas é a técnica TDR (Time Domain Reflectometry), utilizando uma 
sonda apropriada. A técnica TDR apresenta como principais vantagens ser rápida não destrutiva e permitir leituras contínuas em tempo real.

O presente estudo teve como finalidade determinar parâmetros de consolidação de um rejeito argiloso pela técnica HCT. Com estes parâmetros foi possível traçar curvas de compressibilidade que foram comparadas com a curva de compressibilidade determinada em campo com o auxílio da técnica TDR.

Parte deste estudo foi realizada numa lagoa de contenção de rejeito da empresa Mineração Jundu Ltda., localizada no município de Descalvado/SP. Um dos principais produtos produzidos por esta empresa é a areia quartzosa utilizada para a fabricação de vidros e em processos de fundição, sendo o rejeito deste material composto basicamente por argila. Por fim o rejeito coletado foi encaminhado para o Departamento de Geotecnia da Escola de Engenharia de São Carlos, onde foram realizados os estudos em laboratório. 


\section{REVISÃO BIBLIOGRÁFICA}

\subsection{MÉTODOS DE DISPOSIÇÃO DE REJEITOS}

O beneficiamento de minérios é o tratamento industrial que prepara granulometricamente, purifica ou enriquece minérios por métodos físicos ou químicos, sem alteração da constituição química dos minerais. O beneficiamento divide o mineral bruto em concentrado e rejeito. A parcela que não apresenta valor econômico é disposta como rejeito no sistema de armazenamento e é, comumente, contida por diques ou barragens.

Os rejeitos podem ser descartados da unidade de beneficiamento sob a forma sólida (pasta, torta ou granel) ou líquida (lama). Rotineiramente o transporte dos rejeitos na forma líquida é feito por meio de canaletas ou tubulações utilizando-se da ação da gravidade. Em situações de desnível desfavorável é efetuado o bombeamento. Existem técnicas de transporte a seco por meio de caminhões ou correias transportadoras, porém são pouco econômicas e somente se justificam no caso de volumes relativamente reduzidos.

Observa-se uma diversidade nos métodos de disposição de rejeitos. A disposição dos rejeitos pode ser feita a céu aberto, de forma subterrânea, ou subaquática. A disposição mais comum é a céu aberto, que pode ser feita em pilhas controladas ou em estruturas de contenção localizadas em bacias ou vales. A disposição subterrânea é feita em câmaras remanescentes da extração do minério. Os rejeitos são bombeados na maioria dos casos e depositados de forma a preencher essas câmaras. A disposição subaquática não é muito utilizada devido aos problemas ambientais que gera. Também existem métodos de disposições 
dos rejeitos vinculadas com os sistemas de extração do minério, utilizando-se a deposição subterrânea e a céu aberto. Nesse caso, os rejeitos formam camadas de fundação para os equipamentos de extração.

No Brasil, é comum a disposição dos rejeitos na forma de polpa, sendo contidos em vales por meio de barragens. Essas estruturas devem ter uma vida útil equivalente ao período de extração dos minerais. As atividades para instalação de uma barragem de rejeitos compreendem a procura do local, o projeto da instalação, a construção, a operação e o fechamento definitivo (Figura 2.1).

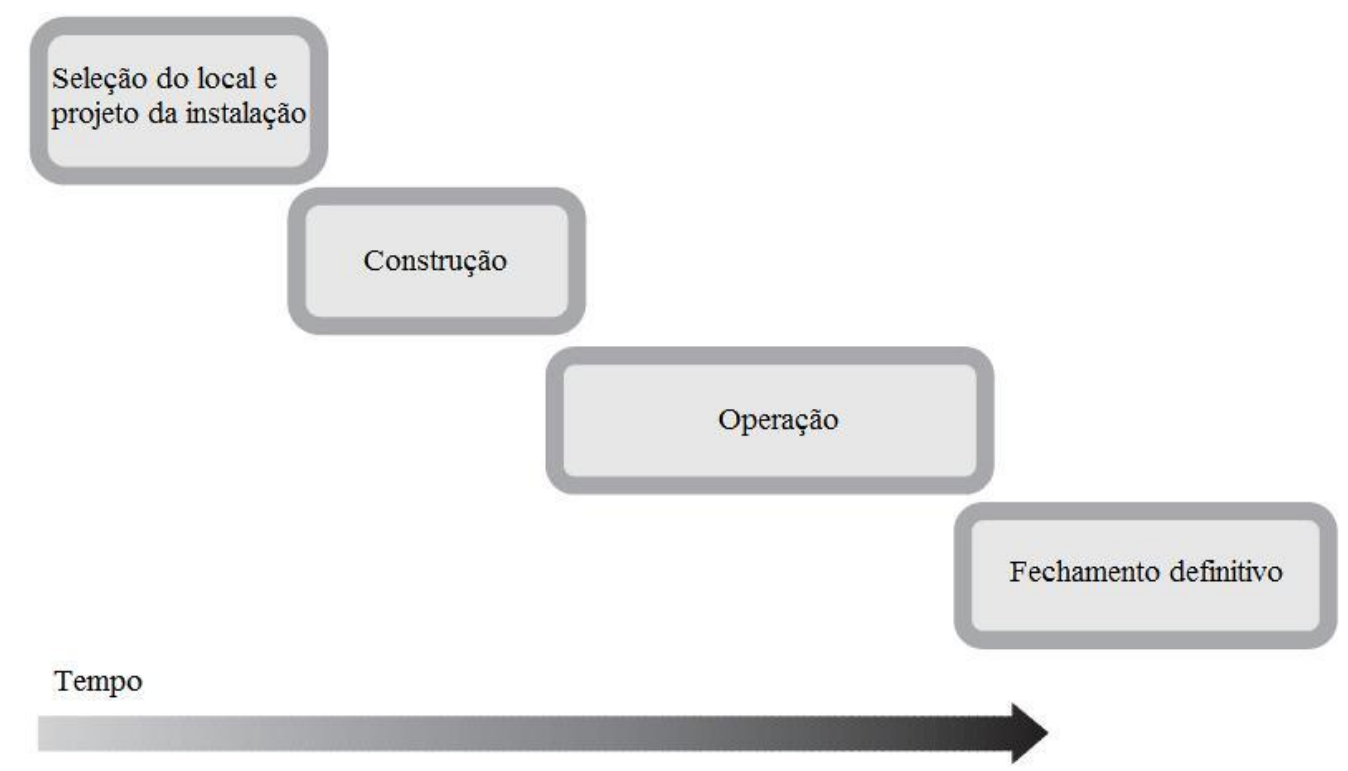

Figura 2.1 - Evolução no tempo das atividades relativas a barragens de rejeitos (modificado - Gordon,1998)

As barragens de rejeito podem ser construídas com material compactado proveniente de áreas de empréstimo, ou com material do próprio rejeito. Quando se utiliza o rejeito na construção da barragem, devem-se separar suas frações, pois as partículas finas são impróprias para o uso, devido a sua baixa resistência ao cisalhamento e sua alta compressibilidade. 


\subsubsection{Métodos de separação das frações do rejeito}

A separação das frações do rejeito é feita por dois métodos: espigotamento e o uso de hidrociclone. No espigotamento as partículas mais grossas sedimentam-se em locais mais próximos à descarga e as mais finas em locais mais distantes. Os hidrociclones são equipamentos que executam a separação das partículas por tamanho (Figura 2.2). A separação com uso do hidrociclone tem como resultado uma areia com 10 a $20 \%$ de partículas passando na peneira \# 200. A polpa que é injetada sob pressão, com porcentagem de sólidos préestabelecida segue uma trajetória helicoidal, onde as partículas mais grossas se direcionam para as paredes do hidrociclone devido à força centrípeta, e os finos se acumulam no centro do equipamento. $\mathrm{O}$ material mais grosseiro sai por baixo do equipamento - porção chamada de underflow, com pouca quantidade de água. As partículas finas transbordam do equipamento, misturados em água. Essa porção é chamada de overflow Araújo (2006).

Os rejeitos do underflow apresentam melhores características de resistência e condutividade hidráulica, sendo mais adequados para o uso como material de construção em alteamentos de barragens, comparados com o overflow.

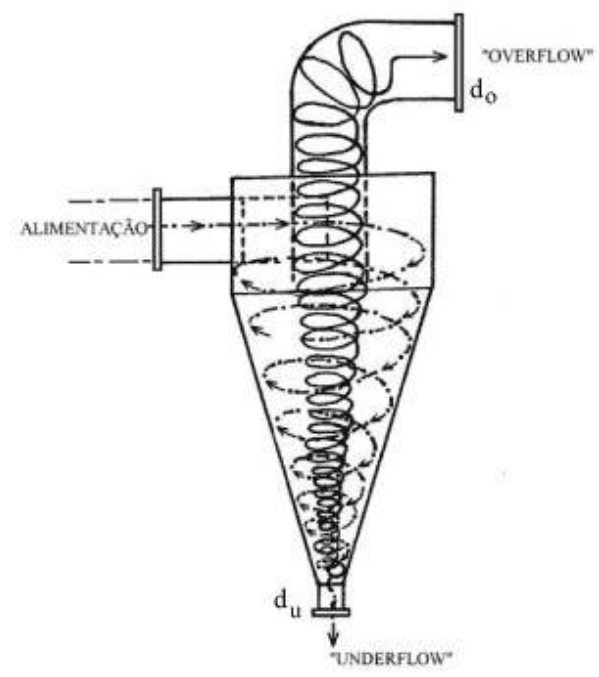

Figura 2.2 - Esquema de um hidrociclone. 


\subsubsection{Métodos de alteamento de barragens de rejeito}

As barragens de rejeito construídas ou alteadas com o próprio material de rejeito podem ser construídas pelos métodos de montante, de jusante e de linha de centro. Os rejeitos não são materiais ideais para a construção de barragens por apresentarem uma série de desvantagens, mas podem ser aproveitados pela grande disponibilidade como material de construção, o que desonera a obra. Entre os principais riscos relacionados à utilização de rejeito em barragens estão: susceptibilidade ao piping, liquefação, erobilidade superficial além de dificuldade na sua compactação. A seguir serão expostos os métodos de alteamento de barragens de rejeitos, citando-se suas características, especificações, vantagens e desvantagens.

\subsubsection{Método de montante}

O método de montante é o mais antigo, simples e econômico utilizado na construção de barragens de rejeito. A etapa inicial na execução deste tipo de barragem consiste na construção de um dique de partida, conforme a Figura 2.3a, normalmente de material argiloso ou enrocamento compactados. Depois de realizada esta etapa, a polpa é lançada por hidrociclones ou com uma sequência de tubulações menores perpendiculares à tubulação principal, chamados "spigots", que permitem uma melhor uniformidade na formação da praia. Como os rejeitos têm uma distribuição granulométrica ampla, as partículas mais grossas e mais pesadas sedimentam mais rapidamente, ficando nas zonas perto do dique formando, assim, a praia de deposição, a qual se tornará a fundação e eventualmente fornecerá material de construção para o próximo alteamento. Já as partículas menores e menos densas ficam em suspensão e são transportadas para as zonas periféricas da bacia de sedimentação. 


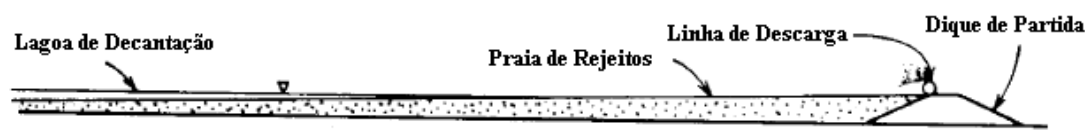

(a)

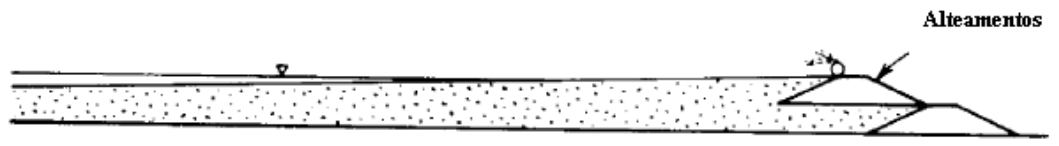

(b)

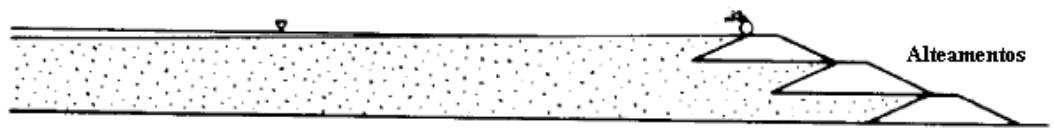

(c)

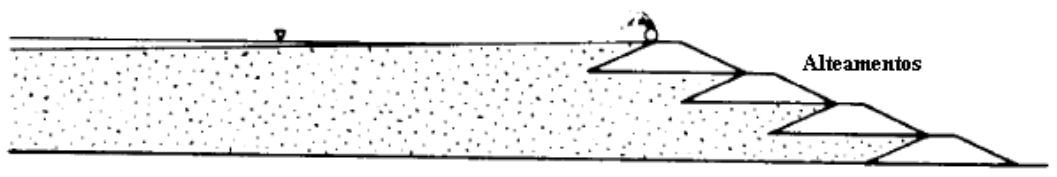

(d)

Figura 2.3 - Método construtivo de montante (modificado - Vick 1983).

Este processo continua sucessivamente até que a cota final prevista em projeto seja atingida, conforme visto na Figura 2.3d. Segundo Vick (1983), se os alteamentos forem construídos com rejeitos, faz-se necessário que esses contenham de 40 a 50\% de areia e que na descarga, a polpa seja de baixa taxa de sólidos por peso para que ocorra a segregação granulométrica. Tal porcentagem de sólidos pode ser obtida pela ciclonagem da polpa.

O método de montante para alteamento de barragens de rejeito é o mais econômico, pois permite obter a menor relação entre volumes de areia e de lama. Embora essa economia leve a uma grande utilização pela maioria das mineradoras, o método de montante apresenta um baixo controle construtivo, tornando-se crítica a segurança da barragem. O fator agravante neste caso está ligado ao fato dos alteamentos serem realizados sobre materiais previamente depositados e não consolidados. Assim, a fundação dos diques de montantes é formada por rejeitos (granulares) saturados e fofos, que tendem a apresentar baixa resistência ao cisalhamento e susceptibilidade à liquefação por carregamentos dinâmicos, especialmente em regiões de alta sismicidade (Troncoso, 1997). 
Outros tipos de ruptura passíveis de ocorrência em barragens de rejeitos construídas pelo método de montante são as rupturas por percolação e "piping", devido à pequena distância entre a lagoa de decantação e o talude de jusante. Esse problema pode ser evitado por meio de um controle de comprimento mínimo da praia de deposição junto à face de montante. Sistemas de drenagem e filtros (e.g tapetes drenantes) evitam aumentos excessivos de poropressões e controlam a poluição da água subterrânea, quando for necessário.

É necessário lembrar que, com esse método construtivo, existe uma dificuldade na implantação de um sistema interno de drenagem eficiente para controlar o nível d'água dentro da barragem. Esse fator constitui um problema adicional com reflexos na estabilidade da estrutura.

\subsubsection{Método de jusante}

O método de jusante foi desenvolvido com o objetivo de reduzir os riscos de colapsos que são comuns nas barragens construídas pelo método de montante. Consiste do alteamento para jusante do dique inicial. A construção poder ser feita empregando-se o próprio rejeito ou solos de áreas de empréstimo.

O procedimento de construção tem início com a construção de um dique inicial impermeável, o qual deve possuir uma drenagem interna, composta por filtro inclinado e tapete drenante. Depois de realizada esta etapa, os alteamentos subsequentes são realizados para jusante do dique de partida (Figura 2.4). A drenagem interna e a impermeabilização do talude a montante não são obrigatórias se os rejeitos possuírem características de alta condutividade hidráulica e ângulo de atrito elevado. 


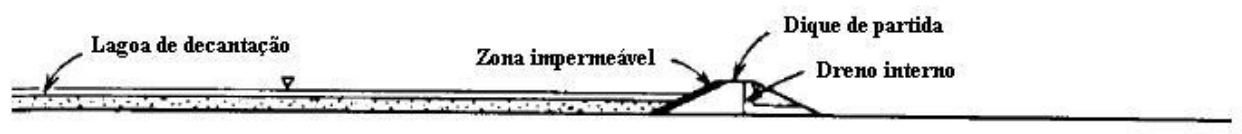

(a)

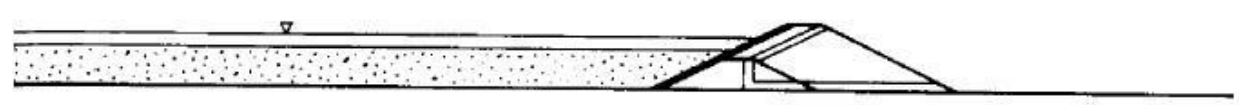

(b)

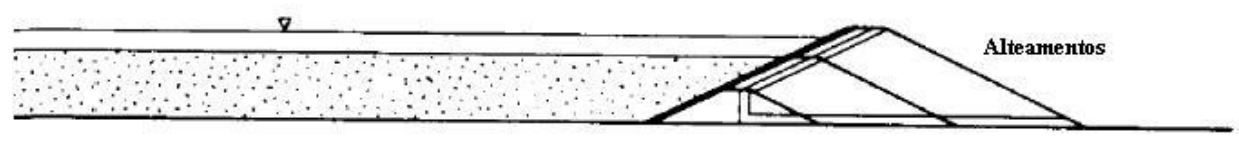

(c)

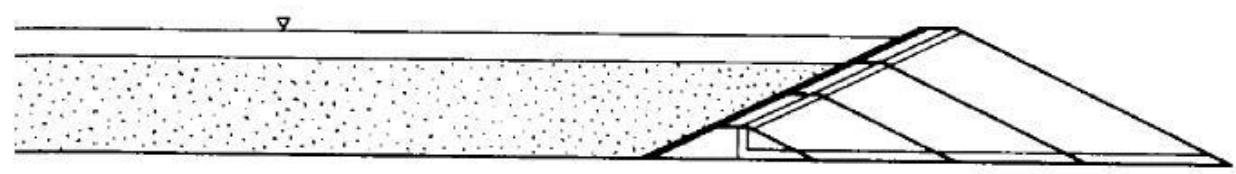

(d)

Figura 2.4 - Método construtivo de jusante (modificado - Vick 1983).

As vantagens e desvantagens do método de jusante estão apresentadas a seguir

(Nieble 1976, Burke 1973, Vick 1981-1983, Assis e Espósito 1995, Sanchez 2000).

Vantagens:

- O método é eficiente para o controle das superfícies freáticas, pela construção de sistemas contínuos de drenagem;

- Operação bastante simples;

- Possibilita a compactação de todo o corpo da barragem;

- Maior segurança devido aos alteamentos controlados (disposição da fração grossa dos rejeitos a jusante, sistemas de drenagem e compactação): as probabilidades de ocorrência de "piping" e de rupturas horizontais são muito menores;

- O material estéril proveniente da lavra pode ser utilizado, e/ou misturado nos alteamentos. 


\section{Desvantagens:}

- Necessidade de grandes quantidades de rejeitos nas primeiras etapas da construção;

- Dependendo das características dos rejeitos, podem ocorrer perdas de áreas, devido aos taludes serem bastante abatidos;

- Necessidade de sistemas de drenagem eficientes, havendo probabilidade de colmatação;

- Complexidade dos diques de partida e de enrocamento em relação à drenagem;

- Em zonas de alta precipitação é possível que os rejeitos a jusante não possam ser compactados adequadamente, devendo-se esperar épocas de pouca precipitação para a operação de equipamentos sobre os rejeitos;

- Não possibilita a proteção com cobertura vegetal no talude de jusante, e tampouco drenagem superficial durante a fase construtiva, devido à superposição dos rejeitos;

- É necessário o emprego de ciclones para garantir uma ótima separação dos rejeitos.

\subsubsection{Método de linha de centro}

Este tipo de alteamento apresenta condições intermediárias entre os outros tipos de alteamentos apresentados. Apesar disso, segundo Assis e Espósito (1995), o comportamento geotécnico desta barragem se assemelha mais ao tipo de barragem alteada para jusante, com uma variação no alteamento da crista que é realizado de forma vertical, sendo coincidente com o dique de partida. Outro ponto positivo neste método é a utilização de zonas de drenagem internas em todas as fases de alteamento, permitindo assim o controle da linha freática. 


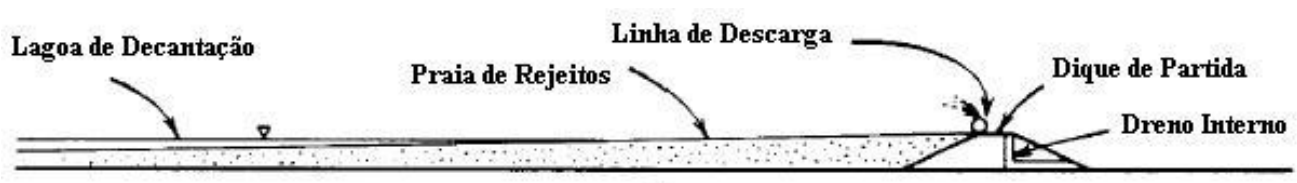

(a)

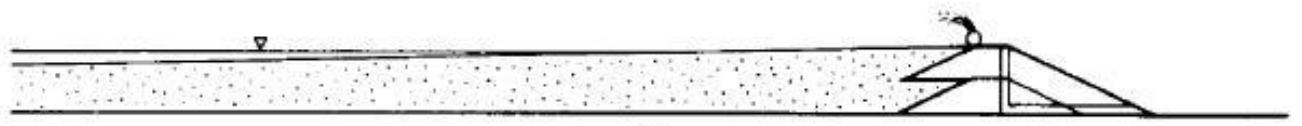

(b)

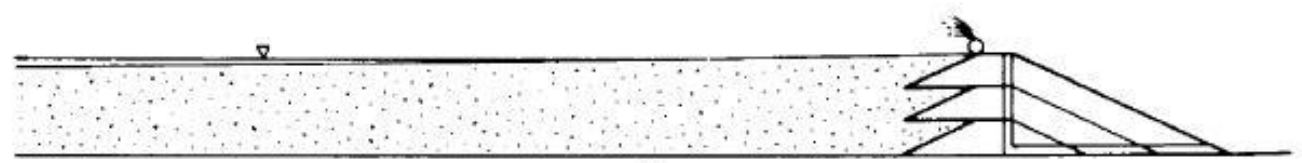

(c)

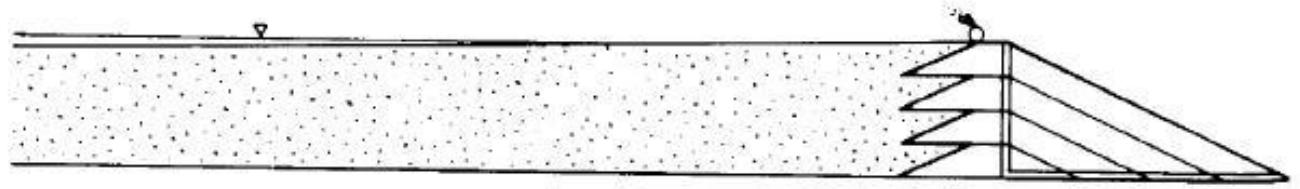

(d)

Figura 2.5 - Método construtivo de Linha de Centro (modificado - Vick 1983).

Troncoso (1997) afirma que este tipo de estrutura pode apresentar ângulos muito inclinados na face de montante. Como conseqüência, se a parte superior do talude eventualmente perder o confinamento, podem aparecer fissuras, causando problemas de erosão, e aumentos de poropressão.

Como vantagens e desvantagens, há uma combinação dos métodos de jusante e montante, descritos anteriormente.

Vantagens:

- Facilidade na construção;

- Eixo dos alteamentos constante,

- Redução do volume de "underflow", necessário em relação ao método da jusante. 
Desvantagens:

- Necessidade de sistemas de drenagem eficientes e sistemas de contenção a jusante (se o material de rejeito ficar saturado a jusante, a estabilidade do maciço poderá ser comprometida;

- Operação complexa (é necessário equipamento para deposição mecânica a jusante);

- Pela complexidade da operação, os investimentos globais podem ser altos.

\subsubsection{Comparação do volume utilizado nos métodos de alteamentos de barragens de rejeito}

Como grande vantagem do método de linha de centro em relação ao de jusante, pode-se destacar a necessidade de um menor volume de material compactado para a construção do corpo da barragem. O método de jusante tem as melhores características de estabilidade, porém o volume necessário de "underflow", material de empréstimo ou estéril da lavra, é três vezes o do método de montante (Figura 2.6), o que se relaciona, logicamente, com os custos do projeto total (Vick, 1993). 


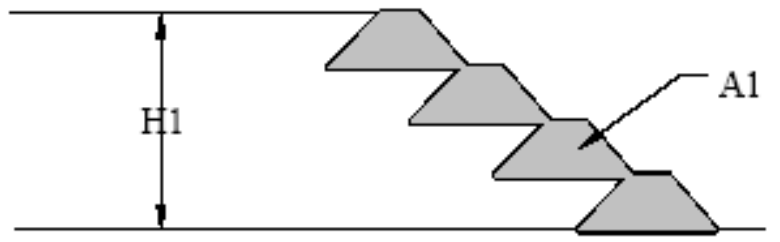

(a)

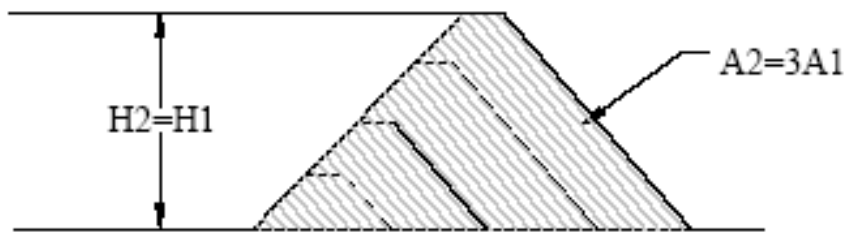

(b)

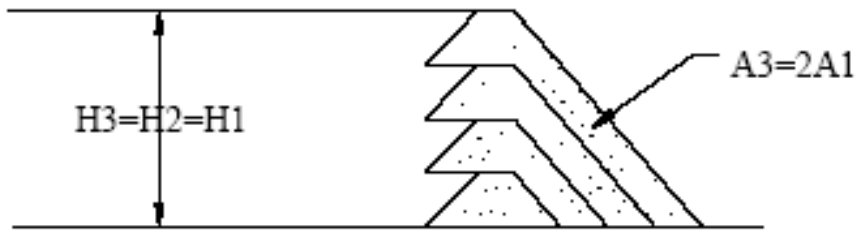

(c)

Figura 2.6 - Comparação de volumes para os três tipos de barragens: (a) método de montante, (b) método de Jusante e (c) método de linha de centro (modificado - Vick 1983).

\subsection{ENSAIO DE CONSOLIDAÇÃO INDUZIDA POR PERCOLAÇÃO (HCT)}

A teoria clássica de Terzaghi assume que as deformações são pequenas, não sendo portanto adequada para a previsão do processo de consolidação de solos altamente compressíveis. Nestes solos são esperadas grandes deformações em relação à espessura inicial da camada em análise e, portanto, é essencial que a teoria de consolidação unidimensional não linear para tal nível de deformações seja usada. As teorias de Mikasa (1963) e a de Gibson et al. (1967) contemplam deformações finitas, adequando-se a análise do processo de consolidação de solos com alta taxa de compressibilidade.

As teorias citadas acima requerem o conhecimento dos parâmetros de consolidação. Estes parâmetros podem ser obtidos por técnicas que utilizem métodos diretos 
ou indiretos. Nos métodos diretos, com a ajuda dos princípios fundamentais da mecânica dos solos, os parâmetros de consolidação do material podem ser medidas diretamente no experimento. Os métodos indiretos requerem um modelo matemático adequado, para que através de uma retroanálise utilizando os resultados experimentais possam ser determinadas os parâmetros de consolidação do material.

De um modo geral, os métodos indiretos mostram menores desvantagens que os métodos diretos, em termos de simplicidade dos equipamentos de teste, conveniência dos processo experimentais, economia de tempo, e menos restrições na formulação da teoria de consolidação (Liu, 1990).

Esta pesquisa utilizou um método indireto HCT que foi proposto originalmente por Imai (1979). Este método fornece parâmetros de consolidação que são utilizados para determinar a curva de compressibilidade e a curva de condutividade hidráulica de solos altamente compressíveis.

Para obter as curvas de compressibilidade e condutividade hidráulica de solos moles é necessário escolher o modelo constitutivo que melhor represente as características deste material.

\subsubsection{Modelos constitutivos}

A compressão unidimensional de solos é usualmente representada por um modelo logarítmico-linear, no qual o índice de vazios $(e)$ se relaciona com a tensão efetiva $(\sigma)$ da seguinte forma: 


$$
e=e_{o}-C_{c} \log \left[\frac{\sigma_{v}^{\prime}}{\sigma_{o}^{\prime}}\right]
$$

onde o índice de compressão $\mathrm{C}_{\mathrm{c}}$ é uma constante para um determinado solo. Esta expressão produz índice de vazios infinito para tensão efetiva nula e índices de vazios negativos para altas tensões efetivas. Estas deficiências impedem a sua utilização no estudo da consolidação de argilas moles .

Para eliminar este problema de índices de vazios negativos, alguns autores (Somogyi, 1979; Ávila e Soares, 1995) propuseram a seguinte função de potência:

$$
e=A \sigma^{\prime B}
$$

na qual A e B são coeficientes empíricos determinados experimentalmente. Entretanto, esta expressão ainda produz índice de vazios infinito para tensão efetiva nula, uma vez que o coeficiente B é sempre negativo. Além do mais, esta expressão não é capaz de representar a compressibilidade de solos normalmente adensados e sobreadensados continuamente.

Estudando o comportamento de consolidação de solos moles, Liu e Znidarcic (1991) propuseram um modelo no qual a expressão de Somogyi é expandida com uma constante $Z$, para evitar o problema de índice de vazios infinito para tensão efetiva nula. A expressão possui a forma:

$e=A\left(\sigma^{\prime}+Z\right)^{B}$

Como foi demonstrada por Liu e Znidarcic, esta expressão possui ainda o mérito de poder representar a compressibilidade de solos tanto normalmente adensados como 
sobreadensados. Entretanto, eles chamam atenção para o fato de que este modelo não tem a capacidade de representar corretamente a região sobreadensada de argilas sensíveis.

A relação entre condutividade hidráulica $(k)$ e índice de vazios $(e)$ foi apresentada em trabalhos experimentais realizados por Pane (1985) e Aiban e Znidarcic (1989), dentre as relações entre índice de vazios $(e)$ e condutividade hidráulica $(k)$, a que melhor representa o comportamento de solos moles é aquela proposta por Somogyi (1979):

$k=C(e)^{D}$

onde $C$ e $D$ são coeficientes empíricos determinados experimentalmente.

\subsubsection{Teoria da consolidação unidimensional com grandes deformações}

A teoria de consolidação unidimensional de Terzaghi é válida somente para os casos nos quais as deformações sejam pequenas, ou seja para solos rijos pré-adensados. Segundo esta teoria, a permeabilidade e a compressibilidade permanecem constantes durante o processo de consolidação.

Para caracterizar convenientemente os recalques e prever razoavelmente o progresso da consolidação de solos moles, tais como resíduos na forma de lamas compostas por partículas finas, é necessária a utilização de uma teoria de consolidação não linear que considere grandes deslocamentos. Na teoria de Gibson, England e Hussey (1967) foram consideradas as variações que ocorrem nas propriedades dos materiais, além de ser eliminada a limitação de validade somente para pequenas deformações. Esta teoria foi originalmente desenvolvida para camadas finas e homogêneas de argilas saturadas. Mais tarde, ficou provado que a teoria também era válida para a consolidação com grandes deformações de 
camadas espessas, podendo-se considerar o peso próprio, tanto da fase sólida como da fase líquida (Gibson, et al., 1981).

\subsubsection{Considerações iniciais}

O modelo para o processo de consolidação com grandes deformações requer as seguintes equações fundamentais para a dedução das equações de governo do processo:

- equações de equilíbrio (sistema e fase fluida);

- $\quad$ equações da continuidade (fase fluída; fase sólida e sistema);

- princípio das tensões efetivas;

- lei de Darcy-Gersevanov (1934).

Antes de iniciar a dedução das equações de governo é útil apresentar alguns conceitos a serem utilizados, incluindo sistemas de coordenadas, equações de equilíbrio, equações de continuidade, princípio das tensões efetivas e lei de Darcy-Gersevanov.

\subsubsection{Sistema de coordenadas}

Para o desenvolvimento da teoria de consolidação com grandes deformações são necessários três tipos de sistemas de coordenadas (Schiffman, 1987):

- $\quad$ sistema de coordenadas iniciais (descrição lagrangeana)

- $\quad$ sistema de coordenadas convectivas (descrição euleriana)

- sistema de coordenadas materiais

Na mecânica dos solos, é usual a utilização da descrição euleriana para análise de problemas com pequenas deformações. A descrição lagrangeana é mais utilizada no 
desenvolvimento de modelos válidos para grandes deformações, comuns no tratamento de deposição de rejeitos descartados em forma de lama.

O sistema de coordenadas materiais ( $z$ ) por sua vez é independente do tempo como o sistema de coordenada lagrangeana (a). Uma de suas vantagens é apresentar simplificações na formulação analítica e na resolução de problemas com grandes deformações, quando comparado com os sistemas de coordenadas eulerianas ( $\xi$ ) e lagrangeanas (a). A Figura 2.7 mostra uma representação dos diferentes sistemas de coordenadas.

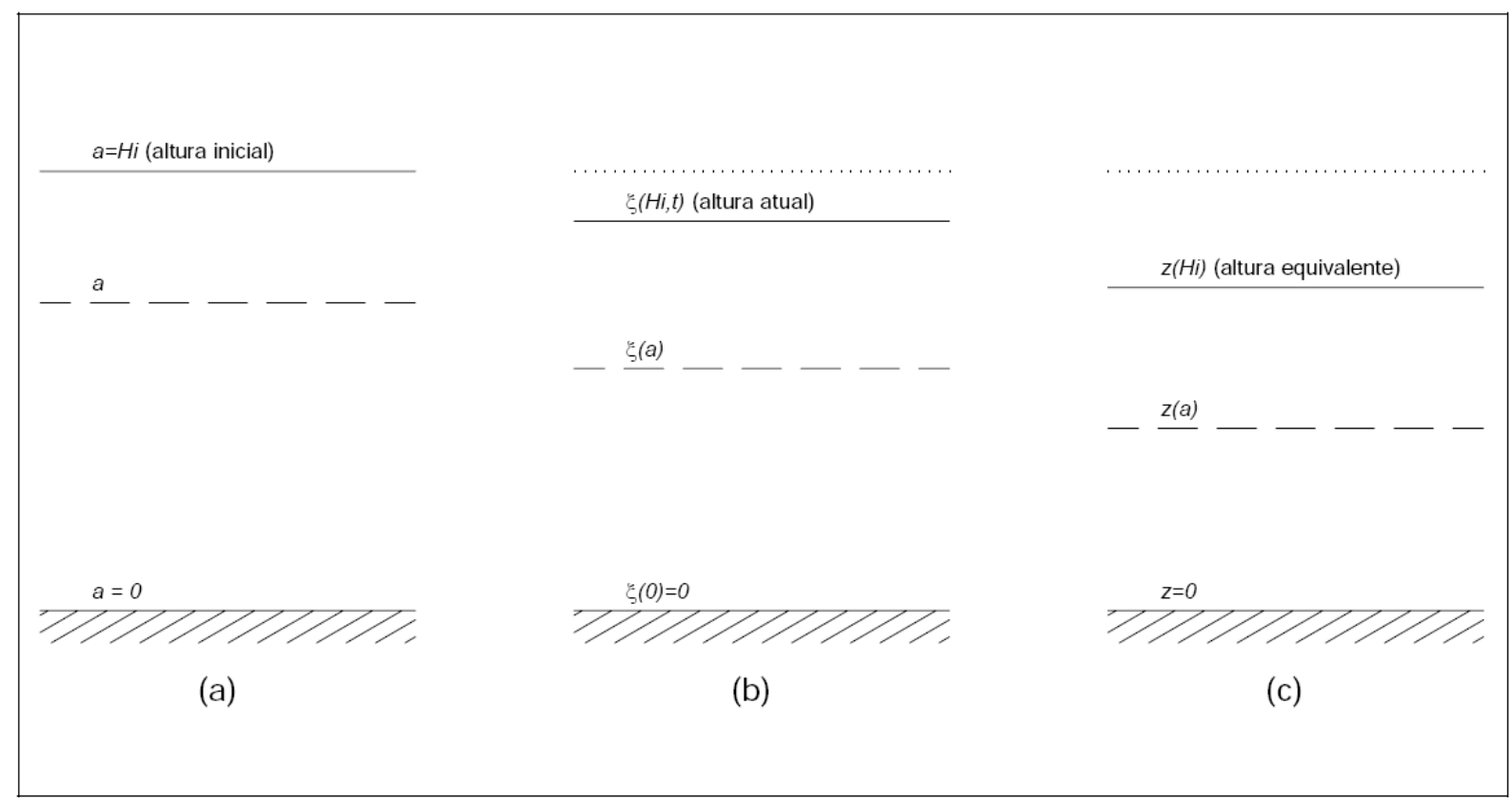

Figura 2.7 - Sistemas de coordenadas: (a) Sistema de coordenada lagrangeana no instante $t=0$; (b) sistema de coordenada euleriana no instante $t$; (c) sistema de coordenada material no instante $t$.

A conversão das coordenadas é apresentada nas equações a seguir:

- Relação entre $a$ e $\xi$ :

$\frac{\partial \xi}{\partial a}=\frac{1+e}{1+e_{0}}$ 
- Relação entre $z$ e $a$ :

$\frac{\partial z}{\partial a}=\frac{1}{1+e_{0}}$

- Relação entre $z$ e $\xi$ :

$\frac{\partial z}{\partial \xi}=\frac{1}{1+e}$

Uma explicação mais detalhada dos sistemas de coordenadas é apresentada nos seguintes trabalhos: Pane (1985), Gibson et al. (1981), Schiffman (1988), Liu (1990) e Botelho (2001).

A seguir serão detalhadas as principais equações utilizadas para dedução da equação que governa o processo de consolidação com grandes deformações. $\mathrm{O}$ sequenciamento das equações e as principais deduções foram baseadas nos trabalhos de AbuHejleh. e Znidarcic (1992) e Esquivel (2001).

As seguintes equações governam o ensaio de fluxo estacionário, que podem ser escritas em coordenadas lagrangeanas $(a)$, a seguir:

\subsubsection{Equação de equilíbrio}

Para um sistema constituído de duas fases, assumindo que a saturação seja total, pode-se deduzir três equações de equilíbrio: equilíbrio do sistema, equilíbrio da fase fluida e equilíbrio das tensões.

a) Equação de equilíbrio do sistema 
Seja considerado o elemento de solo mostrado na Figura 2.8, com altura unitária $(\delta \xi=1)$. O volume total do elemento, representado por $V_{m}$, é a soma dos volumes de sólidos $\left(V_{s}\right)$ e de vazios $\left(V_{v}\right)$. O peso total do elemento $\left(W_{m}\right)$ é a soma dos pesos dos sólidos $\left(W_{s}\right)$ e do fluído $\left(W_{w}\right)$. A condição de equilíbrio das forças na direção vertical é dada pela equação:

$$
\left(\sigma+\frac{\partial \sigma}{\partial \xi} \delta \xi\right) A \pm W_{m}=\sigma A
$$

ou

$$
\frac{\partial \sigma}{\partial \xi} \delta \xi A \pm W_{m}=0
$$

ou

$$
\frac{\partial \sigma}{\partial \xi} \pm \frac{W_{m}}{V_{m}}=0
$$

onde

$\sigma=$ tensão vertical total

$W_{m}=$ peso total do elemento

$V_{m}=$ volume do elemento

$A=$ área da base do elemento

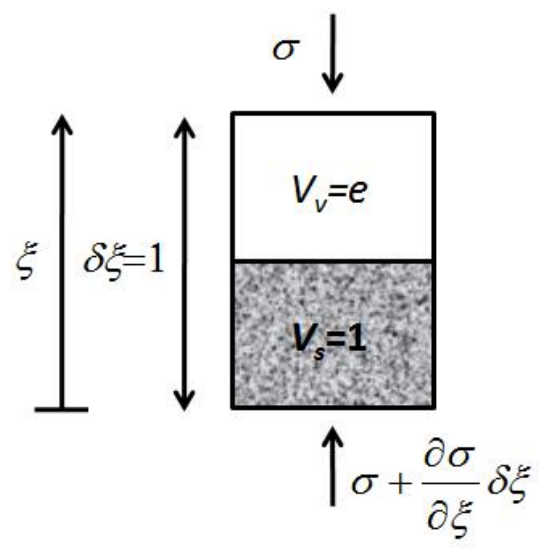

Figura 2.8 - Equilíbrio de um elemento de solo. 
Sabendo que $\frac{W_{m}}{V_{m}}=-\frac{e \gamma_{w}+\gamma_{s}}{1+e}$ resulta:

$\frac{\partial \sigma}{\partial \xi}=\mp \frac{e \gamma_{w}+\gamma_{s}}{1+e}$

deve-se notar que o sinal $\frac{\text { sup erior }}{\text { inf erior }}$ indica que a direção do eixo de coordenadas é $\frac{\text { contra a }}{\text { a favor } d a}$ gravidade.

Colocando a Equação (2.11) em termos de coordenadas lagrangeanas, obtêm-se a Equação (2.12):

$\frac{\partial \sigma}{\partial a} \pm \frac{e \gamma_{w}+\gamma_{s}}{1+e_{i}}=0$

b) Equação de equilíbrio da fase fluida

A poropressão $\left(u_{w}\right)$ para um instante qualquer é constituída de duas componentes: poropressão estática $\left(u_{s}\right)$ e excesso de poro pressão $(u)$.

$u_{w}=u_{s}+u_{e}$

Derivando ambos os membros da Equação (2.13), resulta na equação do equilíbrio do fluido em termos de $u_{w}$ e $u$, resultando: 


$$
\frac{\partial u_{w}}{\partial \xi}=\mp \gamma_{w}+\frac{\partial u}{\partial \xi}
$$

Em termos de coordenadas lagrangeanas, a Equação (2.14) se transforma em:

$$
\frac{\partial u}{\partial a}=\frac{\partial u_{w}}{\partial a} \pm \frac{1+e}{1+e_{i}} \gamma_{w}
$$

c) Equação de equilíbrio da fase fluida

Assumindo que seja válido o princípio das tensões efetivas para o sistema sólidoságua, então tem-se:

$\sigma=\sigma^{\prime}+u_{w}$

Substituindo-se as Equações (2.15)e (2.16) na Equação (2.12), resulta:

$$
\frac{\partial \sigma^{\prime}}{\partial a}+\frac{\partial u}{\partial a}=\mp \frac{\gamma_{s}-\gamma_{w}}{1+e_{i}}
$$

No caso de não haver excesso de poro-pressão, a equação acima é simplificada para:

$$
\frac{\partial \sigma^{\prime}}{\partial a}=\mp \frac{\gamma_{s}-\gamma_{w}}{1+e_{i}}
$$

Em termos de coordenadas convectivas, a equação de equilíbrio de tensões torna-se: 


$$
\frac{\partial \sigma^{\prime}}{\partial \xi}=\mp \frac{\gamma_{s}-\gamma_{w}}{1+e}
$$

\subsubsection{Equações da continuidade}

Para um sistema constituído de duas fases, a continuidade é expressa através de três equações: continuidade da fase fluida, continuidade da fase sólida e continuidade do sistema.

a) Continuidade da fase fluida

Seja considerada a variação da massa de fluido que atravessa um elemento com volume igual a $\xi \delta A$, com a velocidade $v_{w}$ durante um intervalo de tempo $\delta t$, igual ao tempo necessário para que ocorra a troca total do fluido contido no elemento. Supondo que a direção do fluxo de fluido seja normal à seção transversal de área $\delta A$, pode-se escrever:

$$
\left[\rho_{w} \bar{v}_{w} \delta A \delta t+\frac{\partial\left(\rho_{w} \bar{v}_{w} \delta A \delta t\right)}{\partial \xi} \delta \xi\right]-\rho_{w} \bar{v}_{w} \delta A \delta t=-\frac{\partial\left(\rho_{w} V_{w}\right)}{\partial t} \delta t
$$

onde:

$$
\begin{aligned}
& \rho_{w}=\text { massa específica da fase fluida } \\
& \bar{v}_{w}=\text { velocidade aparente do fluido } \\
& V_{w}=\text { volume ocupado pela fase fluida }
\end{aligned}
$$

Sendo $n$ a porosidade do sistema e $v_{w}$ a velocidade real da fase fluida, pode-se então escrever: 


$$
\frac{\partial\left(\rho_{w} n v_{w}\right)}{\partial \xi}+\frac{\partial\left(\rho_{w} n\right)}{\partial t}=0
$$

b) Continuidade da fase sólida

Aplicando-se semelhante processo à fase sólida, pode-se escrever:

$$
\left[\rho_{s} \bar{v}_{s} \delta A \delta t+\frac{\partial\left(\rho_{s} \bar{v}_{s} \delta A \delta t\right)}{\partial \xi} \delta \xi\right]-\rho_{s} \bar{v}_{s} \delta A \delta t=-\frac{\partial\left(\rho_{s} V_{s}\right)}{\partial t} \delta t
$$

onde

$$
\begin{aligned}
& \rho_{s}=\text { massa específica da fase sólida } \\
& \bar{v}_{s}=\text { velocidade aparente da fase sólida } \\
& V_{s}=\text { volume ocupado pela fase sólida }
\end{aligned}
$$

Sendo $n$ a porosidade do sistema e $v_{s}$ a velocidade real da fase sólida, pode-se então escrever:

$$
\frac{\partial\left[\rho_{s}(1-n) v_{s}\right]}{\partial \xi}+\frac{\partial\left[\left(\rho_{s}(1-n)\right]\right.}{\partial t}=0
$$

c) Continuidade do sistema

Assumindo que as partículas fluidas e sólidas sejam incompressíveis, combinando-se as Equações (2.21) e (2.23) obtém-se a equação da continuidade para o sistema constituído de duas fases, representada pela Equação (2.24): 


$$
\frac{\partial\left[n\left(v_{w}-v_{s}\right)\right]}{\partial \xi}+\frac{\partial v_{s}}{\partial \xi}=0
$$

Fazendo $n\left(v_{w}-v_{s}\right)=q_{v}$, a Equação (2.24) torna-se:

$$
\frac{\partial q_{v}}{\partial \xi}+\frac{\partial v_{s}}{\partial \xi}=0
$$

A Equação (2.23) pode ser reescrita como:

$$
(1-n) \frac{\partial v_{s}}{\partial \xi}-v_{s} \frac{\partial n}{\partial \xi}-\frac{\partial n}{\partial t}=0
$$

Aplicando-se o conceito de derivada material à porosidade na Equação (2.26) resulta a Equação (2.27):

$$
(1-n) \frac{\partial v_{s}}{\partial \xi}-\frac{D n}{D t}=0
$$

Combinando as equações (2.25) e (2.27), obtêm-se a equação (2.28)

$$
(1-n) \frac{\partial q_{v}}{\partial \xi}+\frac{D n}{D t}=0
$$

A equação (2.28) pode ser transformada na Equação (2.29) fazendo $n=e /(1+e)$, aplicando-se o conceito de derivada material a porosidade e transformando o sistema de coordenadas eulerianas para lagrangeanas. 


$$
\frac{\partial q_{v}}{\partial a}+\frac{1}{1+e_{i}} \frac{\partial e}{\partial t}=0
$$

Em coordenadas eulerianas, a Equação (2.29) pode ser transformada na Equação (2.30)

$$
\frac{\partial q_{v}}{\partial \xi}+\frac{1}{1+e} \frac{D e}{D t}=0
$$

Transformando a equação (2.30) para o sistema de coordenadas materiais e sabendo-se que z é independente do tempo, obtemos a Equação (2.31):

$$
\frac{\partial q_{v}}{\partial z}+\frac{\partial e}{\partial t}=0
$$

\subsubsection{Princípio das Tensões Efetivas}

O princípio das tensões efetivas, considerando o excesso de poropressão estabelece:

$$
\sigma^{\prime}=\sigma-u_{e}-u_{s}
$$

onde:

$$
\begin{aligned}
& \sigma=\text { tensão total }(\mathrm{kPa}) \\
& \sigma^{\prime}=\text { tensão vertical efetiva vertical }(\mathrm{kPa}) ; \\
& u_{e}=\text { excesso de poropressão }(\mathrm{kPa}) \\
& u_{s}=\text { poropressão estática }(\mathrm{kPa}) \text { definida como. }
\end{aligned}
$$


$u_{s}=\frac{1+e_{0}}{1+e} \gamma_{w} a$

onde:

$$
\begin{aligned}
& e_{0}=\text { índice de vazios inicial; } \\
& e=\text { índice de vazios; } \\
& \gamma_{w}=\text { peso especifico da água }\left(\mathrm{kN} / \mathrm{m}^{3}\right) ; \\
& a=\text { coordenada lagrangeana. } \\
& \text { ou } \\
& \frac{\partial u_{s}}{\partial a}=\frac{1+e_{0}}{1+e} \gamma_{w}
\end{aligned}
$$

\subsubsection{Lei de Darcy-Gersevanov}

A chamada lei de Darcy-Gersevanov, descreve de uma forma geral um fluxo de água através de um esqueleto sólido. Observa-se que as forças de arraste no esqueleto sólido dependem da velocidade relativa $\left(v_{w^{*}}-v_{s}\right)$ entre o fluido que preenche os poros e os grãos do solo.

A formulação da consolidação com deformações finitas ( Mikasa, 1963 e Gibson, 1967) levam em consideração a lei de Darcy modificada, que descreve de uma forma geral um fluxo. Essa lei modificada foi apresentada inicialmente por Gersevanov.

$\eta\left(v_{w}-v_{s}\right)=-\frac{k}{\gamma_{w}} \frac{\partial u_{e}}{\partial \xi}$

onde

$$
\begin{aligned}
& \eta=\text { viscosidade do fluido } \\
& v_{w}=\text { velocidade da água }
\end{aligned}
$$




$$
\begin{aligned}
& v_{s}=\text { velocidade dos sólidos } \\
& k=\text { condutividade hidrálica do sistema } \\
& u_{e}=\text { excesso de poro-pressão }
\end{aligned}
$$

Fazendo $v_{s}=0$ na Equação (2.35), recai-se na conhecida lei de Darcy:

$$
\eta v_{w}=-\frac{k}{\gamma_{w}} \frac{\partial u}{\partial \xi}
$$

\subsubsection{Equações de controle}

Na dedução das equações de controle são adotadas as seguintes hipóteses:

- O esqueleto sólido é homogêneo e não apresenta efeitos de tempo intrínsecos;

- Existe uma total interação entre as partículas durante o processo de consolidação.

Desta forma as relações constitutivas dos materiais são função exclusiva do índice de vazios:

$$
\begin{gathered}
\sigma^{\prime}=\sigma^{\prime}(e) \\
k=k(e)
\end{gathered}
$$

Pode-se demonstrar que a Equação (2.39), representa o processo de consolidação unidimensional não-linear, para os sistemas de coordenadas lagrangeanas.

$$
\pm\left(\frac{\gamma_{s}}{\gamma_{w}}-1\right)\left[\frac{d}{d e}\left(\frac{k}{1+e}\right)\right] \frac{\partial e}{\partial a}+\frac{\partial}{\partial a}\left[\frac{k\left(1+e_{i}\right)}{\gamma_{w}(1+e)} \frac{d \sigma^{\prime}}{d e} \frac{\partial e}{\partial a}\right]=\frac{1}{1+e_{i}} \frac{\partial e}{\partial t}
$$


Quando o interesse maior estiver na situação permanente final, e não no progresso do processo de consolidação, a Equação (2.39) poderá ser simplificada removendo-se o seu membro direito, já que $\partial e / \partial t=0$. Como fica restando então uma única variável independente (a), a equação para o problema estacionário torna-se uma equação diferencial ordinária de segunda ordem:

$$
\mp\left(\frac{\gamma_{s}}{\gamma_{w}}-1\right)\left[\frac{d}{d e}\left(\frac{k}{1+e}\right)\right] \frac{\partial e}{\partial a}-\frac{\partial}{\partial a}\left[\frac{k\left(1+e_{i}\right)}{\gamma_{w}(1+e)} \frac{d \sigma^{\prime}}{d e} \frac{\partial e}{\partial a}\right]=0
$$

As Equações (2.41) e (2.42) representam o processo de consolidação unidimensional nãolinear para os sistemas de coordenadas eulerianas e materiais, respectivamente.

$$
\begin{aligned}
& \mp\left(\frac{\gamma_{s}}{\gamma_{w}}-1\right)\left[\frac{d}{d e}\left(\frac{k}{1+e}\right)\right] \frac{\partial e}{\partial \xi}-\frac{\partial}{\partial \xi}\left[\frac{k}{\gamma_{w}} \frac{d \sigma^{\prime}}{d e} \frac{\partial e}{\partial \xi}\right]=\frac{1}{1+e} \frac{D e}{D t} \\
& \mp\left(\frac{\gamma_{s}}{\gamma_{w}}-1\right)\left[\frac{d}{d e}\left(\frac{k}{1+e}\right)\right] \frac{\partial e}{\partial z}-\frac{\partial}{\partial z}\left[\frac{k}{\gamma_{w}(1+e)} \frac{d \sigma^{\prime}}{d e} \frac{\partial e}{\partial z}\right]=\frac{\partial e}{\partial t}
\end{aligned}
$$

Essas equações valem tanto para camadas finas como espessas, levando em conta o peso próprio, tanto da fase sólida como da fase fluida,

\subsubsection{Tensão efetiva vertical}

A tensão efetiva vertical pode ser determinada com seguinte equação: 
$\sigma^{\prime}(z)=\sigma_{0}^{\prime}+\int_{0}^{z}\left(e \gamma_{w}+\gamma_{s}\right) d z-\int_{0}^{z}(1+e) d z+\int_{0}^{z} \frac{q_{v} \gamma_{w}}{k}(1+e) d z$

ou

$\sigma^{\prime}(z)=\sigma_{0}^{\prime}+\left(\gamma_{s}-\gamma_{w}\right) z+\int_{0}^{z} \frac{q_{v} \gamma_{w}}{k}(1+e) d z$

No segundo membro desta equação, o primeiro termo representa a sobrecarga aplicada na superfície e o segundo termo representa a parcela da tensão efetiva devido ao peso próprio. $\mathrm{O}$ terceiro termo representa a parcela da tensão efetiva devido às forças de percolação. Deve-se notar, que no caso de regime estacionário, $q_{v}$ é a velocidade da água imposta através da amostra.

\subsubsection{Condições de contorno e iniciais}

A solução de problemas de consolidação unidimensional controlados pelas Equações (2.39) ou (2.40) necessita a definição de uma condição inicial e um conjunto de contorno. A condição inicial deve especificar a distribuição de índices de vazios ao longo da altura, no instante inicial. As condições de contorno devem especificar o índice de vazios ou o fluxo de fluido em determinadas fronteiras do domínio.

Nos problemas de consolidação unidimensional, os dois fatores primários para a realização do processo são as tensões aplicadas, incluindo o peso próprio, e o fluxo imposto ao meio. As condições de contorno associadas a estes dois fatores podem ser expressos respectivamente por: 


$$
e=e(a, t), \quad t>0, \quad a=\left\langle\begin{array}{c}
H_{i} \\
0
\end{array}\right.
$$

$\mathrm{E}$

$$
\frac{\partial e(a, t)}{\partial a}=\left[q_{v} \frac{\gamma_{w}}{k} \frac{1+e(a, t)}{1+e_{i}} \mp\left(\frac{\gamma_{s}-\gamma_{w}}{1+e_{i}}\right)\right] \frac{1}{\frac{d \sigma^{\prime}}{d e}}, \quad t>0, \quad a=\left\langle\begin{array}{c}
H_{i} \\
0
\end{array}\right.
$$

No caso específico de ensaios de consolidação, tanto o índice de vazios como o fluxo na superfície superior da amostra são especificados.

\subsubsection{Determinação da condutividade hidráulica}

Em 1966, Olsen propôs a técnica que utiliza a vazão constante para a determinação da condutividade hidráulica de solos finos. Na técnica da bomba de fluxo, um fluxo de vazão constante é forçado através da amostra por meio da bomba. Medindo-se a diferença de pressão entre as faces da amostra com o auxílio de um transdutor diferencial de pressão, determina-se então o gradiente hidráulico. Este conceito se contrapõem ao conceito do ensaio convencional de carga constante, no qual um gradiente hidráulico constante e conhecido é imposto à amostra de solo, medindo-se a correspondente vazão. A vantagem da técnica que utiliza vazão constante reside no fato de que é muito mais fácil controlar e manter uma pequena vazão do que medir a diferença de carga constante.

Ao final do ensaio, determinam-se a altura e o diâmetro da amostra, bem como o seu peso seco e teor de umidade. O coeficiente de condutividade hidráulica é então calculado pela seguinte expressão:

$$
k=\frac{q H}{A h}
$$


onde

$q=$ vazão através da amostra

$h=$ diferença de carga através da amostra

$A$ = área da seção transversal da amostra

$H=$ altura da amostra

\subsubsection{Programa SICTA}

O programa SICTA (Seepage Induced Consolidation Test Analysis). foi desenvolvido por Abu-Hejleh e Znidarcic (1992), a partir da teoria de Gibson, representada pela Equação (2.39) que governa o sistema, e baseado no ensaio de consolidação hidráulica proposto por Imai. Este programa fornece como resultado os parâmetros de consolidação de solos moles, identificados como A, B, C, D e Z. Tais parâmetros são utilizados nos modelos matemáticos de compressibilidade e condutividade hidráulica propostos por Liu (1990) e Somogyi (1979), respectivamente.

$\pm \boldsymbol{G}_{s}-1\left[\frac{d}{d e}\left(\frac{k}{1+e}\right)\right] \frac{\partial e}{\partial z}-\frac{\partial}{\partial z}\left[\frac{k}{\gamma_{w}(1+e)} \frac{d \sigma^{\prime}}{d e} \frac{\partial e}{\partial z}\right]=\frac{\partial e}{\partial t}$

onde:

$z=$ coordenada material (positiva na direção da ação da gravidade) em metros;

$t=$ tempo $(\mathrm{s})$

$e=$ índice de vazios;

$k=$ coeficiente de condutividade hidráulica $(\mathrm{m} / \mathrm{s})$;

$\gamma_{s}=$ peso específico dos sólidos $\left(\mathrm{kN} / \mathrm{m}^{3}\right)$;

$\gamma_{w}=$ peso específico da água $\left(\mathrm{kN} / \mathrm{m}^{3}\right)$;

$\sigma^{\prime}=$ tensão efetiva vertical $(\mathrm{kPa})$. 


\subsection{TÉCNICA DA REFLECTOMETRIA NO DOMÍNIO DO TEMPO (TDR)}

\subsubsection{Princípios}

A técnica da TDR (Reflectometria no Domínio de Tempo) é amplamente utilizada no campo das telecomunicações para a identificação de descontinuidades em cabos. O testador de cabos emite um pulso ou sinal eletromagnético que se propaga pelo cabo a uma velocidade $V_{p}$ (que é função da constante dielétrica do cabo). Este sinal é refletido de volta quando encontra uma descontinuidade, ou seja, uma variação de impedância. O testador de cabos capta então este sinal refletido e determina o tempo de percurso do sinal. $\mathrm{O}$ conhecimento da velocidade de propagação do sinal e do tempo de percurso permite calcular a distância da obstrução, falha ou variação de impedância. A amplitude das ondas que retornam permite determinar o tipo da obstrução, falha ou variação de impedância.

Esta técnica passou a ser utilizada para determinar o teor de umidade dos solos a partir dos estudos de Topp et al. (1980), que a usaram para fins agrícolas. Para fins geotécnicos, a aplicação desta tecnologia foi primeiramente relatada por Kujala e Ravaska (1994). Benson et al. (1994) empregaram a técnica TDR para monitorar a umidade de tapetes impermeabilizantes em aterros sanitários, e Dowding e Huang (1994) aplicaram a técnica TDR para estudar a descontinuidade de rochas. Conciani et al. (1996) empregaram a técnica TDR para medir a umidade e estimar a sucção do solo durante provas de carga.

Nas aplicações geotécnicas, através de um cabo coaxial, o equipamento TDR envia um pulso a uma sonda previamente introduzida no solo. O sinal ao atingir o final da sonda é refletido de volta para o equipamento TDR. Como são conhecidos o comprimento da 
sonda $(L)$ e o tempo de percurso do sinal $(t)$, pode-se determinar a constante dielétrica do solo, que por sua vez está diretamente relacionada com o teor de umidade volumétrico do solo.

Um equipamento TDR é constituído de quatro elementos principais: um gerador de pulsos, um cabo coaxial, um amostrador e um osciloscópio (Figura 2.9). O gerador de pulsos emite as ondas eletromagnéticas, que são constituídas de uma componente elétrica e uma componente magnética. Pode-se demonstrar que, no caso da aplicação da técnica TDR para a determinação do teor de umidade dos solos, a componente magnética não apresenta interesse. Entretanto, a componente elétrica é influenciada pelas propriedades do solo, especialmente o seu teor de umidade.

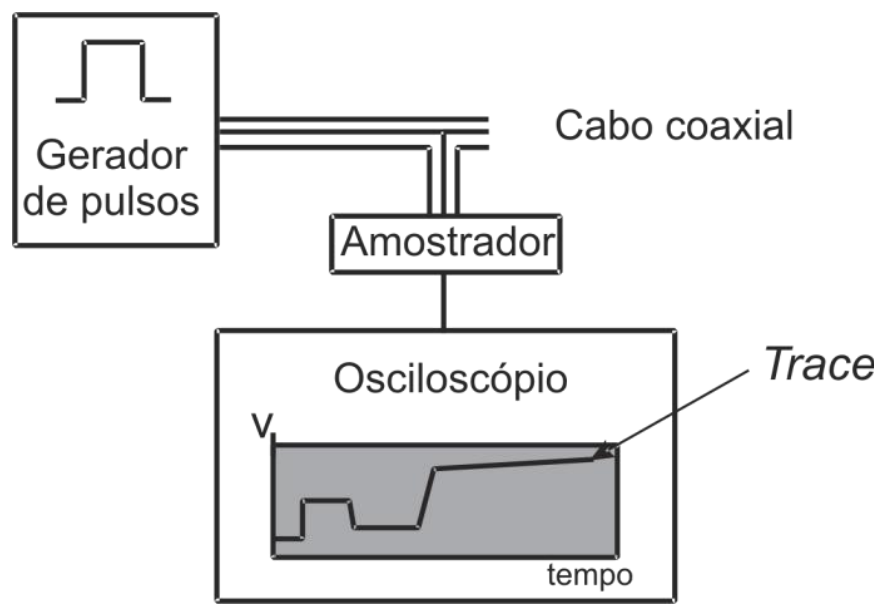

Figura 2.9 - Componentes constituintes de um equipamento que utiliza a técnica TDR (Esquivel, R. E., 2006).

O gerador de pulsos e o amostrador estão conectados por meio do cabo coaxial, que também funciona como uma antena (Figura 2.10). 


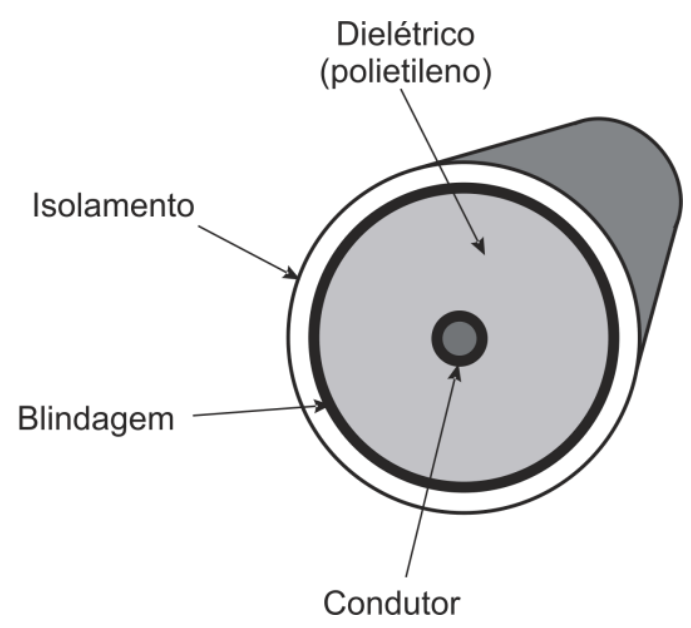

Figura 2.10 - Cabo coaxial

O amostrador é constituído por dois dispositivos principais e de alta precisão: um voltímetro e um medidor de tempo. Quando as ondas eletromagnéticas são lançadas pelo gerador de pulsos, elas são detectadas pelo amostrador, que mede a diferença de potencial entre o condutor e a blindagem do cabo coaxial num determinado intervalo de tempo.

O osciloscópio tem como finalidade mostrar simultaneamente as medidas de tempo e diferença de potencial, determinadas pelo amostrador. O gráfico mostrado pelo osciloscópio é denominado trace.

Quando ondas eletromagnéticas são lançadas num cabo conectado ao testador de cabos e caso haja qualquer alteração nas propriedades elétricas do cabo (variação de impedância, interrupção, etc.), estas ondas serão refletidas parcial ou totalmente. A amplitude das ondas refletidas vai depender do tipo de alteração no cabo. As ondas refletidas serão superpostas às ondas emitidas, retornando ao equipamento. $\mathrm{O}$ amostrador registra então a variação de voltagem entre o condutor e a blindagem do cabo e o intervalo de tempo entre o início da transmissão das ondas e a detecção das suas reflexões.

A técnica TDR mede a velocidade de propagação de um pulso eletromagnético (onda EM), ou o tempo que um pulso leva para retornar ao sistema após percorrer uma sonda instalada no solo. O tempo de transmissão depende da constante dielétrica do meio no qual a 
sonda está imersa. No método TDR convencional, um pulso eletromagnético é transmitido ao longo de um par de barras paralelas (sondas) inseridas no solo. No final das sondas, o pulso é refletido de volta para a sua fonte. Como o comprimento da trajetória é o dobro do comprimento da sonda, medindo-se o tempo de percurso do pulso, pode-se determinar a velocidade de sua propagação:

$v=\frac{2 L}{t}$

onde

$v=$ velocidade de propagação do pulso

$L=$ comprimento das guias

$t=$ tempo de percurso do pulso na sonda ou tempo de transmissão

Pela Teoria do Eletromagnetismo, tem-se:

$v=\frac{c}{\sqrt{\varepsilon}}$ ou $\varepsilon=\left(\frac{c}{v}\right)^{2}$

onde:

$c=$ velocidade de ondas eletromagnéticas no vácuo $\left(3 \times 10^{8} \mathrm{~m} / \mathrm{s}\right)$

$\varepsilon=$ constante dielétrica do meio

De acordo com a expressão (2.49), a constante dielétrica pode ser definida como sendo o quadrado da relação entre a velocidade de propagação no vácuo e a velocidade de propagação no meio. A constante dielétrica do ar $\left(\varepsilon_{\mathrm{ar}}\right)$ é igual a 1 , enquanto que a da água $\left(\varepsilon_{\mathrm{w}}\right)$ 
é aproximadamente igual a 81. A constante dielétrica dos minerais que constituem o solo varia entre 3 e 5 .

Como a constante dielétrica da água apresenta um valor tão elevado (quando comparado ao ar e aos sólidos), a quantidade de água presente na mistura sólidos-água-ar é que determina a constante dielétrica desta mistura, localizada entre as superfícies dos eletrodos de uma sonda TDR. Para um solo completamente seco, a sua constante dielétrica é ligeiramente inferior àquela apresentada pelos seus sólidos. À medida que a umidade do solo aumenta, a sua constante dielétrica também aumenta, devido ao elevado valor da constante dielétrica da água.

Combinando as expressões (2.48) e (2.49) resulta:

$\varepsilon=\left(\frac{c t}{2 L}\right)^{2}$ ou $t=\frac{2 L \sqrt{\varepsilon}}{c}$

onde:

$c=$ velocidade da luz no vácuo $(\mathrm{m} / \mathrm{s}) ;$

$L=$ comprimento da sonda $(\mathrm{m})$;

$t=$ tempo de viagem do pulso eletromagnético em segundos (ida e volta).

Pelo fato da constante dielétrica da água ser muito mais elevada que a do ar e do solo, ela torna-se dominante nesta equação. Assim, o tempo de transmissão varia com a quantidade de água presente, podendo então ser determinado o teor de umidade volumétrico.

Quando se utiliza a tradicional sonda TDR de nível único deve-se inicialmente determinar a constante dielétrica do meio através da expressão: 


$$
\varepsilon=\left(\frac{L_{a} C_{m}}{L V_{p}}\right)^{2}
$$

onde

$$
\begin{aligned}
& L=\text { comprimento da sonda }(\mathrm{m}) ; \\
& C_{m}=\text { constante de calibração do aparelho; } \\
& V_{p}=\text { velocidade real de propagação do pulso por velocidade da luz }(\cong 0.99) \\
& L_{a}=\text { comprimento aparente da sonda determinado no aparelho (Figura 2.11). }
\end{aligned}
$$

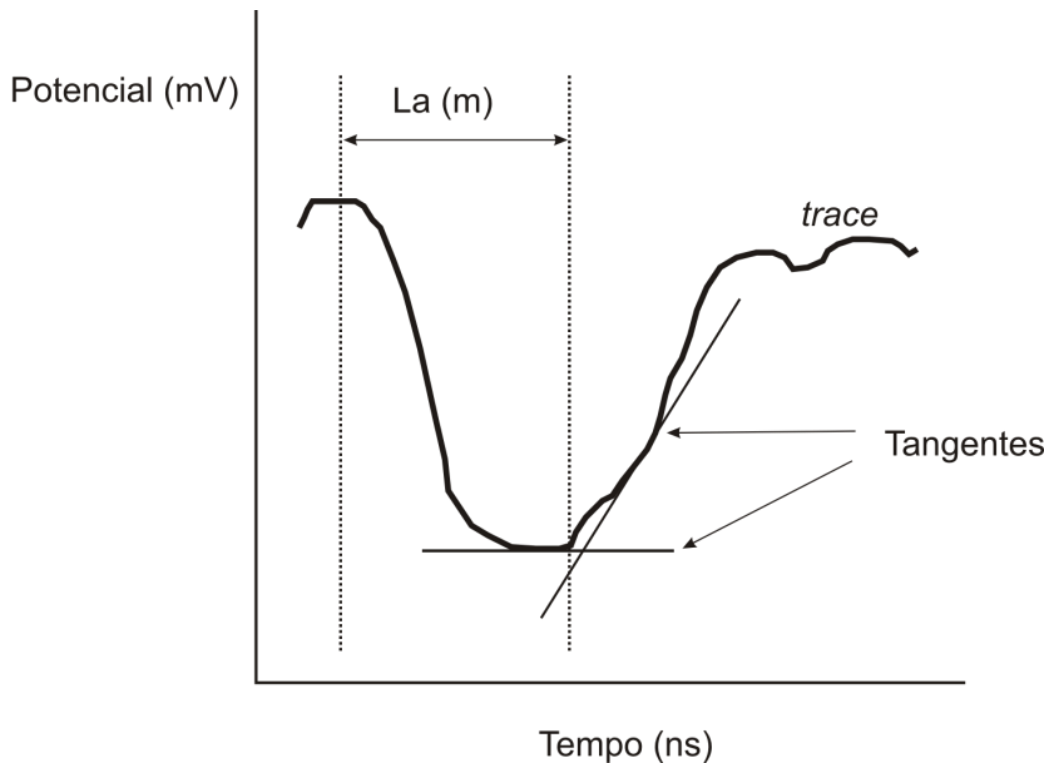

Figura 2.11 - Forma da onda (trace)

Na realidade, a constante dielétrica é um número complexo, contendo tanto uma parte real como uma parte imaginária de uma perda elétrica. Entretanto, para frequiências no intervalo de $1 \mathrm{MHz}$ a $1 \mathrm{GHz}$, a parte real da constante dielétrica não exerce uma influência significativa. Para os solos usuais, a perda elétrica é pequena e não altera significativamente a medida da velocidade de propagação (Klemunes Jr., 1998). Como conseqüência, a constante dielétrica determinada é referida como constante dielétrica aparente $(K a)$, e é definida pela seguinte expressão: 


$$
K a=\left[\frac{L_{a}}{L \cdot V_{p}}\right]^{2}=\left[\frac{(B-A)}{L \cdot V_{p}}\right]^{2}
$$

onde

$K a=$ constante dielétrica aparente;

$L_{a}=(B-A)=$ comprimento aparente da sonda $(\mathrm{m}) ;$

$\mathrm{B}=$ distância aparente correspondente ao ponto de inflexão final;

$A=$ distância aparente correspondente ao ponto de inflexão inicial;

$L=$ comprimento real da sonda $(\mathrm{m})$;

$V_{p}=$ relação entre a velocidade real de propagação e a velocidade da luz $(\cong 0,99)$.

Como a constante dielétrica aparente $\left(K_{a}\right)$ é proporcional ao quadrado do comprimento aparente $\left(L_{a}\right)$, qualquer erro ou diferença na determinação deste comprimento pode influenciar significativamente na determinação de $K_{a}$ do solo. Assim, existem procedimentos padrões para a determinação de $L_{a}$. Os métodos mais conhecidos são:

- Método das tangentes

- Método dos picos

- Método das linhas divergentes

- Método das tangentes alternativo

Neste trabalho de pesquisa foi utilizado o método das tangentes, no qual o ponto de inflexão inicial (Ponto A) é dado pela interseção da tangente horizontal com a tangente com declividade negativa, no ponto de máximo valor da curva. O ponto de inflexão final é determinado pela interseção da tangente horizontal com a tangente com declividade positiva, no ponto de mínimo valor da curva. (Figura 2.12). 


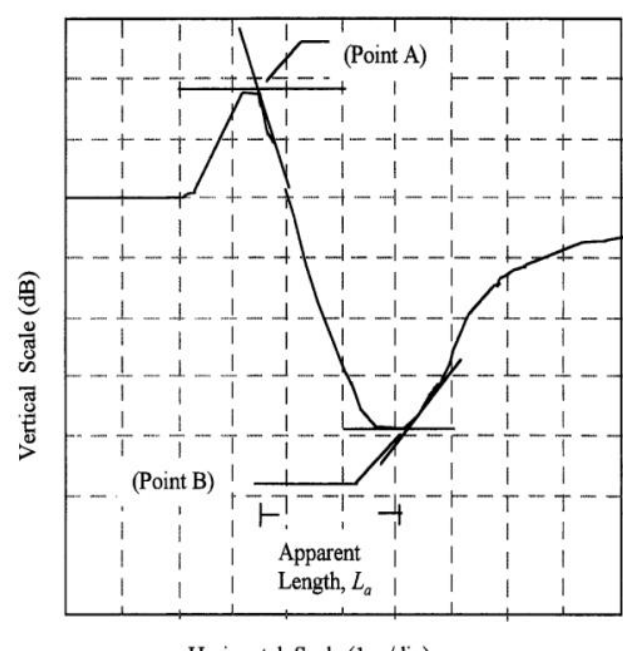

Horizontal Scale $(1 \mathrm{~m} / \mathrm{div})$

Figura 2.12 - Método das tangentes (Klemunes Jr., 1998)

\subsubsection{Equipamentos}

Os principais equipamentos TDR disponíveis no mercado estão relacionados abaixo e mostrados na Figura 2.13(Jones et al., 2002):

- $\quad 1502 \mathrm{C}$ (Tektronix Inc., Beaverton, OR)

- $\quad$ TRIME-FM (IMKO, Ettlingen, Germany)

- TRASE System I (Soil Moisture Equipment Corp., Goleta, CA)

- TDR100 (Campbell Scientific Inc., Logan, UT)

(a)

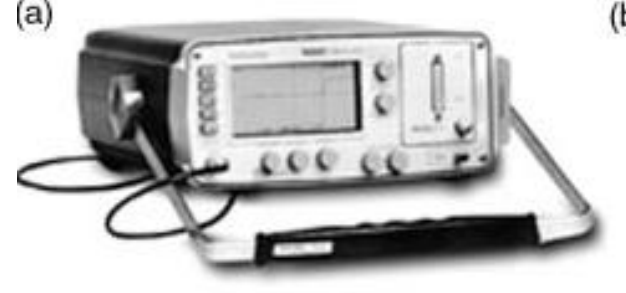

(c)

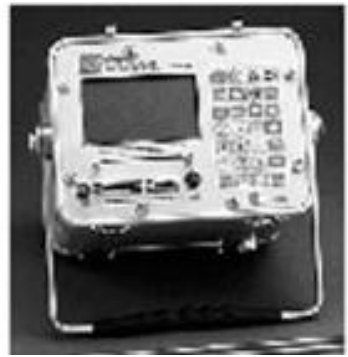

(b)

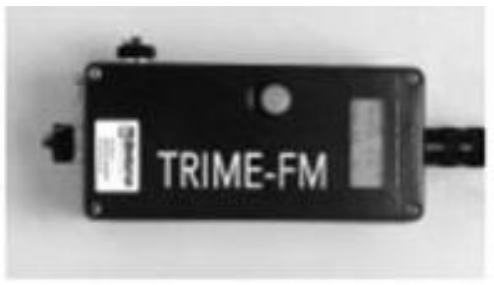

(d)

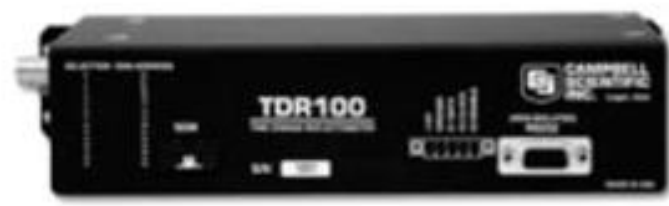

Figura 2.13 - Principais equipamentos TDR comerciais: 1502C (a), TRIME-FM (b), TRASE System I (c), TDR100 (d) (Jones et al., 2002). 


\subsubsection{Tipos de sondas}

As sondas que utilizam a técnica TDR geralmente são constituídas de uma base não condutora, onde são acopladas hastes metálicas, sendo uma delas o condutor e a outra o terra. É desejável que o condutor da sonda ocupe uma posição axial em relação às hastesterra. A sonda é conectada ao equipamento TDR através de um cabo coaxial, de forma que a haste condutora é conectada ao condutor do cabo coaxial e as hastes-terra à blindagem do mesmo.

Algumas configurações de sondas são mostradas na Figura 2.14.

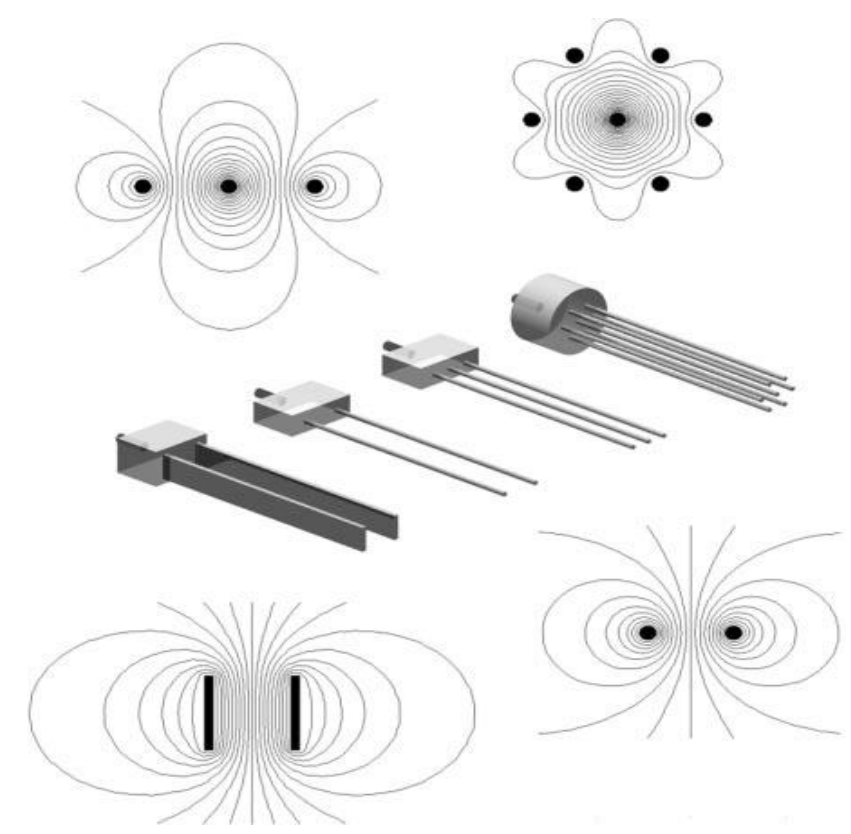

Figura 2.14 - Diferentes configurações de sondas (Jones et al., 2002).

A sonda apresenta certa região de influência que está baseada no seu projeto. Pesquisas têm mostrado que a área de influência para a estimativa do teor de umidade pela técnica TDR apresenta uma forma cilíndrica, cujo eixo está situado entre as hastes e com diâmetro aproximadamente igual a 1,4 vezes o espaçamento entre as barras (Topp e Davis, 1985). 
A sonda de dois elementos apresenta a vantagem de causar menos perturbação no solo, mas produz um sinal não balanceado, que leva a uma perda de sinal e ruídos indesejáveis. As sondas com três ou mais elementos proporcionam um sinal mais balanceado, embora haja um pouco mais de perturbação no solo.

\subsubsection{Metódos de Calibração}

O estudo da técnica passou a ser considerada muito promissora a partir dos estudos de Topp et al. (1980), que estabeleceram uma calibração empírica por meio da correlação entre a constante dielétrica aparente $\left(K_{a}\right)$ e o teor de umidade volumétrico $(\theta)$ para a estimativa do teor de umidade. Tal mecanismo ficou conhecido como relação universal, pois se acreditava que serviria para qualquer tipo de solo, estabelecendo uma correlação geral empírica para solos de diversas texturas, utilizando-se um polinômio de terceiro grau. A seguir, é mostrada a Equação (2.53), de calibração proposta por estes autores.

$$
\theta=-5,3 \times 10^{-2}+2,92 \times 10^{-2} \mathrm{~K}_{a}-5,5 \times 10^{-4} \mathrm{~K}_{a}^{2}+4,3 \times 10^{-6} \mathrm{~K}_{a}^{3}
$$

Os modelos empíricos são apenas relações funcionais entre as variáveis e não há, necessariamente, significado físico para a relação encontrada. Os modelos assim ajustados têm sua aplicabilidade limitada aos dados que lhes deram origem e podem eventualmente, ajustar-se bem a outros dados provenientes de condições semelhantes. Contudo, tais modelos são relativamente simples e práticos para estabelecer as curvas de calibração dos equipamentos de TDR. Outros modelos de ajuste fazem correlações entre $K_{a}$ e $\theta$, como o de Yu e Drenevich (2004) e o modelo conhecido como de fases (mixing model) que foi estudado 
por diversos autores, como Dobson et al. (1985), Roth et al. (1990) e Dasberg \& Hopmans (1992).

\subsubsection{Fatores que afetam a determinação da constante dielétrica aparente}

De maneira geral, os trabalhos citados na literatura identificaram diversos fatores influentes na constante dielétrica dos solos, entre eles:

- Temperatura: Davis \& Chudobiak (1975) encontraram um aumento de $10 \%$ na constante dielétrica para um aumento de $39^{\circ} \mathrm{C}$ na temperatura de solos arenosos e argilosos. Segundo Look \& Reeves (1982), temperaturas na faixa de $0^{\circ} \mathrm{C}$ a $25^{\circ} \mathrm{C}$ tem efeito mínimo sobre a constante dielétrica do solo, contradizendo Mansukhani e Selig (1975) e Rada et al. (1994) que encontraram efeito significativo para essa mesma faixa de temperatura.

- Textura do solo: de acordo com Dobson et al. (1985), Roth et al. (1990) e Dasberg \& Hopmans (1992), este efeito não deve ser desprezado tal como colocado por Topp (1980), principalmente no caso de solos argilosos. Segundo Klemunes Jr. (1998), solos argilosos e arenosos tem composições minerais distintas: nos argilosos predominam magnésio e cálcio, enquanto nos arenosos, sílica e quartzo. Essa diferença produz uma grande variação nos valores de constante dielétrica: cerca de 4,0 para solos de textura argilosa e 8,0 para solos de textura arenosa

- Densidade do solo: de acordo com Hallikhainen et al. (1985), a constante dielétrica do solo é função da sua densidade. Para solos de textura fina, a densidade é uma variável importante na determinação da constante dielétrica (Tommaselli, 1997).

- Teor de matéria orgânica: de acordo com Herkelrath et al. (1991), a constante dielétrica está relacionada ao conteúdo de matéria orgânica. 
- Teor de sais no solo: Na técnica TDR a constante dielétrica é representada por um numero complexo, assumindo-se que a componente imaginária é desprezível (Roth et al. 1990). Porém, este fato não é verdadeiro sob condições alta salinidade. Nestas condições pode ocorrer um curto-circuito, tornando difícil a identificação do ponto de inflexão final (Scott et al., 1983)

- Teor de óxido de ferro e manganês no solo: para Tommaselli (1997) não é variável significativa. Roth et al. (1990) detectaram variações na curva de calibração para solos com altos teores de óxido de ferro.

- Outros: além dos efeitos das propriedades do solo sobre a constante dielétrica, existem fatores de ordem técnica que afetam as medidas, tais como: ruídos eletromagnéticos, especificação do cabo coaxial e metodologia para obtenção do comprimento aparente (Klemunes Jr. 1998). 


\section{MATERIAIS E MÉTODOS}

Neste capítulo estão apresentados detalhadamente os materiais, equipamentos utilizados, procedimentos e metodologias utilizados nas etapas de campo e de laboratório.

\subsection{REJEITOS}

A empresa Mineração Jundu Ltda. trabalha com a mineração de areias para diversas aplicações industriais dentre as quais a fabricação de vidro e moldes de fundição para a indústria metalúrgica. A fração de argila (rejeito) é separada da fração de areia através de processos físicos. Sendo o rejeito encaminhado para lagoas de decantação contidas por barragens.

Foram coletadas amostras de rejeitos da lagoa de contenção número 9 da Mineração Jundu Ltda, localizada no município de Descalvado/SP. As coletas foram realizadas na região do vertedouro da barragem (saída dos fluidos) (Figura 3.1b) e no canal de descarga do rejeito (entrada dos fluidos) na lagoa de contenção (Figura 3.1d). Esta coleta possibilitou a amostragem dos extremos em termos de variabilidade.

A região da lavra é pertencente à Formação Pirambóia Figura 3.1a. Na área estudada foram caracterizados corpos de arenitos grossos e conglomeráticos, de origem fluvial, sempre intercalados verticalmente ou associados lateralmente a arenitos finos a médios, de origem eólica (Caetano-Chang e Wu, 2006). 

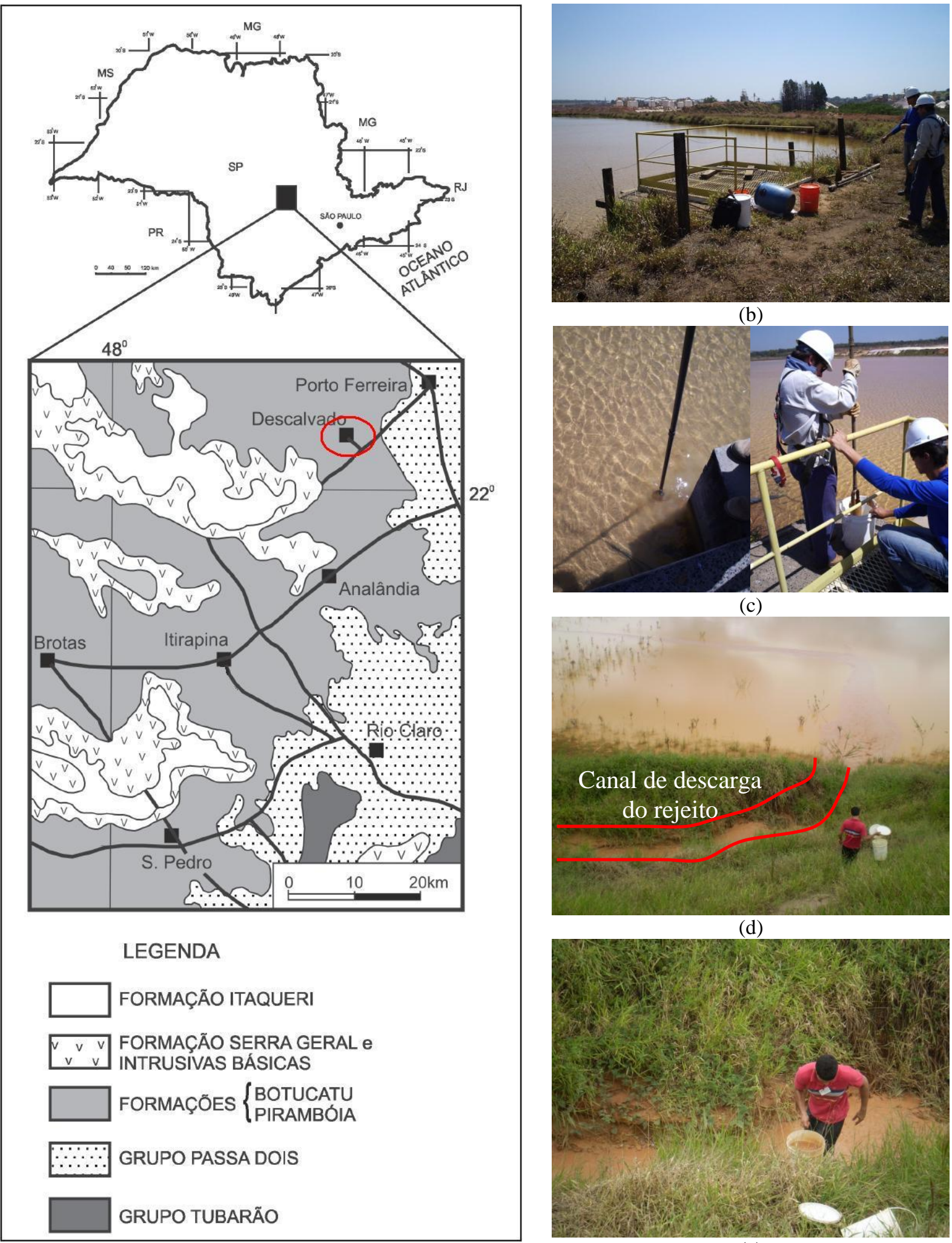

(c)

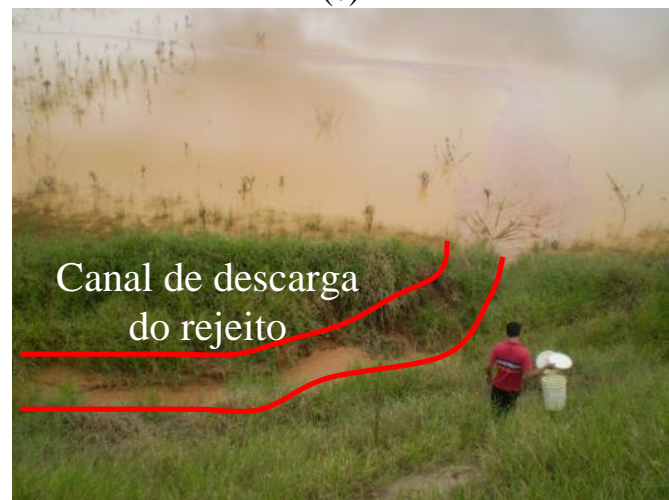

(d)

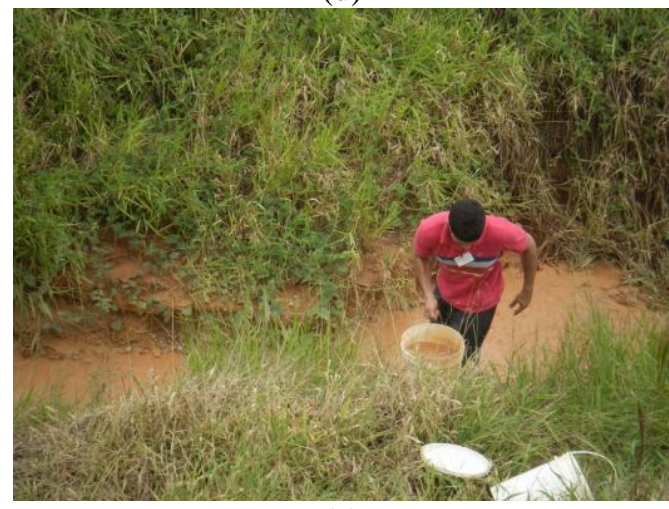

(e)

Figura 3.1 - Local de coleta das amostras: (a) mapa geológico do local de lançamento do rejeito na lagoa; (b) e (c) detalhes da coleta da amostra do vertedouro; (d) e (e) detalhes da coleta no local no lançamento dos rejeitos (espigotamento). 
A caracterização geotécnica do rejeito foi realizada de acordo com os métodos propostos pela Associação Brasileira de Técnicas (ABNT): NBR 7181/84 - Análise Granulométrica; NBR 6508/84 - Solo: Massa Específica Real dos Grânulos; NBR 6459/84 Determinação do Limite de Liquidez; NBR 7180/84 - Determinação do Limite de Plasticidade.

\subsection{CONSOLIDAÇÃO INDUZIDA POR PERCOLAÇÃO (HCT)}

\subsubsection{Base do procedimento para a determinação dos parâmetros de consolidação}

Como já foi mencionado anteriormente, para relacionar a tensão efetiva $\left(\sigma^{\prime}\right)$ com o índice de vazios (e) utiliza-se a função de potência estendida

$$
e=A\left(\sigma^{\prime}+Z\right)^{B}
$$

Esta expressão elimina a maioria das deficiências dos modelos logarítmicos convencionais. $\mathrm{O}$ índice de vazios além de ser perfeitamente definido para tensão efetiva nula, nunca se torna negativo independentemente do valor da tensão efetiva.

A condutividade hidráulica $(k)$ é relacionada com o índice de vazios (e) através da função de potência convencional.

$k=C e^{D}$

O processo de consolidação de solos moles pode ser adequadamente representado através da teoria da consolidação com grandes deformações, originalmente formulada por Gibson et al.(1967). A equação que governa o processo é dada por: 
$\mp\left(\frac{\gamma_{s}}{\gamma_{w}}-1\right)\left[\frac{d}{d e}\left(\frac{k}{1+e}\right)\right] \frac{\partial e}{\partial z}-\frac{\partial}{\partial z}\left[\frac{k}{\gamma_{w}(1+e)} \frac{d \sigma^{\prime}}{d e} \frac{\partial e}{\partial z}\right]=\frac{\partial e}{\partial t}$

onde $z$ representa a coordenada material, sendo considerada positiva na direção da ação da gravidade, e $t$ representa o tempo. No caso de condição estacionária, o índice de vazios não varia com o tempo, e a Equação (2.39) pode ser reescrita na forma:

$\left[\frac{d}{d e}\left(\frac{k}{1+e}\right)\right] \frac{\partial e}{\partial z}-\frac{\partial}{\partial z}\left[\frac{k}{\gamma_{w}(1+e)} \frac{d \sigma^{\prime}}{d e} \frac{\partial e}{\partial z}\right]=0$

Quando utilizada com as condições de contorno apropriadas, a Equação (3.1) proporciona a distribuição dos índices de vazios através de uma camada de solo mole, submetida a um fluxo de água estacionário.

A partir da distribuição dos índices de vazios, pode-se então determinar a distribuição de tensões efetivas, bem como a altura da camada. A Equação (3.1) deixa claro que as relações constitutivas tanto de permeabilidade como de compressibilidade influenciam na distribuição dos índices de vazios para uma condição estacionária. Desta forma, o ensaio de adensamento induzido por percolação em um estado estacionário é apropriado e suficiente para a determinação das propriedades constitutivas de adensamento.

A utilização de um estado estacionário, ao invés de um estado transiente, traz muitas vantagens. Por exemplo, é muito mais fácil efetuar medições confiáveis no estado estacionário do que no estado transiente do teste. Eventuais retardos na resposta da instrumentação, devido à acomodação do sistema, tem menor efeito em quantidades medidas em condições estacionárias do que em condições transientes. 
A utilização da condição estacionária como a base para a determinação das características de adensamento é que distingue o presente método de outros baseados na análise ensaios com estados transientes (Been e Sills, 1981).

No ensaio de adensamento induzido por percolação, na condição estacionária, a velocidade da fase sólida da amostra é nula, sendo a velocidade aparente da fase líquida constante ao longo da amostra e constante com o tempo. Desta forma, a velocidade relativa aparente entre a fase sólida e a fase líquida é igual à velocidade de Darcy $\left(q_{v}=Q / A\right)$. Combinando-se a equação de equilíbrio, o princípio da tensão efetiva e a lei de Darcy, em termos de velocidade aparente relativa entre as fases líquida e sólida, pode-se deduzir a seguinte expressão:

$q_{v}= \pm\left(\frac{\gamma_{s}}{\gamma_{w}}-1\right) \frac{k}{1+e}+\frac{k}{\gamma_{w}(1+e)} \frac{d \sigma^{\prime}}{d e} \frac{\partial e}{\partial z}$

A coordenada material $(z)$ identifica a altura de sólidos a partir da face superior da amostra $(z=0)$ ao ponto de interesse. Deve-se notar que na base da amostra a coordenada material $(z)$ é igual à altura de sólidos $(H s)$ contidos na amostra.

A Equação (3.3) fornece a tensão efetiva vertical em qualquer profundidade da amostra, em função da distribuição dos índices de vazios acima da coordenada material $z$.

$\sigma^{\prime}(z)=\sigma_{0}^{\prime}+\left(\gamma_{s}-\gamma_{w}\right) z+\int_{0}^{z} \frac{q_{v} \gamma_{w}}{k}(1+e) d z$

Nesta expressão, a tensão efetiva e a permeabilidade são expressas em termos de índice de vazios utilizando-se as Equações (2.7) e (2.8.), respectivamente. 


\subsubsection{Realização do ensaio}

O ensaio de HCT consiste de quatro etapas distintas: determinação do índice de vazios para tensão efetiva nula, consolidação hidráulica induzida por percolação, ensaio de carregamento em etapas e o ensaio de condutividade hidráulica. Conforme descrito a seguir:

a. Após a preparação da amostra com teor de umidade superior a $450 \%$ determina-se o índice de vazios correspondente à tensão efetiva nula $\left(e_{o o}\right)$, conforme será visto no item 3.2.7;

b. Aplicar uma vazão constante através da amostra com auxílio de uma bomba de fluxo. Medir a diferença de pressão entre o topo e a base da amostra $\left(\Delta P_{S}\right)$. Quando essa diferença de pressão tornar-se constante, a altura final da amostra $\left(H_{f}\right)$ é medida. Segundo Znidarcic et al. (1992) esse valor de diferença de pressão nunca pode ser inferior a $0,3 \mathrm{kPa}$ e superior a $10 \mathrm{kPa}$. Em seguida calcula-se a tensão efetiva na sua base $\left(\sigma_{b}^{\prime}\right)$ com a Equação (3.4);

$\sigma_{b}^{\prime}=\sigma_{0}^{\prime}+\gamma_{w} H s\left(G_{S}-1\right)+\Delta P_{S}$

onde:

$H_{S}=\frac{W_{d}}{G_{S} \gamma_{w} A_{S}}=$ altura equivalente de sólidos contidos na amostra (m);

$W_{d}=$ peso seco da amostra $(\mathrm{kN})$;

$A_{s}=$ área da seção transversal da amostra $\left(\mathrm{m}^{2}\right)$;

$\Delta P_{s}=$ Diferença de pressão entre o topo e a base para a etapa de consolidação hidráulica induzida por forças de percolação $(\mathrm{kPa})$. 
c. Aplicação de tensões efetivas verticais incrementais $\left(\sigma_{L}^{\prime}\right)$ no topo da amostra, monitorando o deslocamento vertical resultante ao longo do tempo. Quando esse deslocamento estabilizar, mede-se a altura da amostra $\left(H_{L}\right)$ e calcula-se o índice de vazios correspondente $\left(e_{L}\right)$ utilizando a Equação (3.5).

$e_{L}=\left(\frac{{ }_{H_{L}}}{{ }_{H}}\right)-1$

d. Finalmente, para o mesmo carregamento, realiza-se o ensaio de condutividade hidráulica, impondo-se uma vazão $(q)$ constante. Uma vez alcançada atingida à condição permanente, ou seja, quando a diferença de pressão entre o topo e a base for constante, registra-se este valor $\left(\Delta P_{L}\right)$ e calcula-se o coeficiente de condutividade hidráulica $\left(k_{L}\right)$ por meio da Equação (3.6).

$k_{L}=\frac{v^{*} H_{L} * \gamma_{w}}{\Delta P_{L}}$

onde:

$v=\frac{q}{A_{S}}=$ velocidade de fluxo imposta $(\mathrm{m} / \mathrm{s})$

$\Delta P_{L}=$ Diferença de pressão para o ensaio de condutividade hidráulica $(\mathrm{kPa})$.

\subsubsection{Determinação dos parâmetros constitutivos do processo de consolidação.}

Os parâmetros constitutivos do processo de consolidação podem ser determinados com o auxilio do programa SICTA desenvolvido na Universidade do Colorado. O objetivo desse programa é determinar o melhor conjunto de parâmetros constitutivos A, B, C, D e Z 
que aparecem nas expressões de compressibilidade e condutividade hidráulica. O programa foi escrito em linguagem FORTRAN, adotando a técnica sugerida por Abu-Hejeleh et al. (1996).

Com os valores de tensão efetiva nula $\left(e_{00}\right)$, e resultados índice de vazios $e_{L} \mathrm{e}$ tensão efetiva na base $\sigma_{L}^{\prime}$ para a etapa de condutividade hidráulica, além do coeficiente de condutividade hidráulica $k_{L}$. pode-se reduzir o número de parâmetros a serem determinados de cinco para apenas dois. Escolhendo-se $B$ e $D$ como parâmetros independentes, os demais parâmetros são determinados com o auxílio das seguintes expressões:

$$
\begin{aligned}
& Z=\frac{\sigma_{L}^{\prime}}{\left(\frac{e_{L}}{e_{00}}\right)^{\frac{1}{B}}-1} \\
& A=\frac{e_{00}}{Z^{B}} \\
& C=\frac{k_{L}}{\left(e_{L}\right)^{D}}
\end{aligned}
$$

Onde:

$\sigma_{L}^{\prime}=$ tensão efetiva vertical medida no ensaio de carregamento

$e_{L}=$ índice de vazios medido no ensaio de carregamento

$e_{00}=$ índice de vazios correspondente à tensão efetiva nula

$k_{L}=$ coeficiente de permeabilidade medido no ensaio de permeabilidade

Os outros dados necessários para a estimativa dos parâmetros de adensamento são:

- $\quad$ estimativa inicial dos parâmetros $B$ e $D$;

- limites superiores e inferiores para os parâmetros $B(b l, b h)$ e $D(d l, d h)$. 
Os parâmetros atuais $B$ e $D$ são armazenados em um vetor $x(2)$. Na iteração $k$, o parâmetro $B$ é armazenado como $a 1(k)$ e o parâmetro $D$ é armazenado como $a 2(k)$.

A atualização dos antigos valores dos parâmetros $B$ e $D$ (ou vetor $x$ ) para uma melhor estimativa é feita utilizando-se a aproximação de Newton. Este método está baseado na linearização das alterações no vetor de diferenças normalizadas $h b$ em relação ao vetor $x$, na atual iteração.

O programa SICTA requer os seguintes dados de entrada:

- Ensaio de adensamento induzido por percolação:

1. título:

2. peso específico da água: $\gamma_{w}$

3. peso específico das partículas sólidas: $\gamma_{s}$

4. altura inicial do corpo de prova: $H_{\mathrm{o}}$

5. índice de vazios correspondente à tensão efetiva nula: $e_{o o}$

6. tensão efetiva aplicada à superfície do corpo de prova: $\sigma_{o}$,

7. velocidade de Darcy: $v$

8. altura final do corpo de prova: $H_{f}$

9. tensão efetiva final na base do corpo de prova: $\sigma_{b}$,

- Ensaio de carregamento por etapas e determinação da condutividade hidráulica:

1. índice de vazios: $e_{L}$

2. tensão efetiva: $\sigma_{L}{ }^{\prime}$

3. coeficiente de permeabilidade: $k_{L}$

A saída do programa, além de fornecer os valores dos parâmetros constitutivos $A$, $B, Z$, $C$ e $D$, fornecem também o perfil dos índices de vazios ao longo da altura do corpo de prova. 


\subsubsection{Equipamento}

Para realização do ensaio de adensamento hidráulico induzido (HCT) foi construído um equipamento ilustrado esquematicamente na Figura 3.2. e Figura 3.3. O equipamento é composto por:

- Câmara de adensamento composta por uma célula triaxial modificada (ELE modelo T-1221);

- Transdutor diferencial de pressão da marca Sensotec, modelo Z-2 com capacidade de $69 \mathrm{kPa}$, um transdutor de pressão convencional da marca Instrutherm, modelo PS-100 com capacidade de $690 \mathrm{kPa}$;

- Bomba de fluxo da marca Cole-Parmer, modelo E-74900-20;

- Célula de carga da marca MK Controle, modelo CSA/ZL-200 com capacidade de $1,96 \mathrm{kN}$;

- Transdutor de deslocamento linear (LVDT) da marca Sensotec, modelo MVL7 com cursor de 50,8 mm;

- Painel de controle de pressões;

- Interface de pressão;

- Sistema de carregamento (cilindro pneumático) da marca Parker modelo EH49STD;

- Sistema de aquisição de dados da marca Wykeham Farrance, modelo WF17920. 


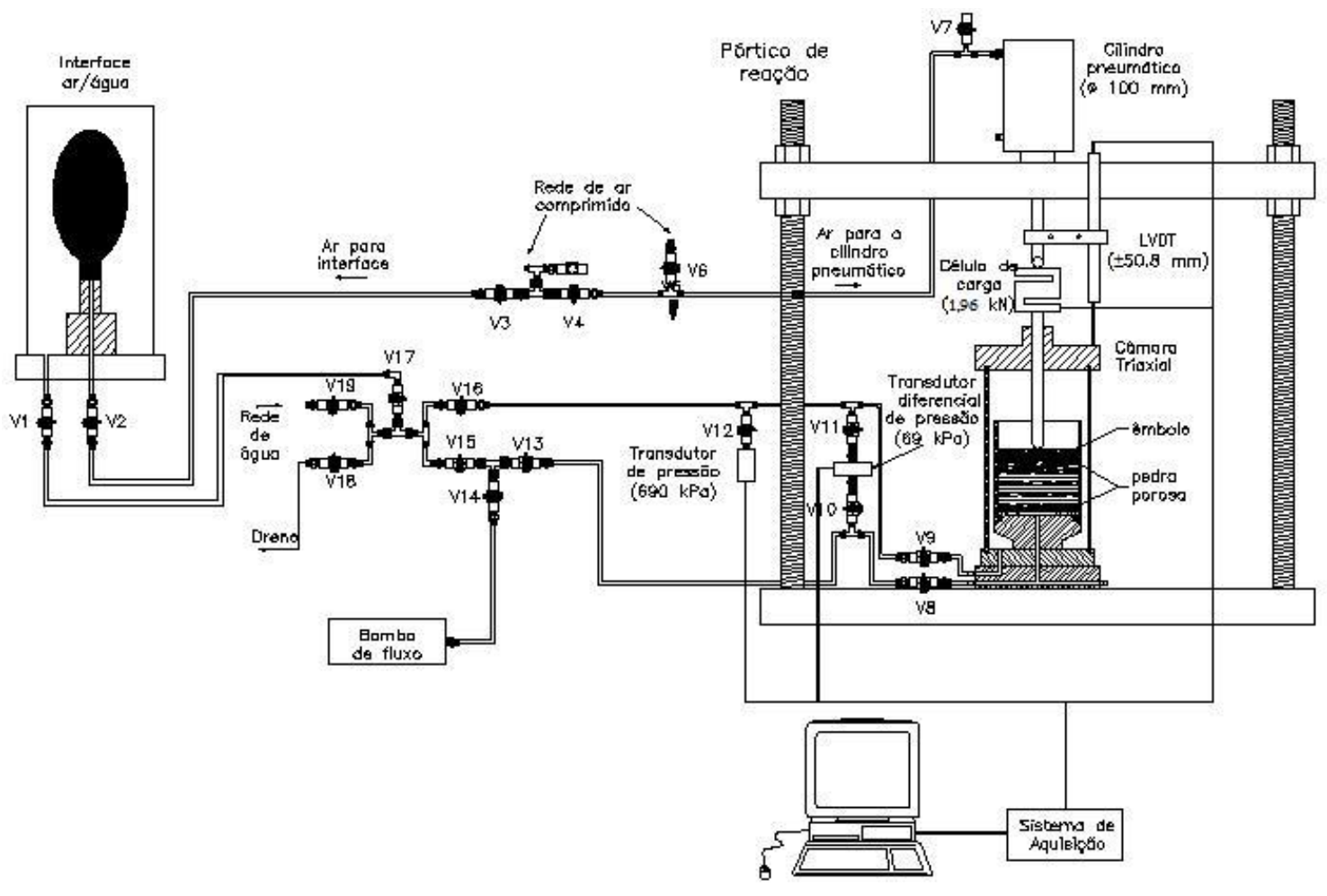

Figura 3.2 - Esquema geral do equipamento para a realização do Ensaio HCT

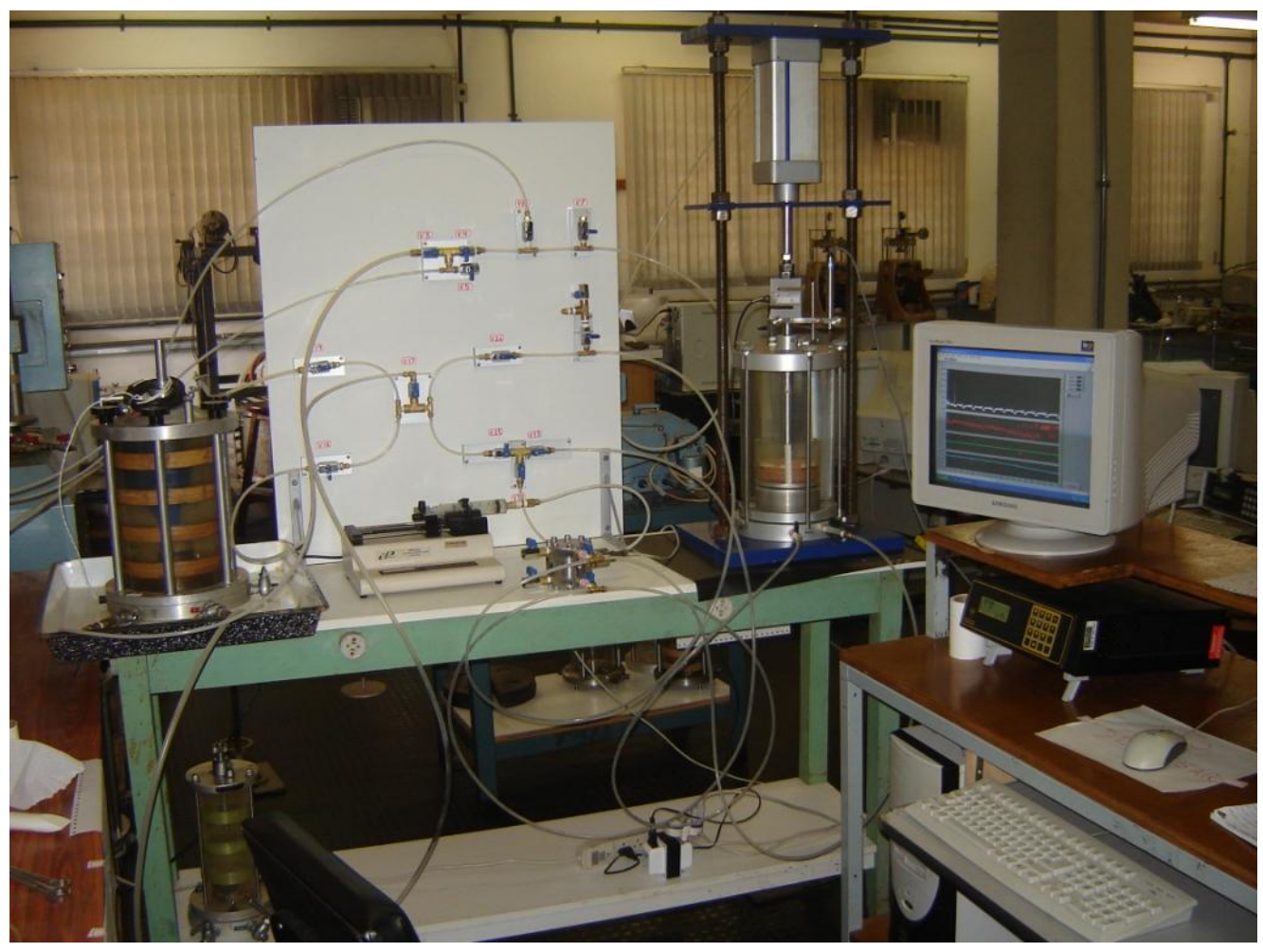

Figura 3.3 - Foto do equipamento HCT 


\subsubsection{Câmara de adensamento}

A câmara de adensamento é composta por uma célula triaxial triaxial, cuja base é modificada para possibilitar o encaixe de um tubo de acrílico, formando então, a célula onde é colocado o material a ser ensaiado Figura 3.4a. A célula da amostra tem um diâmetro interno de $92,4 \mathrm{~mm}$ e uma altura máxima de $210 \mathrm{~mm}$. A estanqueidade da célula da amostra é conseguida através da instalação de um $O$-ring no contato entre a base e tubo de acrílico, garantindo assim que todo o fluxo de água controlado pela bomba de fluxo seja forçado através da amostra.

Para facilitar a uniformização do fluxo de água através da amostra, a base da célula da amostra é provida de sulcos radiais e circunferências na sua face superior Figura 3.3b. Entre a amostra e a base é colocada uma placa de material poroso e papel filtro. A célula da amostra é parafusada na base da câmara de adensamento. A vedação é feita com o auxílio de $O$-rings.

As cargas são aplicadas à amostra por meio de um êmbolo de plástico (Top Cap) e uma pedra poroso Figura 3.3c. O êmbolo é dimensionado de modo que, quando a amostra está submersa, a carga devido ao seu peso próprio seja de aproximadamente $0,1 \mathrm{kPa}$. Esta carga é aplicada à amostra desde o início do ensaio, a fim de se prevenir a formação de canais de fluxo durante a fase de adensamento induzido por percolação (Liu, 1990). A carga externa aplicada pelo sistema de carregamento, cuja descrição é apresentada posteriormente, é transferida ao êmbolo através da haste da célula triaxial. 


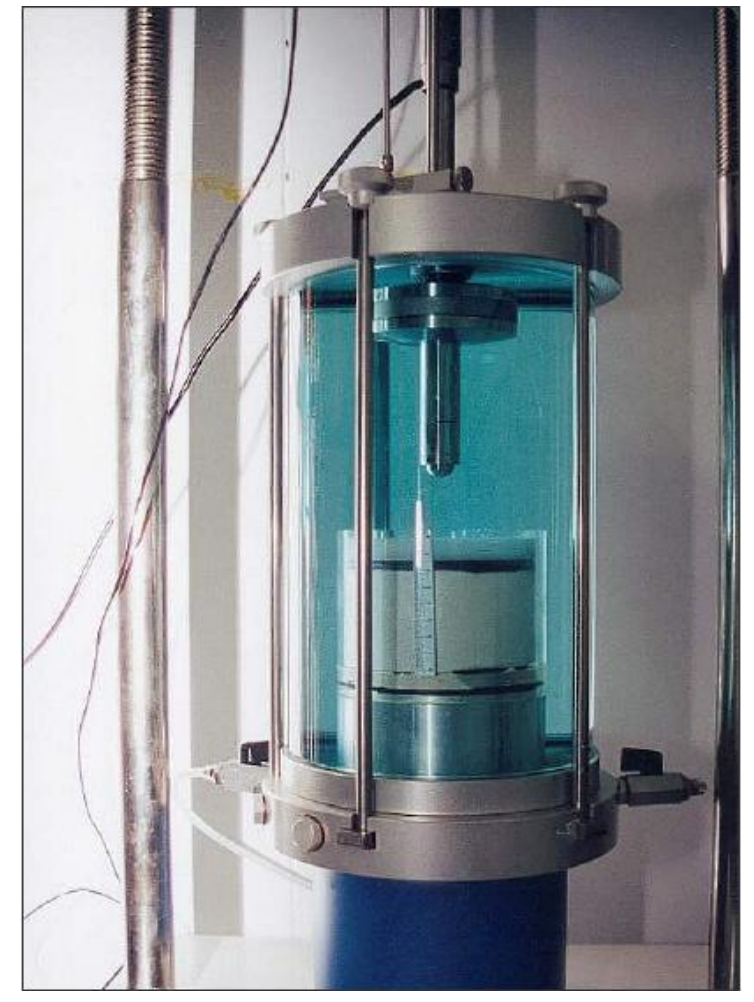

(a)

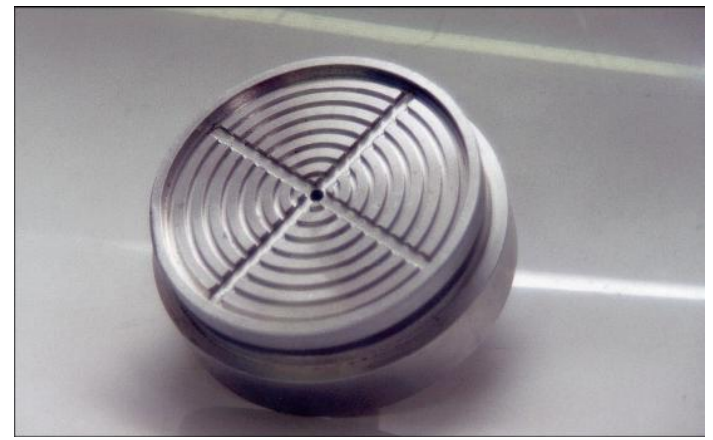

(b)

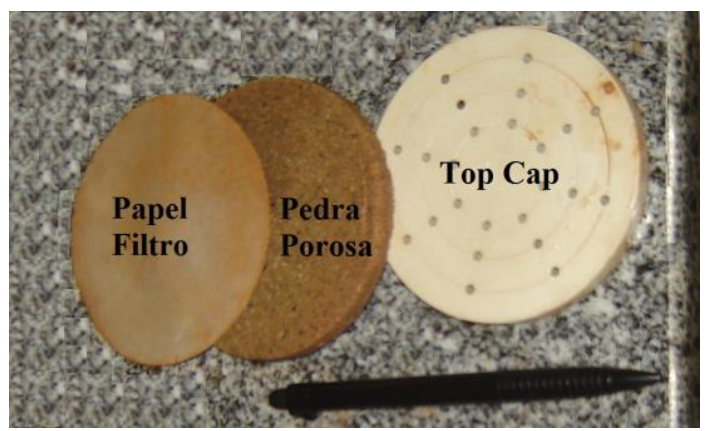

(c)

Figura 3.4 - Câmara de Adensamento: (a) Célula triaxial modificada, (b) Sulcos na face da base da célula da amostra e (c) Itens que vão no topo da amostra: papel filtro, pedra porosa e top cap.

No ensaio de adensamento induzido por percolação, é essencial a determinação da diferença entre a poro-pressão existente na face superior e inferior da amostra. Para tanto, utiliza-se um transdutor de pressão diferencial, com capacidades máximas intercambiáveis de 2 psi $(13,79 \mathrm{kPa})$ e 10 psi $(68,95 \mathrm{kPa})$, respectivamente (Figura 3.5). 


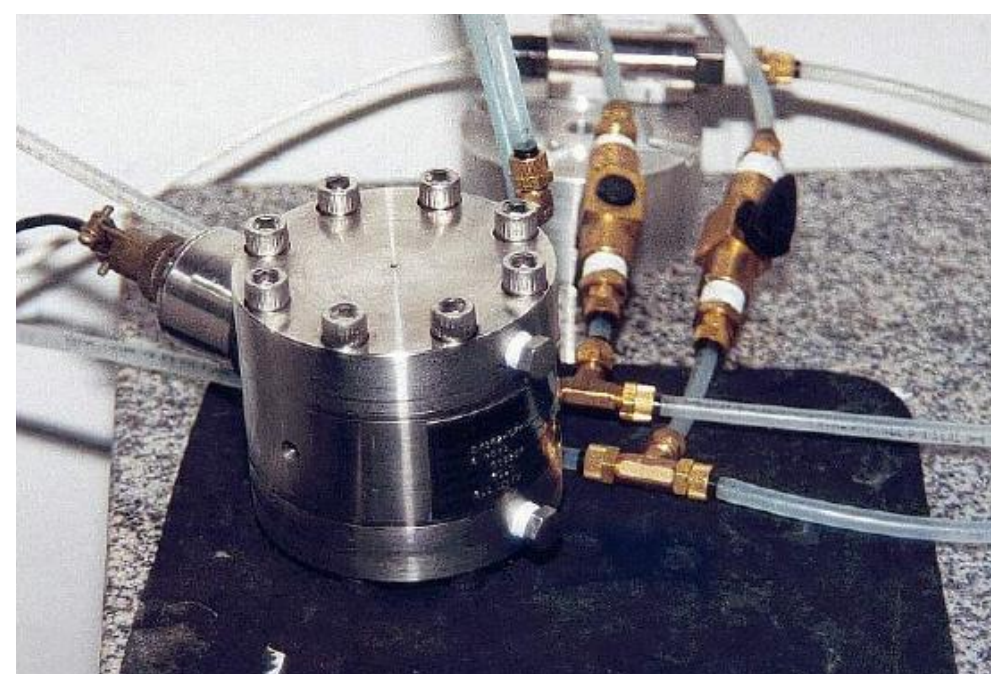

Figura 3.5 - Transdutor de pressão diferencial.

Além das duas portas usadas para medir as pressões, este transdutor também possui duas aberturas que são utilizadas para saturar o sistema. Uma das portas está conectada à base da amostra e a outra à linha de proveniente do reservatório de água que provê a pressão de confinamento. Deve-se notar que, como a pressão de confinamento atua na amostra durante todo o teste, o transdutor de pressão diferencial mede, então, a diferença de pressão induzida nas faces da amostra durante o ensaio.

Para uma avaliação rápida da altura da amostra, durante a fase de adensamento induzido por percolação, o tubo de acrílico é dotado de uma escala milimétrica. Durante a fase de carregamento por etapas, a altura exata da amostra é determinada através de um transdutor de deslocamento linear (LVDT) conectado à haste da célula triaxial. Este transdutor de deslocamento linear tem a capacidade para fazer medidas no intervalo \pm 2 " $( \pm 50,8 \mathrm{~mm}) \mathrm{e}$ possui um condicionador de sinais que os envia para o sistema de aquisição de dados.

Para facilitar o enchimento da câmara de adensamento com água, existe uma válvula (válvula de respiro) na sua parte superior, de modo que o ar possa escapar durante a operação de enchimento. 


\subsubsection{Painel de controle de pressões}

O painel de controle de pressões tem finalidade de proporcionar a pressão de confinamento requerida na câmara de adensamento e prover pressão de ar ao sistema de carregamento.

A seção referente à pressão de confinamento consiste nos seguintes componentes: uma câmara para ensaio triaxial resistente até 1,7 MPa de interface de pressão, um regulador de pressão de ar, um manômetro, um transdutor de pressão, válvulas e tubos de conexão. A interface de pressão (Figura 3.6) foi construída com uma célula triaxial, membrana flexível e O-rings.

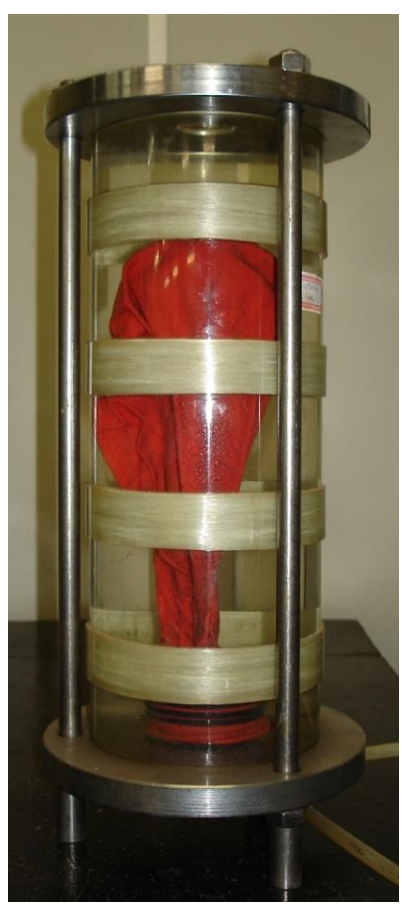

(a)

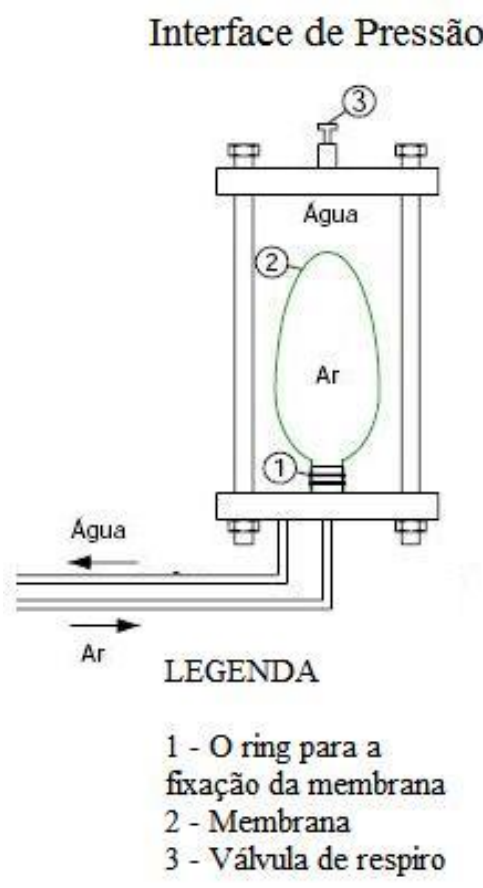

(b)

Figura 3.6 - Interface de Pressão : (a) Foto da Interface e (b) Esquema da Interface

Toda a pressão de ar colocada na membrana é transferida para a água contida na câmara triaxial. A pressão de ar é controlada por meio de um regulador de pressão. A pressão de água é duplamente monitorada: diretamente, com o auxílio de um transdutor de pressão e, 
indiretamente, através de um manômetro que mede a pressão de ar aplicada. $\mathrm{O}$ manômetro permite uma rápida avaliação da pressão de confinamento, enquanto que o transdutor permite o seu registro ao longo do tempo, através do sistema de aquisição de dados.

A seção referente ao sistema de carregamento é constituída do cilindro pneumático, um regulador de pressão de precisão, um manômetro, um transdutor de pressão, válvulas e tubos de conexão. O regulador de pressão é da marca Norgren ${ }^{\circ}$, modelo 11-108A, para pressão de ar de até $1000 \mathrm{kPa}$. A pressão de ar aplicada ao sistema de carregamento é monitorada, através de um manômetro. A importância do transdutor é a possibilidade de se poder registrar o carregamento aplicado ao longo do tempo.

\subsubsection{Bomba de fluxo}

A bomba de fluxo é constituída de uma bomba de seringas, de uso hospitalar, que utiliza seringas comerciais com a capacidade de até $60 \mathrm{ml}$ (Figura 3.7). Esta bomba possibilita a aplicação à amostra de um fluxo preciso, dentro de um intervalo contínuo entre $0,001 \mu 1 /$ hora e $147 \mathrm{ml} /$ minuto.

\subsubsection{Sistema de carregamento}

Para o sistema de carregamento foi utilizado um cilindro pneumático (Figura 3.8), com diâmetro interno nominal de 100 mm. 


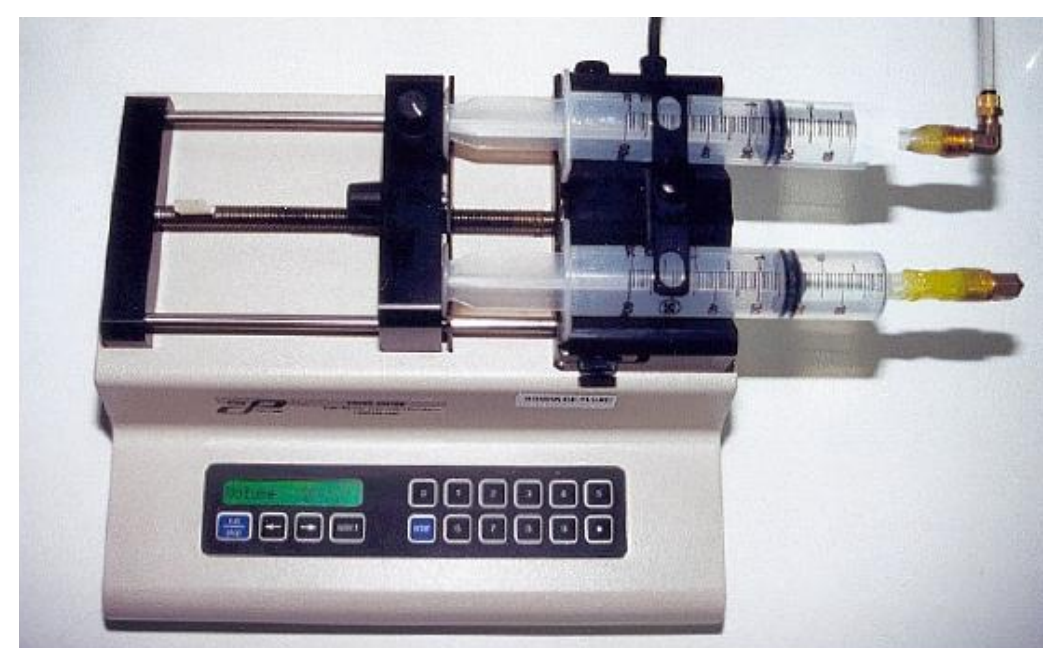

Figura 3.7 - Bomba de Fluxo

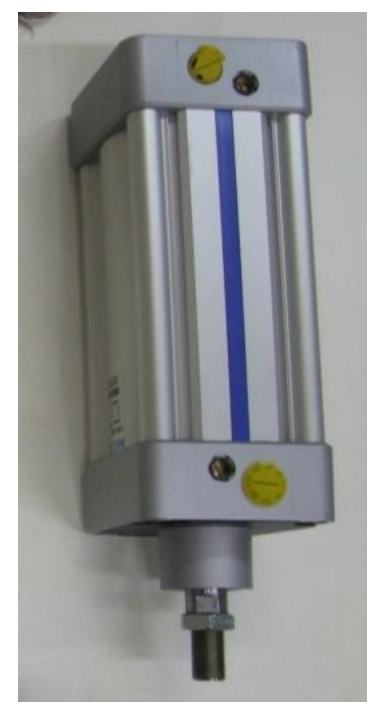

Figura 3.8 - Cilindro Pneumático

\subsubsection{Sistema de aquisição de dados e instrumentação}

O sistema de aquisição de dados é constituído de um computador pessoal, um módulo de monitoramento de dados de 16 bits com quatro canais da marca Wykeham Farrance®, programa de aquisição de dados, um transdutor diferencial de pressão, um transdutor de pressão, um transdutor de deslocamento (LVDT) e uma célula de carga. 
O módulo de monitoramento de dados tem a função de excitar os transdutores e, ao mesmo tempo, ampliar e converter o sinal analógico para um sinal digital, que podem ser tabelados. Outra importante opção no módulo de monitoramento têm a capacidade de realizar leituras a cada segundo. Para este trabalho em virtude do tempo de ensaio e da quantidade de dados gerados, foi feita a escolha de um intervalo de aquisição de 10 segundos.

\subsubsection{Calibração dos sensores}

A calibração do sensor de pressão diferencial foi realizada com o uso de dois atuadores de pressão servo-controlados da marca GDS® e módulo de aquisição de dados. Foram simultaneamente aplicados incrementos de $50 \mathrm{kPa}$ de pressão em ambas as portas do sensor diferencial com o auxilio dos atuadores de pressão, até o limite de $200 \mathrm{kPa}$, pressão adotada como confinamento da amostra durante a realização dos ensaios. Após chegar essa condição, foram aplicados incrementos de pressão de $1 \mathrm{kPa}$ em um dos atuadores até o limite de $20 \mathrm{kPa}$ de diferença de pressão. Foram realizados ciclos de carga e descarga para verificar a ausência de histerese. Os equipamentos utilizados para a realização da calibração do sensor diferencial de pressão estão apresentados na Figura 3.9. 


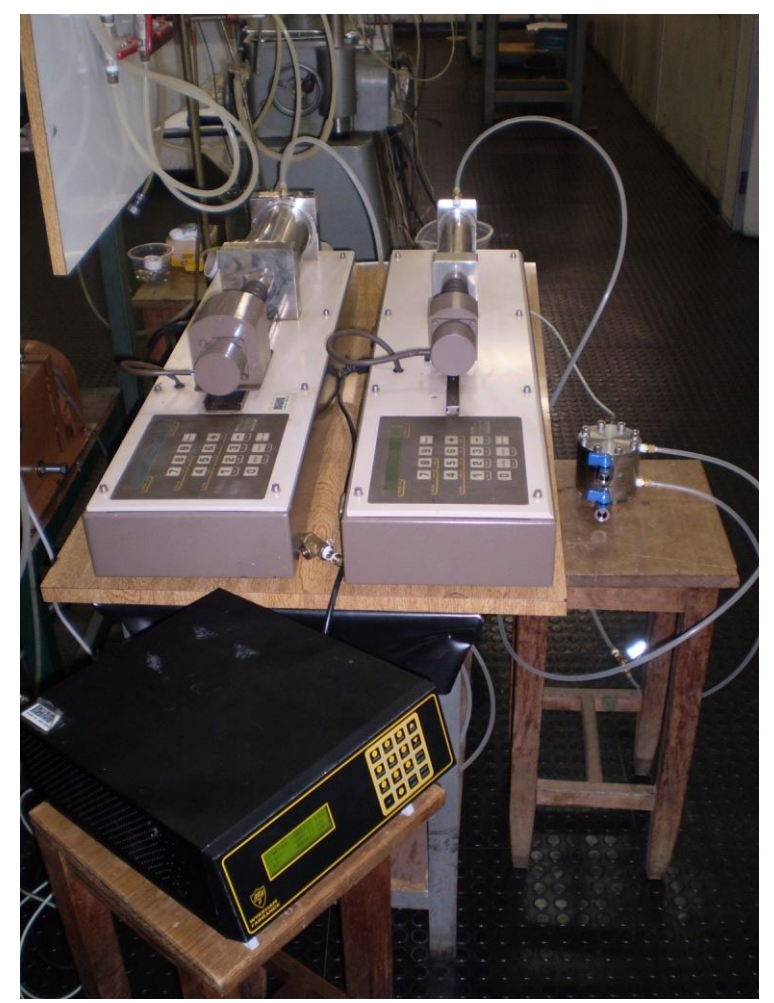

Figura 3.9 - Calibração do sensor diferencial

Na calibração do sensor de pressão convencional também foi utilizado um atuador de pressão, e um módulo de aquisição de dados. Foram aplicados incrementos de carga de 10 $\mathrm{kPa}$ até o limite $250 \mathrm{kPa}$. Sendo realizados ciclos de carga e descarga para verificar a ausência de histerese.

Para a calibração do transdutor de deslocamento linear foi utilizada uma prensa elétrica, um relógio comparador analógico com um cursor de $50 \mathrm{~mm}$ e um módulo de aquisição de dados. Foram realizados deslocamentos incrementais de $5 \mathrm{~mm}$, sendo realizadas leituras para ciclos de encurtamento e alongamento.

Para a calibração da célula de carga foram utilizados: uma prensa elétrica, um módulo de aquisição de dados, outra célula de carga previamente calibrada e um computador. Foram aplicados incrementos de carga de $0,098 \mathrm{kN}$ até o limite de $1 \mathrm{kN}$, bem como realizados ciclos de carregamento e descarregamento, para verificar ausência de histerese. 


\subsubsection{Recomendações operacionais do equipamento que realiza o ensaio HCT}

Este item tem por objetivo descrever toda a seqüência de utilização do equipamento em todas as etapas do ensaio. Deve-se tomar como referência a Figura 3.2

\subsubsection{Saturação do sistema}

1. Abrir a válvula do reservatório de água.

2. Abrir a válvula do reservatório de água deaerada.

3. Abrir a válvula 19.

4. Abrir a válvula 18 e aguardar a saída das bolhas de ar do sistema.

5. Abrir a válvula 17 .

6. Abrir a válvula de respiro da interface de pressão.

7. Abrir a válvula 1 aguardar a saída das bolhas de ar do sistema.

8. Após o enchimento da interface e a saída de todas as bolhas de ar, deve-se fechar a válvula de respiro da mesma.

9. Abrir as válvulas 16 e 12 e aguardar a saída das bolhas de ar do sistema.

10. Desconectar as mangueiras das válvulas 14,9 e 8 e aguardar a saída das bolhas de ar do sistema.

11. Abrir as válvulas 13, 14 e 15 e aguardar a saída das bolhas de ar do sistema.

12. Reconectar as mangueiras das válvulas 9,8 e reconectar a mangueira da seringa da bomba de fluxo.

13. Conectar a mangueira da válvula 14 na seringa, posicionar, prender e travar a seringa na bomba de fluxo. 
14. Saturar o transdutor diferencial de pressão através da abertura de suas portas de saturação e da abertura das válvulas 10 e 11. Após o procedimento anterior deve-se aguardar a saída das bolhas de ar do sistema.

15. Após a saturação da pedra porosa inferior, colocá-la na base da câmera de adensamento.

16. Abrir a válvula 8 para injetar água e garantir a saturação da pedra, mantendo uma camada de $2 \mathrm{~mm}$ de água acima da pedra porosa.

17. Colocar o papel filtro sobre a pedra porosa, tomando cuidado para não formar bolhas de ar entre a pedra porosa e o papel filtro.

18. Depositar o rejeito em forma de lama com um teor de umidade próximo a $450 \%$.

19. Colocar o papel filtro superior e adicionar água formando uma lamina de $40 \mathrm{~mm}$ (tomar cuidado para não perturbar a amostra)

20. Deixar a mesma sedimentar por 2 horas.

21. Com auxilio de 2 linhas de nylon finas, colocar o conjunto pedra porosa e embolo de plástico sobre o material; retirar cuidadosamente as linhas.

22. Fechar a câmera triaxial.

23. Abrir a válvula 9 e a válvula de respiro da câmara triaxial, permitindo a saída de todas as bolhas de ar do sistema.

24. Fechar a válvula do reservatório de água deaerada.

\subsubsection{Etapa de consolidação induzida por percolação}

1. Conectar o sistema a rede de ar. 
2. Fechar a válvula do reservatório de água deaerada.

3. Realizar ajustes de pressão na entrada de ar (iniciar com $50 \mathrm{kPa}$ ).

4. Abrir as válvulas 3 e 2 .

5. Abrir as válvulas $1,19,17,16,13,15$ e 14 .

6. Abrir simultaneamente as válvulas $8,9,10$ e 11 .

7. Aplicar gradualmente a pressão de confinamento até atingir o limite de $200 \mathrm{kPa}$

8. Fecha a válvula 15 .

9. Ajustar a bomba de fluxo para a vazão predeterminada.

10. Ligar a bomba de fluxo.

\subsubsection{Etapa da Condutividade Hidráulica}

1. Fixar o transdutor de deslocamento (LVDT) no pistão de carregamento da câmara triaxial.

2. Destravar o pistão de carregamento, conduzindo manualmente até tocar levemente o Embolo de Plástico. Neste instante deve ser zerada a leitura do módulo de aquisição de dados.

3. Instalar a célula de carga entre o pistão de carregamento da célula triaxial e o pistão do cilindro pneumático.

4. Fechar a válvula 14 e abrir a válvula 6 .

5. Aplicar uma pequena pressão de ar comprimido no cilindro pneumático (de 1 a $5 \mathrm{kPa}$ ) para dar início ao carregamento, evitando-se assim uma grande perturbação na amostra. 
6. Acompanhar a evolução dos deslocamentos. Quando esses deslocamentos estabilizarem; aumentar a pressão de ar até o nível desejado.

7. Repetir os procedimentos 8,10 e 11 da etapa de consolidação induzida por percolação.

\subsubsection{Procedimento para troca de seringa}

Caso a capacidade da seringa não seja suficiente para finalizar o ensaio é necessário realizar trocas das seringas à medida que a sua capacidade seja alcançada. Os procedimentos para troca da seringa são descritos a seguir:

1. Fechar as válvulas 13 e 14

2. Retirar a seringa e esvaziar a mesma.

3. Destravar o cursor da bomba e voltá-lo para a posição inicial.

4. Recolocar a seringa e travar o cursor.

5. Abrir a válvula 15.

6. Abrir vagarosamente a válvula 14 .

7. Abrir a válvula 13.

8. Fechar a válvula 15.

9. Ligar novamente a bomba de fluxo, dando continuidade ao ensaio.

\subsubsection{Procedimentos finais do ensaio}

1. Fechar todas as válvulas.

2. Abrir a válvula 7, para reduzir a pressão no cilindro pneumático. 
3. Retirar a célula de carga e o LVDT e reconduzir manualmente o pistão da câmara triaxial para a posição inicial, isto é, totalmente fora da câmara triaxial.

4. Abrir vagarosamente a válvula de respiro da câmara triaxial, reduzindo assim, a pressão de confinamento.

5. Desconectar as mangueiras das válvulas 8 e 9 e, posteriormente, abrir essas válvulas para permitir a drenagem da água da câmara triaxial

6. A seguir, a câmara triaxial é desmontada e a amostra é removida da câmara de adensamento.

7. Determinar o teor de umidade e o peso seco da amostra $\left(W_{d}\right)$.

\subsubsection{Preparação do ensaio}

As amostras foram coletadas no interior do reservatório da barragem e no canal de descarga do material. Nesta ultima situação o material estava na forma liquida com teor de umidade próximo a 2000\% (água com sólidos suspensos). No caso de haver somente rejeitos secos, esses rejeitos devem ser misturados com água até formar uma pasta totalmente uniforme, com uma consistência tal que seja possível despejar suavemente na câmara de consolidação. O teor de umidade deve ser tal que seja superior àquele correspondente à tensão efetiva nula. Este teor de umidade está em torno de $450 \%$ de forma geral.

Das amostras coletadas é separada então uma quantidade suficiente de material para determinação do índice de vazios nulo correspondente a tensão efetiva nula $\left(e_{00}\right)$. De acordo com o procedimento proposto por Liu (1990) e Abu-Hejeleh e Znidarcic (1996). Neste procedimento o material é colocado em dois beckers de vidro formando uma camada de 50 mm. A seguir esses beckers são fechados com sacos plásticos e elásticos para evitar a 94 
evaporação da água (Figura 3.10a). Esse material é deixado em repouso por alguns dias para que o material se sedimente. Após esse período observa-se a formação de uma lâmina de água na superfície da amostra.

$\mathrm{O}$ procedimento segue com a retirada cuidadosa dessa água excedente, tendo cautela para não retirar materiais sólidos da amostra. Após a retirada da água, coleta-se uma certa quantidade de material localizada na superfície da amostra com o auxilio de uma pipeta Figura 3.10b ou com a bomba de fluxo Figura 3.10c. Observa-se que há um maior controle durante a retirada das amostradas com o uso da bomba de fluxo, havendo uma menor perturbação da camada superficial. Este material é então depositado em cápsulas (Figura 3.10d) e levado à estufa para determinação do teor de umidade e posterior cálculo de $e_{00}$.

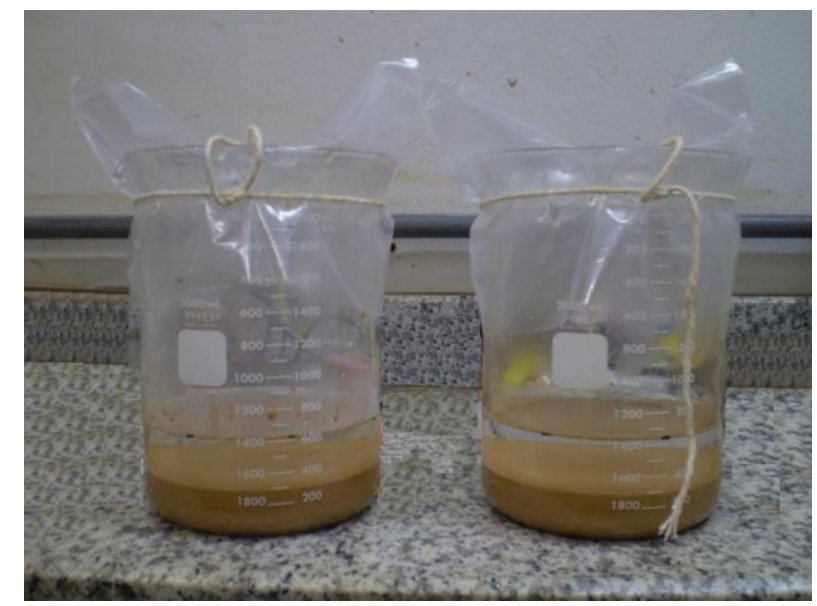

(a)

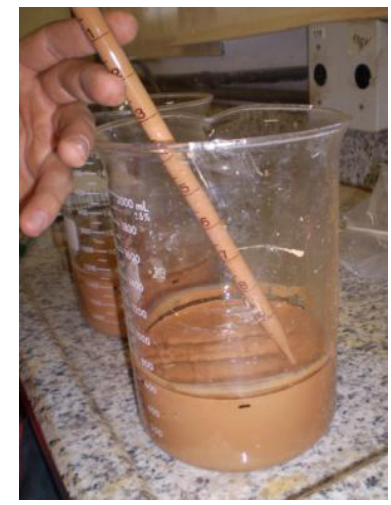

(b)

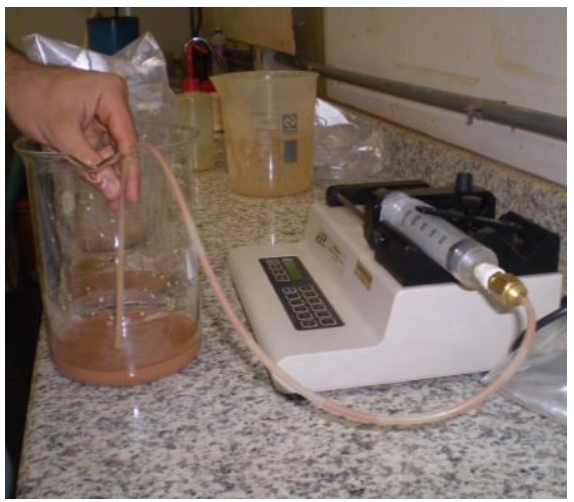

(c)

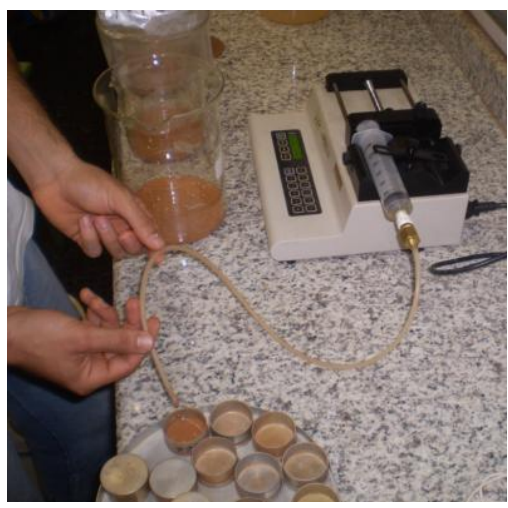

(d)

Figura 3.10 - Procedimento de determinação do $e_{00}$ : (a) amostra adensando por peso próprio, (b) retirada da lamina superficial com pipeta, (c) retirada lamina superficial com auxílio da bomba de fluxo e (d) coleta de amostras para determinação do teor de umidade. 
Após essa etapa, o material restante nos beckers é homogeneizado e colocado na câmara de consolidação com auxílio de um funil Figura 3.11a. Todo o equipamento deve estar previamente preparado conforme os procedimentos 1 a 17 do item 3.2.6.1, antes da colocação da amostra.

A utilização dos fios de nylon (Figura 3.11b) foi necessária quando se trabalhou com amostras retiradas do canal de descarga de material na barragem (Figura 3.1e). Esse material, mesmo após sedimentar por alguns dias, apresentava resistência muito baixa, de modo que após a aplicação da sobrecarga o material extrudava, causando inclinação do êmbolo de plástico (Figura 3.12).

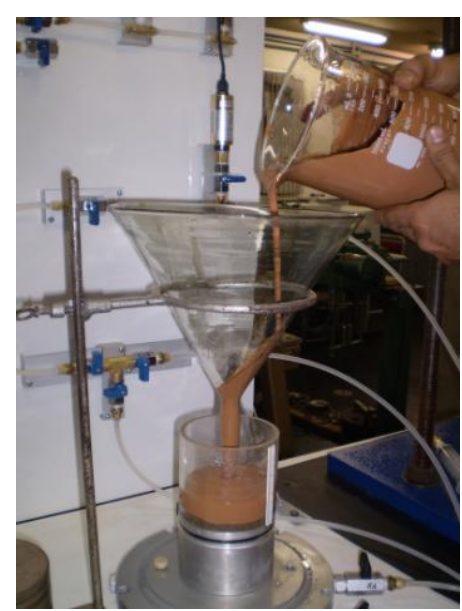

(a)

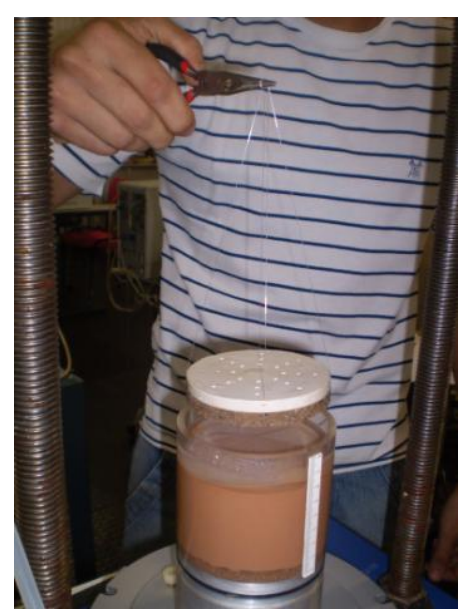

(b)

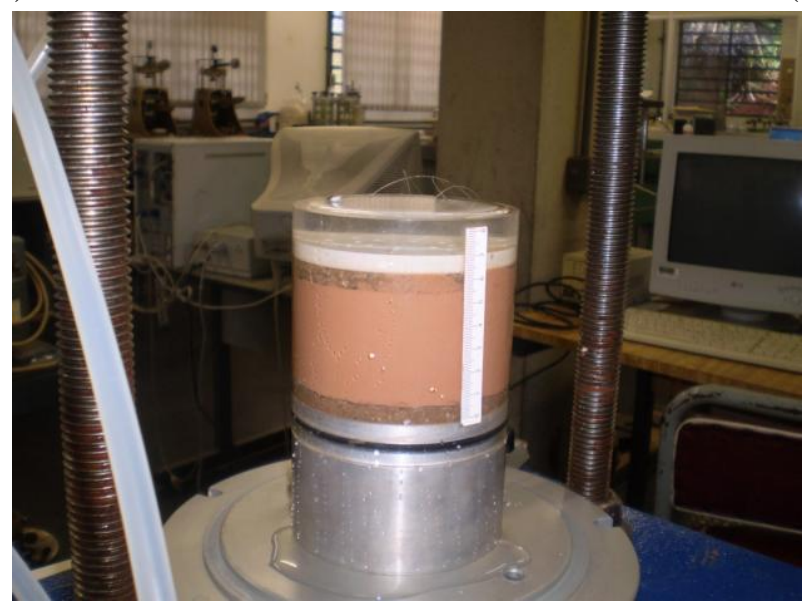

(c)

Figura 3.11 - Preparação da amostra na câmara de consolidação: (a) colocação da amostra com auxílio de um funil, (b) colocação da pedra porosa e do Top Cap com auxílio de fios de nylon e (c) amostra pronta para o fechamento da câmara triaxial. 


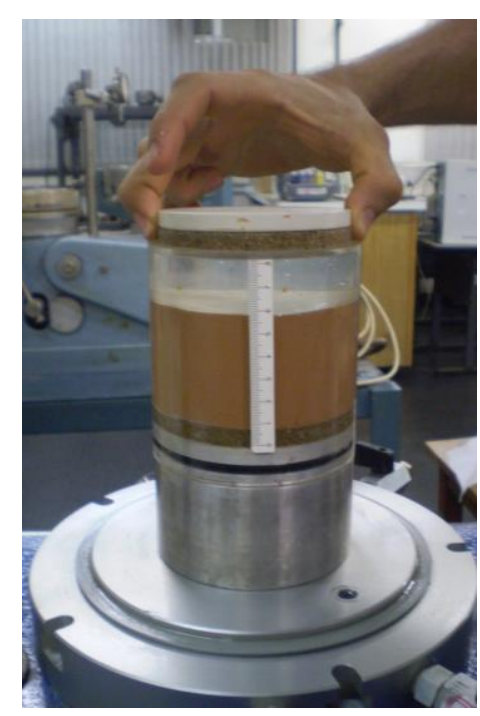

(a)

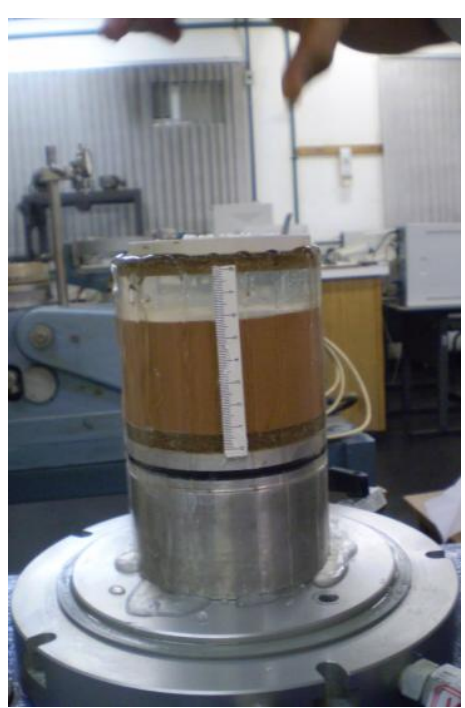

(b)

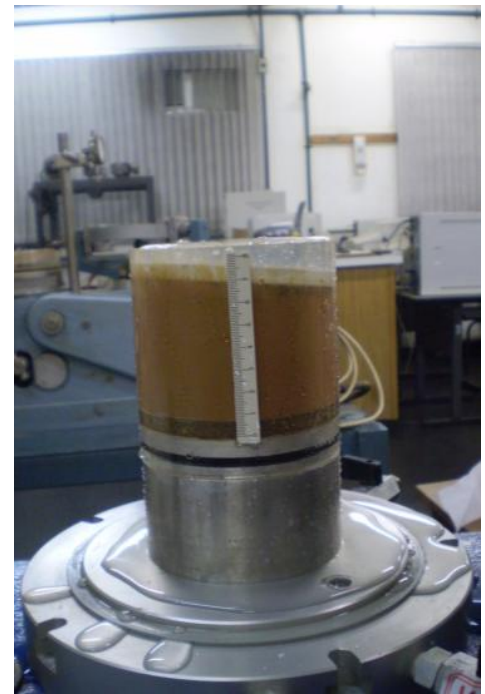

(c)

Figura 3.12 - Procedimento falho de colocação da sobrecarga em material sem resistência vindo diretamente da planta de beneficiamento (a) e (b) colocação da sobrecarga sem amortecimento inicial da carga e (c) ao tocar a amostra o conjunto pedra porosa e Top Cap inclinam.

Após a colocação correta da sobrecarga inicial e da realização de todas as etapas correspondentes ao iten 3.2.6.1 inicia-se o ensaio de consolidação induzido por forças de percolação.

\subsection{REFLECTOMETRIA NO DOMÍNIO DO TEMPO (TDR)}

\subsubsection{Equipamento}

Nesta parte da pesquisa foram utilizados os seguintes equipamentos:

- Testador de cabos da marca Tektronix modelo 1502C;

- Sonda helicoidal;

- Cabos coaxiais para conexão;

- Hastes metálicas

- Computador portátil. 
A sonda utilizada neste trabalho foi idealizada e desenvolvida no Departamento de Geotecnia da Escola de Engenharia de São Carlos - Universidade de São Paulo (Esquível, 2006) foi baseada no conceito de sondas com eletrodos helicoidais (Nissen et al., 1998; Vaz e Hopmans, 2001; Person e Wraith, 2002; Topp et al., 2003). Esta sonda foi utilizada em trabalho anterior por Assis (2008), apresentando bons resultados para diferentes solos da região de São Carlos/SP.

A sonda apresenta o diâmetro de 35,68 mm e comprimento de 302,26 mm. Cada eletrodo helicoidal possui comprimento de $280 \mathrm{~mm}$. Herkelrath et al. (1991) verificaram em estudos realizados em laboratório que cabos com comprimento superior a 27 metros causam problema de atenuação do sinal. Na presente pesquisa foi utilizado um comprimento máximo de cabo de 24 metros.

Na Figura 3.13 são apresentados esquematicamente os componentes do testador de cabos da marca Tektronix ${ }^{\circledR} 1502 \mathrm{C}$.
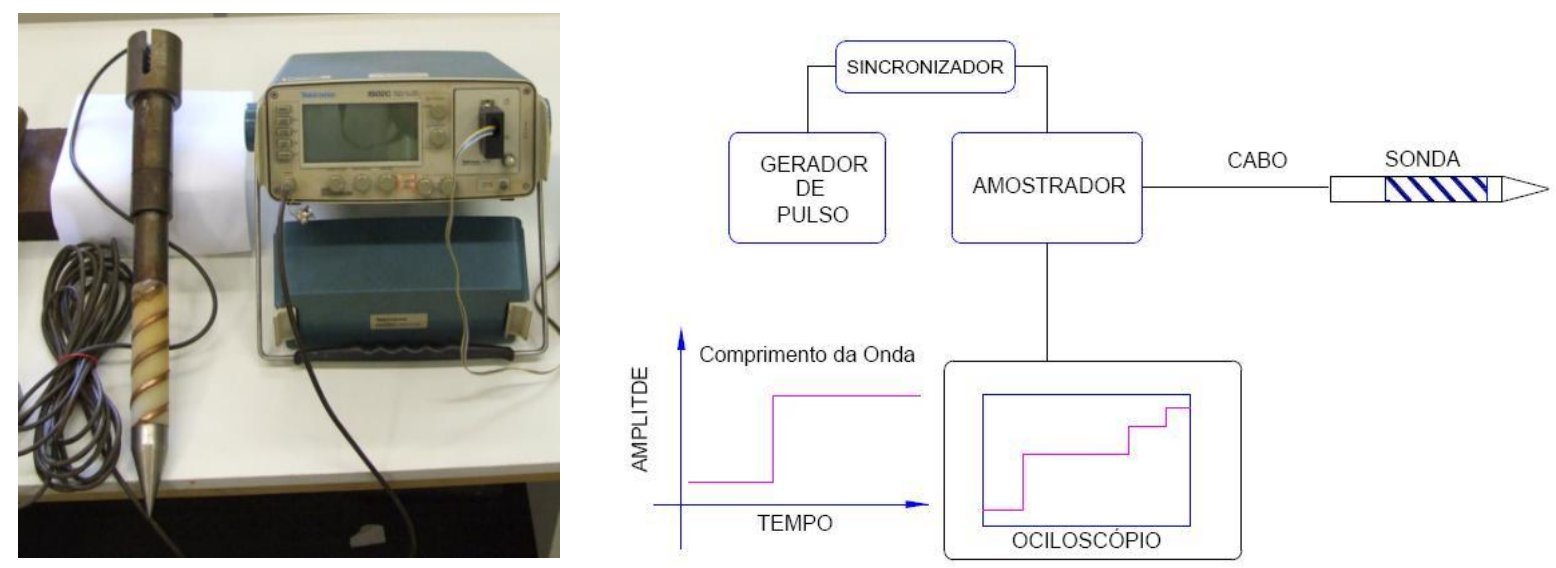

Figura 3.13 - Esquema do testador de cabos da marca Tektronix ${ }^{\circledR} 1502 \mathrm{C}$.

A Figura 3.15 apresenta os detalhes da sonda helicoidal. 

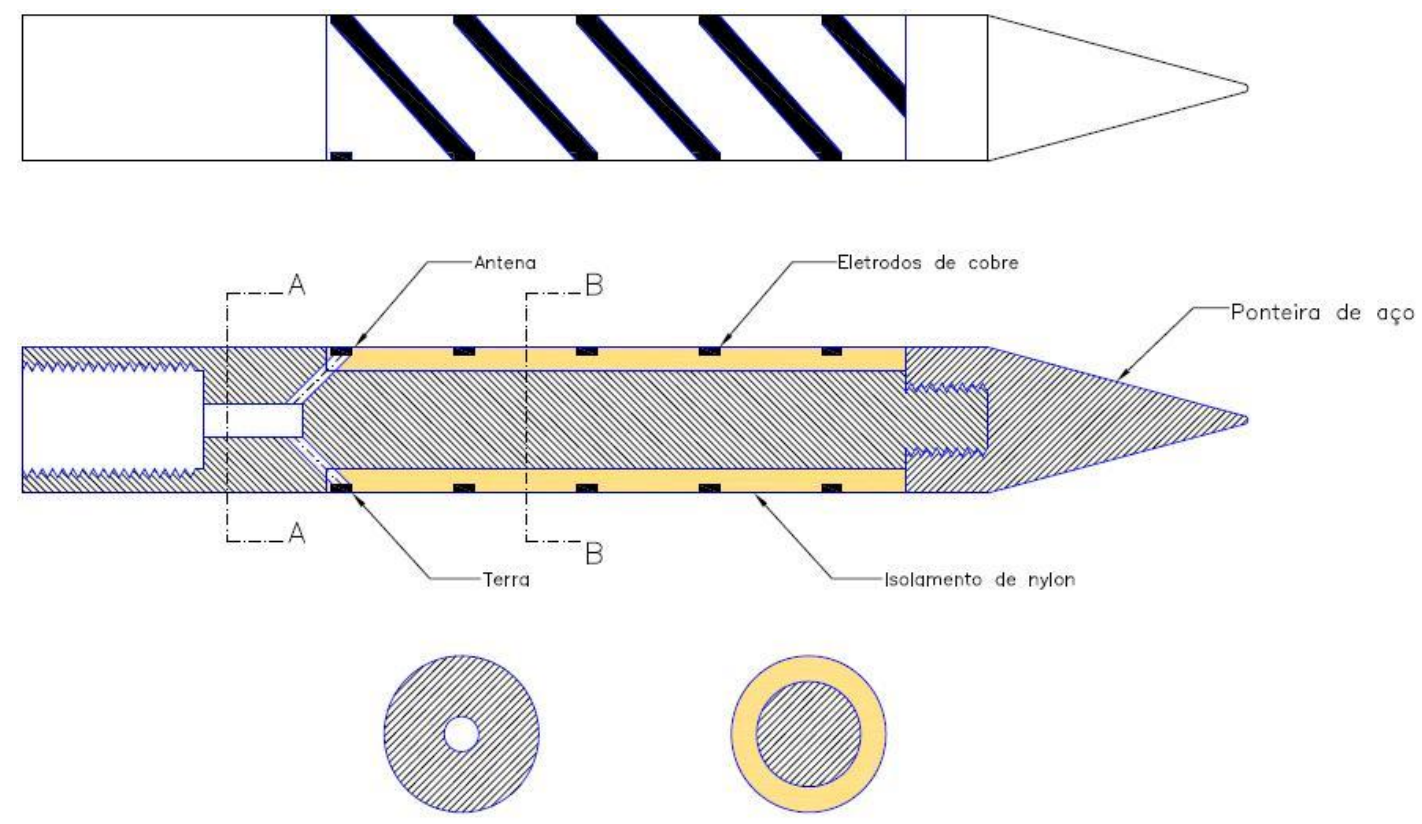

CORTE A-A

CORTE B-B

Figura 3.14 - Projeto da sonda (Esquível, 2006).
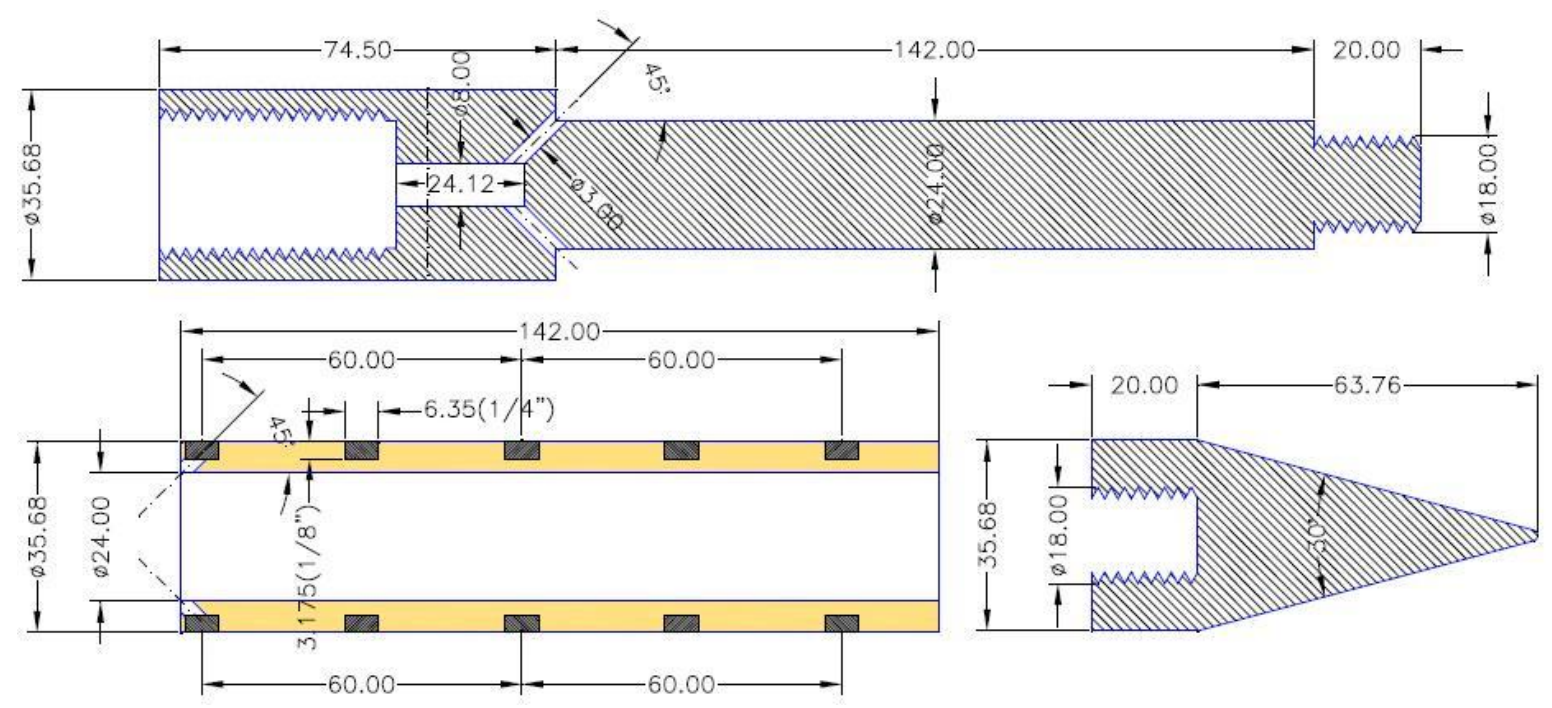

Figura 3.15 - Detalhes construtivos da sonda (Esquível, 2006).

A seguir são relacionados todos os acessórios utilizados nos ensaios de campo:

- Testador de Cabos Tecktronix 1502C;

- Microcomputador portátil;

- 2 sondas TDR calibradas com $20 \mathrm{~m}$ de comprimento de cabo;

- Trado tipo concha 2" e 4"; 
- Trado helicoidal para furar;

- Haste pra trado;

- 1 cruzeta;

- Adaptador sonda haste;

- Haste metálica para guiar a sonda;

- 2 chaves grifo e alavancas;

- Equipamento de Proteção Individual: bota com biqueira, capacete, óculos de proteção e perneira;

- Escova de aço para limpeza da cruzeta e lubrificante;

- Bandeja metálica;

- Ferramentas para coleta de amostra (concha e espátula);

- Barbante ou presilhas de metal;

- Sacos plásticos (pequeno e grande);

- Baldes com capacidade de 20 1;

- Etiqueta e marcador de ponta porosa;

- Recipiente para acondicionamento e transporte das amostras;

- Cinto de proteção tipo pára-quedista;

- Cabo de comunicação entre o testador de cabos e o notebook;

- Mesa, cadeira e tenda;

- Conversor de energia $12 \mathrm{~V}$ para $110 \mathrm{~V}$;

- 2 baterias $12 \mathrm{~V}$;

- Trena. 


\subsubsection{Programa WinTDR}

O WinTDR é um programa que faz a comunicação entre o testador de cabos e o computador. Este programa foi desenvolvido pelo grupo de Física dos Solos da Utah State University (Or et al., 2003) O programa utiliza o símbolo $K_{a}$ para denominar a constante dielétrica aparente do solo e realiza o cálculo da mesma através da Equação (2.45).

$$
K_{a}=\left(\frac{L_{a} \cdot C_{m}}{L \cdot V_{p}}\right)^{2}
$$

Onde:

$L_{a}=$ comprimento aparente da sonda $(m)$

$C_{m}=$ constante de calibração do aparelho (adimensional);

$L=$ comprimento da sonda $(m)$

$V_{p}=$ relação entre a velocidade real de propagação do pulso e a velocidade da luz (adimensional).

O programa calcula o comprimento aparente da sonda $(L a)$, para isso é necessário escolher um método para este calculo. No presente projeto o método utilizado para calculo do comprimento aparente da sonda foi o método das tangentes

A Figura 3.16 mostra uma tela do programa com a identificação dos pontos de inflexão e do comprimento aparente da sonda $(L a)$. Um ponto importante é informar corretamente o comprimento do eletrodo (length) outro dado que deve ser fornecido é a impedância. Os demais dados são ajustes da tela que são modificados pelo operador para uma melhor visualização da forma da onda. 


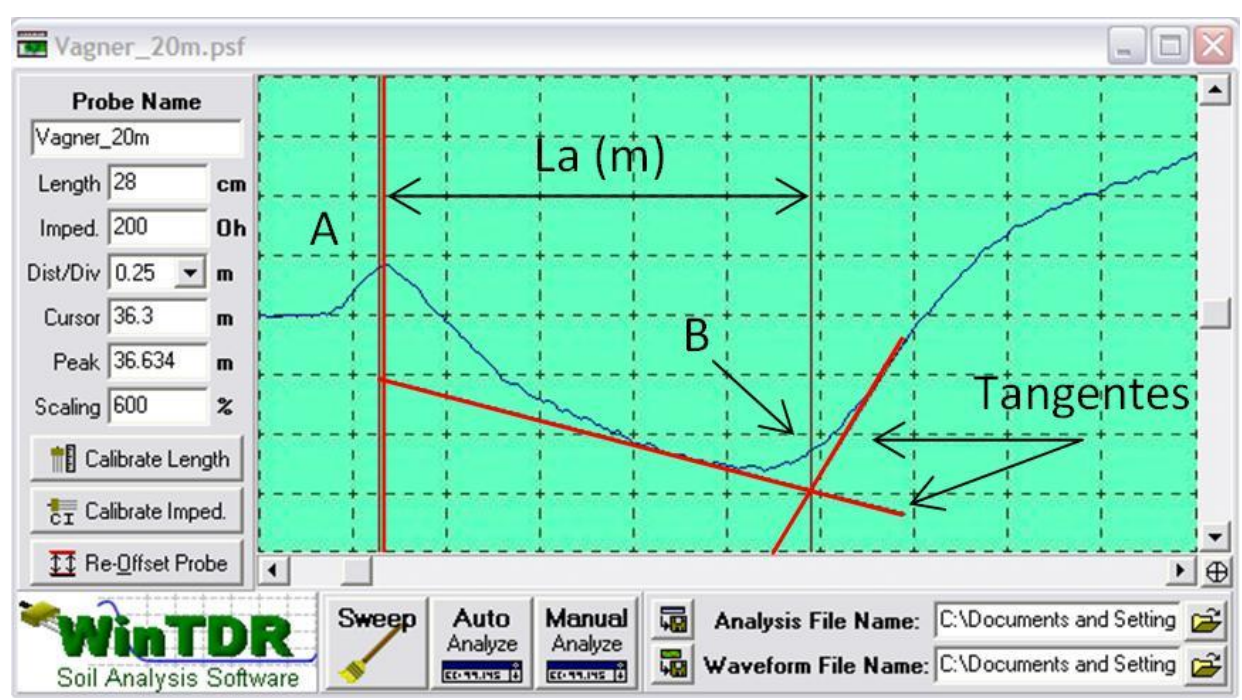

Figura 3.16 - Tela do programa WinTDR.

\subsubsection{Calibração da sonda helicoidal em laboratório}

A calibração da sonda consiste em estabelecer para os diferentes solos uma correlação entre teor de umidade e constante dielétrica aparente $(K a)$. A calibração em laboratório seguiu as seguintes etapas:

1. As amostras foram coletadas com teor de umidade próximo a 150\%, (Figura 3.17a). As mesmas foram colocadas em uma bandeja de aço e deixadas secar a sombra, em local com ventilação moderada, para alcançar o teor de umidade de 80\%. Para teores de umidade inferiores a $80 \%$, não foi possível realizar a homogeneização;

2. Atingido o teor de umidade de $80 \%$ foram separados $20 \mathrm{~kg}$ de material para a execução do ensaio;

3. O material foi homogeneizado com auxílio de uma hélice adaptada a uma furadeira (Figura 3.17c), e a seguir colocado em um recipiente de PVC com $202 \mathrm{~mm}$ de 
diâmetro, $285 \mathrm{~mm}$ de altura e massa de 3,170 kg. Nesta etapa também foi determinado o teor de umidade gravimétrico $(w)$ utilizando o método da estufa Figura $3.17(\mathrm{~d})$;

4. Através da pesagem do recipiente com solo foi determinada a massa específica do solo $(\rho)$ (Figura 3.17e);

5. A seguir, a sonda foi inserida no solo para determinar os valores de constante dielétrica aparente, com o auxílio do programa WinTDR 6.1 (Figura 3.17f);

6. Esses procedimentos, a partir da etapa 3, foram repetidos para o intervalo de teor de umidade variando de 80 a 200\%, com incrementos de $10 \%$ adicionando-se água de forma controlada (Figura 3.17b). Com os dados obtidos no ensaio obteve-se a curva de calibração que é a relação entre o teor de umidade gravimétrico e a constante dielétrica aparente $\left(K_{a}\right)$;

7. Para obter a curva de calibração $\left(K_{a}\right.$ versus $\left.w\right)$ numa faixa representativa de campo, repetiu-se este procedimento em um intervalo previamente determinado de teor de umidade, com incremento de $10 \%$;

Aos pontos experimentais, ajustou-se um polinômio do $3^{\circ}$ grau correlacionando a constante dielétrica aparente com o teor de umidade gravimétrico, conforme sugerido por Assis (2008). 


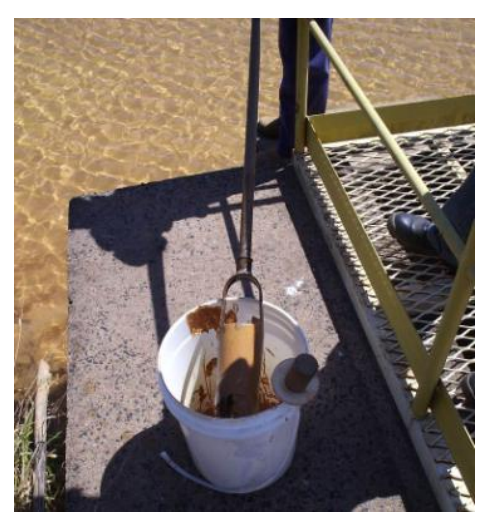

(a)

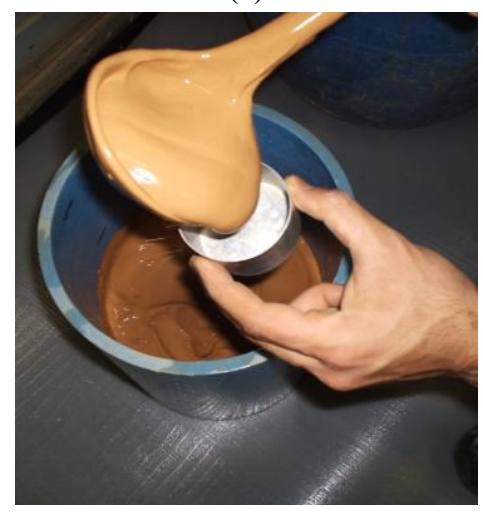

(d)

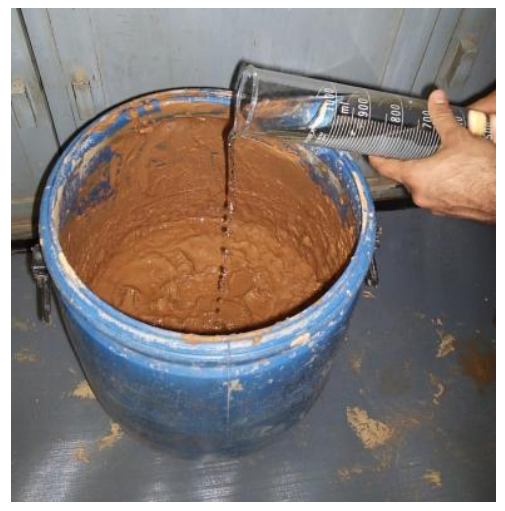

(b)

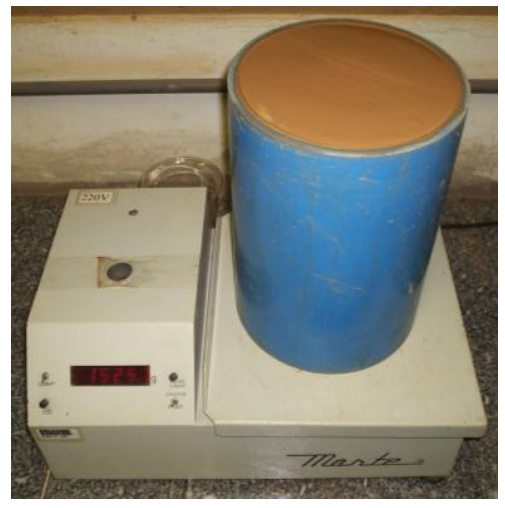

(e)

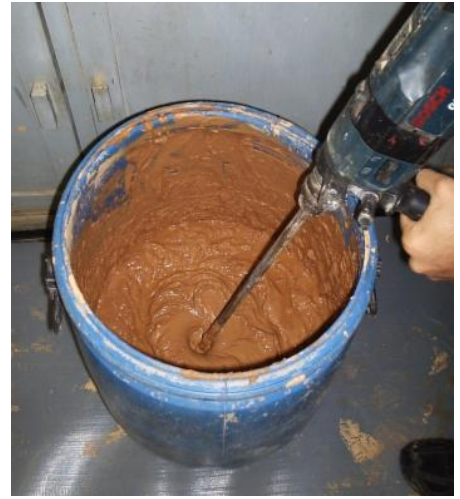

(c)

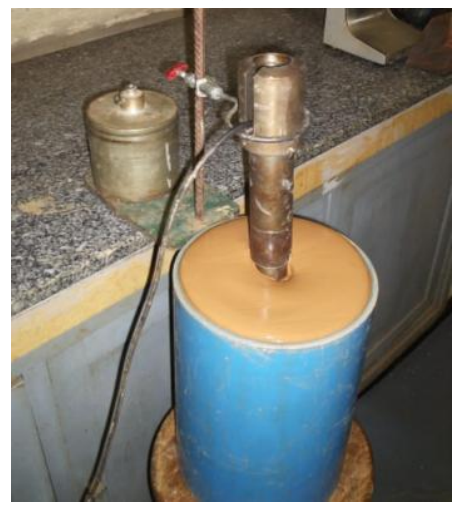

(f)

Figura 3.17 - Etapas da Calibração: (a) Coleta das amostras próximo ao vertedouro da lagoa, (b) adição gradativa de água, (c) homogeneização do material, (e) determinação do teor de umidade gravimétrico, Peso do conjunto e (f) leitura da Constante dielétrica aparente.

Com os dados obtidos, foram calculados a massa específica seca do solo $\left(\rho_{d}\right)$, o índice de vazios $(e)$ e o grau de saturação $\left(S_{r}\right)$. Estes parâmetros foram calculados por meio das seguintes equações:

$\rho_{d}=\frac{\rho}{1+w}$

$e=\frac{\rho_{s}}{\rho_{d}}-1$

$s_{r}=\rho_{s} \cdot \frac{w}{e}$ 


\subsubsection{Etapa de campo}

Foram executadas sondagens com a técnica TDR nas proximidades do vertedouro, em cinco pontos distintos (S1, S2, S3, S4 e S5), conforme indicado na Figura 3.18b. As leituras das constantes dielétricas aparentes foram realizadas entre as cotas 648,9 e 643,9 m, com um espaçamento de $0,5 \mathrm{~m}$ ao longo do eixo vertical, totalizando dez determinações para cada sondagem. As estimativas de teores de umidade foram determinadas a partir das correlações obtidas em laboratório.

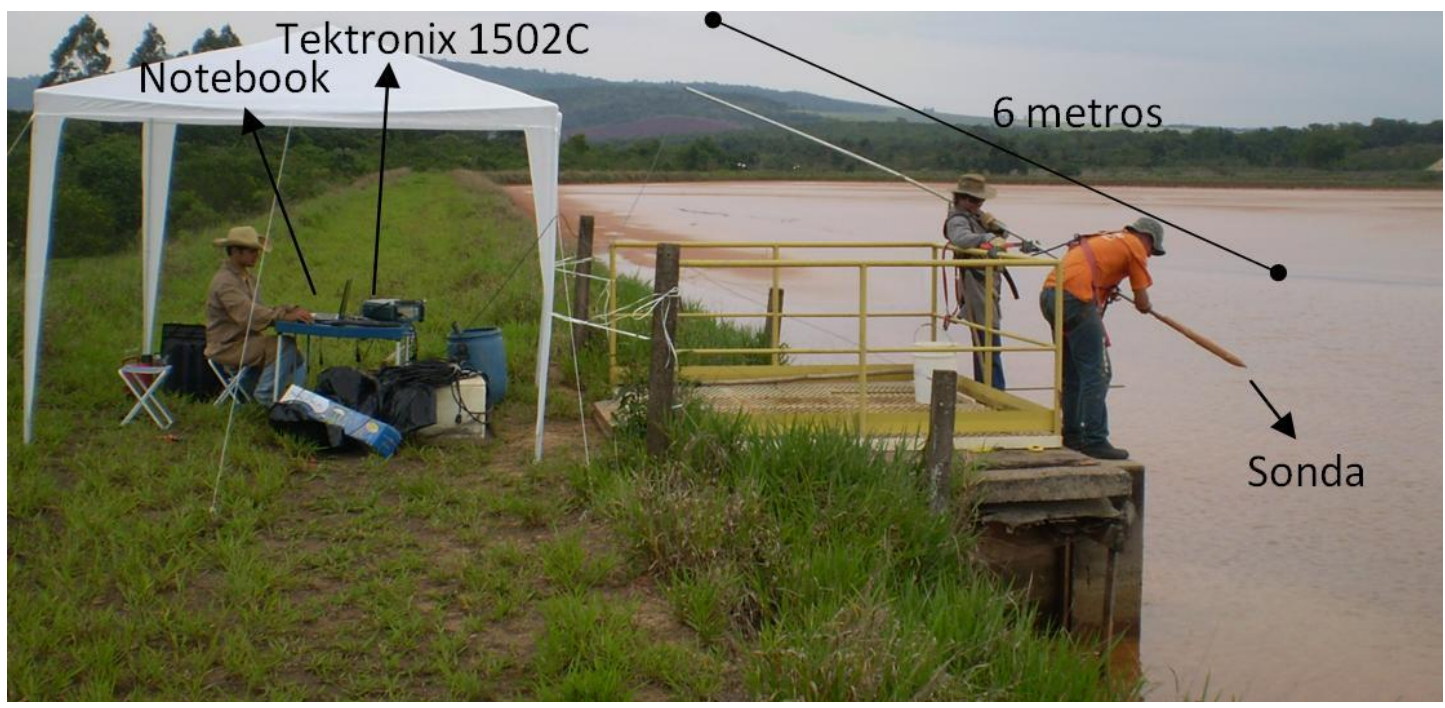

(a)

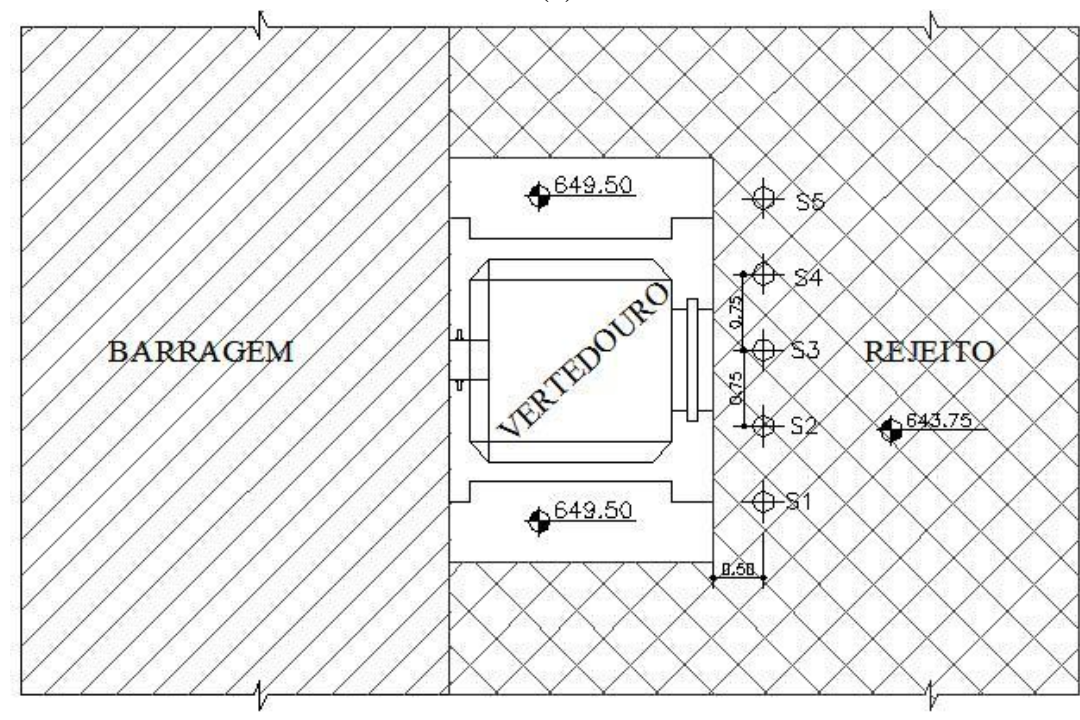

\section{PLANTA BAIXA}

ESC. 1:50 (MEDIDAS EM METRO)

(b) 


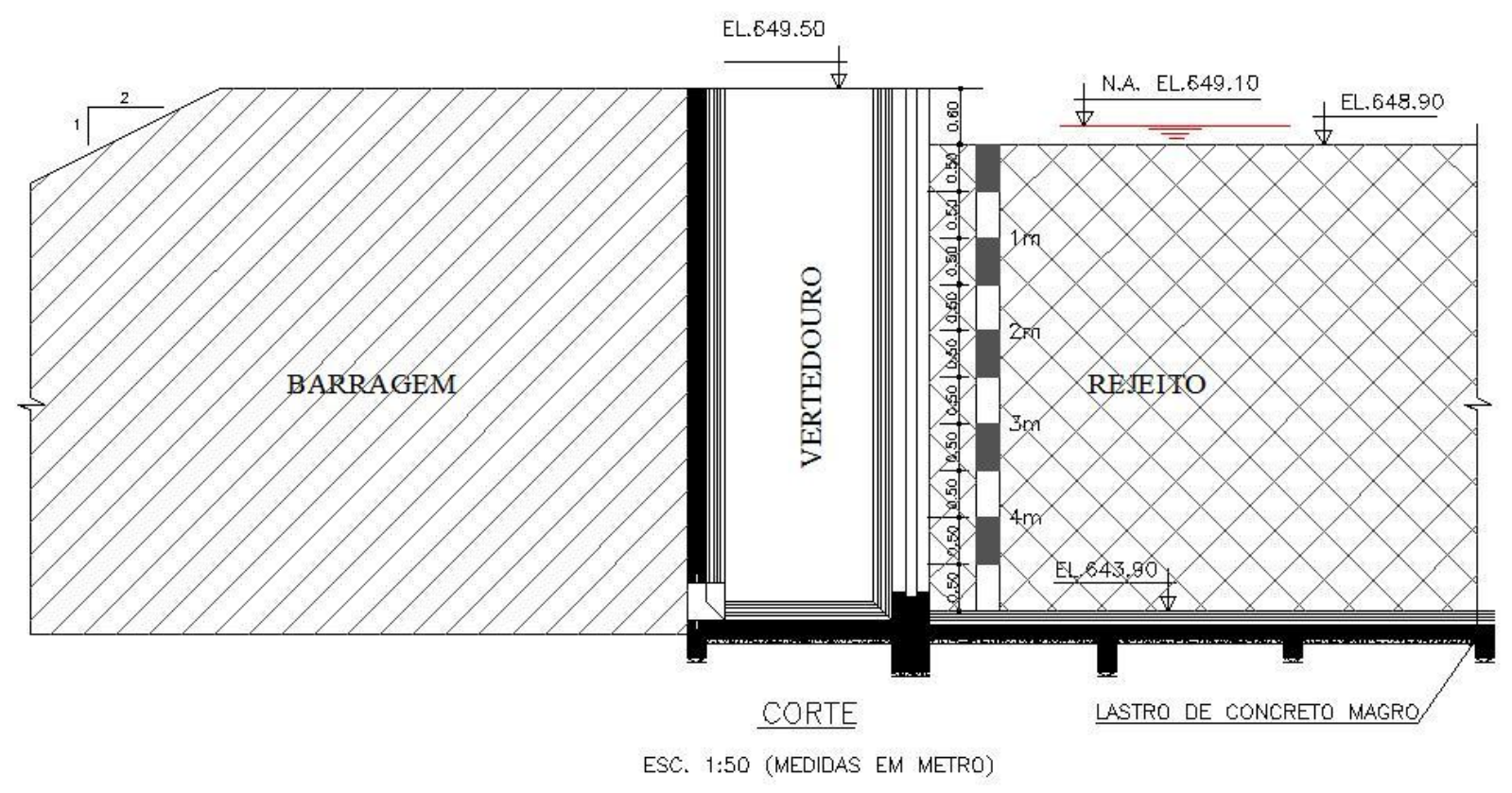

(c)

Figura 3.18 - Detalhe do ensaio de Campo: (a) Equipamentos utilizados em campo, (b) Planta baixa do vertedouro e (c) Corte do vertedouro.

Em cada profundidade foram realizadas leituras de constante dielétrica $\left(K_{a}\right)$ até se obter três valores próximos. Este era o critério de permanência da sonda em cada profundidade.

\subsubsection{Relações entre índices de vazios e tensões efetivas determinadas utilizando-se a técnica TDR.}

As relações entre índices de vazios e tensões efetivas em campo foram determinadas através da técnica TDR, de acordo com as seguintes etapas:

- Determinação ma massa especifica dos sólidos $\left(\rho_{s}\right)$ a partir do material coletado em campo;

- Devido ao local onde a perfilagem foi realizada está encoberto por uma lamina de $0,2 \mathrm{~m}$ (Figura 3.18) o material foi considerado na condição saturada $\left(S_{r}=100 \%\right)$; 
- Através das sondagens realizadas foi possível a estimativa do teor de umidade, através do uso da técnica TDR $\left(w_{T D R}\right)$, para cada profundidade escolhida. Através da Equação (3.13) foi possível a determinação do índice de vazios $(e)$;

$$
e=\frac{\rho_{s}}{\rho_{w}} \cdot \frac{w_{T D R}}{S_{r}}
$$

- Com os dados do massa específico dos sólidos e do índice de vazios, anteriormente calculado, foi possível determinar a massa especifica seca $\left(\rho_{d}\right)$ através da Equação (3.14);

$$
\rho_{d}=\frac{\rho_{s}}{1+e}
$$

- Utilizando a massa específica seca e o teor de umidade na Equação (3.15) foi possível a determinação da massa especifica $(\rho)$;

$$
\rho=\rho_{d}(1+w)
$$

- Com a massa especifica e a gravidade $(g)$ é calculado o peso específico saturado $\left(\gamma_{S A T}\right)$ através da Equação (3.16);

$$
\gamma_{S A T}=\rho \cdot g
$$

- A poro pressão foi estimada em cada profundidade utilizando o peso especifico da água $\left(\gamma_{w}\right)$ e altura de coluna de água $\left(z_{w}\right)$, através da Equação (3.17);

$u=\gamma_{w} \cdot z_{w}$

- A tensão total $(\sigma)$ para cada ponto foi calculada utilizando a poropressão estimada e a somatória do peso de todas as camadas de rejeito acima desta $\left(\Sigma z_{i} \gamma_{i}\right)$, através da Equação (3.18);

$$
\sigma=h_{w} \cdot \gamma_{w}+\Sigma h i \cdot \gamma_{i}
$$

- Por último foi calculado a tensão efetiva $\left(\sigma^{\prime}\right)$ para cada ponto utilizando as Equações (3.17) e (3.18), com o uso da Equação (3.19). 
$\sigma^{\prime}=\sigma-u$

A partir do índice de vazios obtido pela Equação (3.13) e da tensão efetiva obtida pela Equação (3.19) é possível a determinação da curva de compressibilidade de campo.

\subsubsection{Verificação da técnica TDR}

Com o objetivo de validar a técnica TDR, foi executado uma sequência de leituras em diferentes pontos da lagoa, limitando-se a uma profundidade de $0,5 \mathrm{~m}$, com a respectiva coleta de amostras para determinação do teor de umidade pelo método gravimétrico.

Com os valores dos teores de umidade gravimétricos e estimados a partir da técnica TDR, calculou-se o erro padrão $(E P)$ através da Equação (3.20).

$E P=\sqrt{\frac{\sum\left(w-w_{T D R}\right)^{2}}{n}}$

onde:

$w=$ teor de umidade determinado pelo método gravimétrico $(\%) ;$

$w_{T D R}=$ teor de umidade estimado pela técnica TDR;

$n$ = número de amostras; 


\section{RESULTADOS E ANÁLISES}

\subsection{CARACTERIZAÇÃO DO REJEITO}

O rejeito coletado é proveniente de um arenito da formação Pirambóia, segundo mapa geológico da região apresentado por Caetano-Chang e Wu (2006). Foram selecionadas para fins de caracterização, amostras próximas ao vertedouro da barragem e no canal de lançamento.

Na Figura 4.1 estão mostradas as curvas granulométricas da amostras denominadas Vertedouro e Espigotamento. A Tabela 4.1 apresenta os limites de Atterberg e massa específica dos sólidos. De acordo com os resultados obtidos, os materiais podem ser classificados como argila siltosa. 


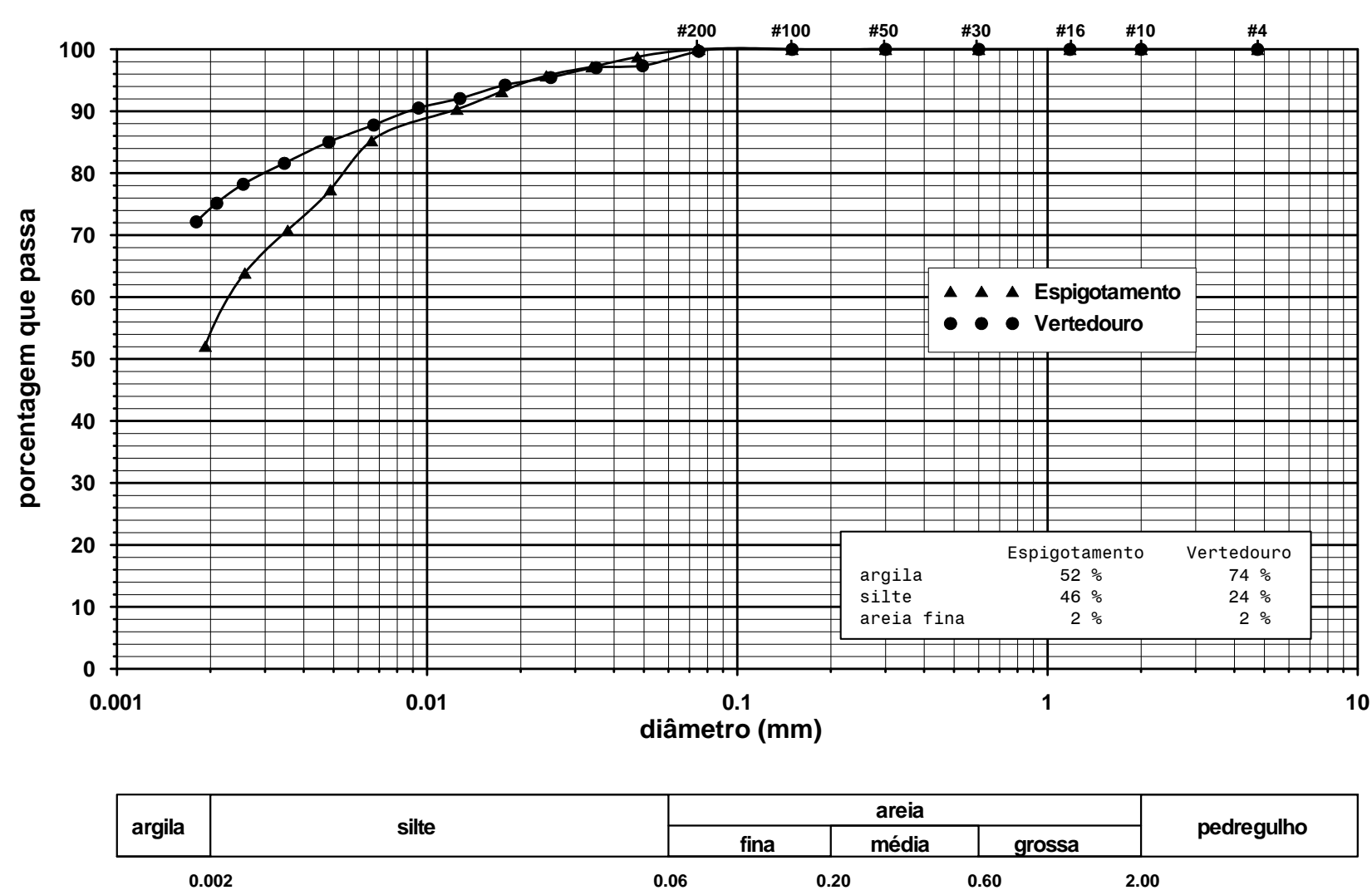

Figura 4.1 - Curva granulométrica das amostras de rejeitos.

Tabela 4.1 - Resultados dos ensaios de caracterização.

\begin{tabular}{lcccc}
\hline \multirow{2}{*}{ Amostra } & \multirow{2}{*}{$\boldsymbol{\rho}_{\boldsymbol{s}}\left(\mathrm{g} / \mathrm{cm}^{\mathbf{3}}\right)$} & \multicolumn{3}{c}{ Limites de Atterberg } \\
& & $\boldsymbol{W}_{\boldsymbol{L}}(\boldsymbol{\%})$ & $\boldsymbol{W}_{\boldsymbol{P}}(\boldsymbol{\%})$ & $\boldsymbol{I P}(\boldsymbol{\%})$ \\
\hline Espigotamento & 2,725 & 83 & 42 & 41 \\
Vertedouro & 2,711 & 84 & 34 & 50 \\
\hline
\end{tabular}

onde

$\rho,=$ massa especifica dos sólidos

$W_{L}=$ limite de liquidez

$W_{P}=$ limite de plasticidade

$I P=$ índice de plasticidade

As amostras retiradas da região próxima ao vertedouro apresentaram uma porcentagem maior de argila. Este fato é justificado pela sedimentação ocorrida ao longo do caminho percorrido pela amostra até chega à região do vertedouro. Esta característica das 
amostras foi observada de forma menos significativa nos valores da massa específica dos sólidos e nos limites de Atterberg. A maior porcentagem de argilas nas amostras da região do vertedouro também justifica a maior plasticidade deste material em relação às amostras do espigotamento

\subsection{ENSAIO DE CONSOLIDAÇÃO INDUZIDA POR PERCOLAÇÃO (HCT)}

Foram realizados ensaios com amostras retiradas da região do vertedouro e do ponto de descarga dos rejeitos (espigotamento).

O ensaio HCT é dividido em quatro etapas, conforme apresentado no item 3.2.2. Serão apresentados e comentados a seguir os resultados das etapas de consolidação hidráulica por percolação e os ensaios de carregamento em etapa com calculo da condutividade hidráulica.

\subsubsection{Consolidação induzida por percolação}

Para as amostras da região do vertedouro foram realizados quatro estágios de consolidação, para o rejeito do espigotamento foram realizados cinco estágios de consolidação. Os resultados de ambas amostras foram analisados e comparados para a verificação da técnica HCT.

A Figura 4.2 mostra o gráfico de diferença de pressão por tempo para os quatro estágios de consolidação induzida por percolação para a amostra da região do vertedouro. Observa-se que a partir de um determinado instante, a diferença de pressão para a fase de consolidação $\left(\Delta P_{s}\right)$ entre o topo e a base torna-se constante, ou seja, alcança a condição 
estacionária sendo este o critério de interrupção do estagio corrente. A seguir um novo estagio é realizado impondo-se uma nova vazão pela bomba de fluxo. Isto irá produzir novas variações no índice de vazios e na tensão efetiva ao longo da amostra. Novos valores de $v, \sigma^{\prime}{ }_{b}$ e $H_{f}$ são obtidos, mas somente um conjunto de valores é necessário para a análise dos resultados.

São mostrados a seguir os resultados dos ensaios de consolidação hidráulica realizados para as amostras do espigotamento(Figura 4.2) e do vertedouro (Figura 4.3).

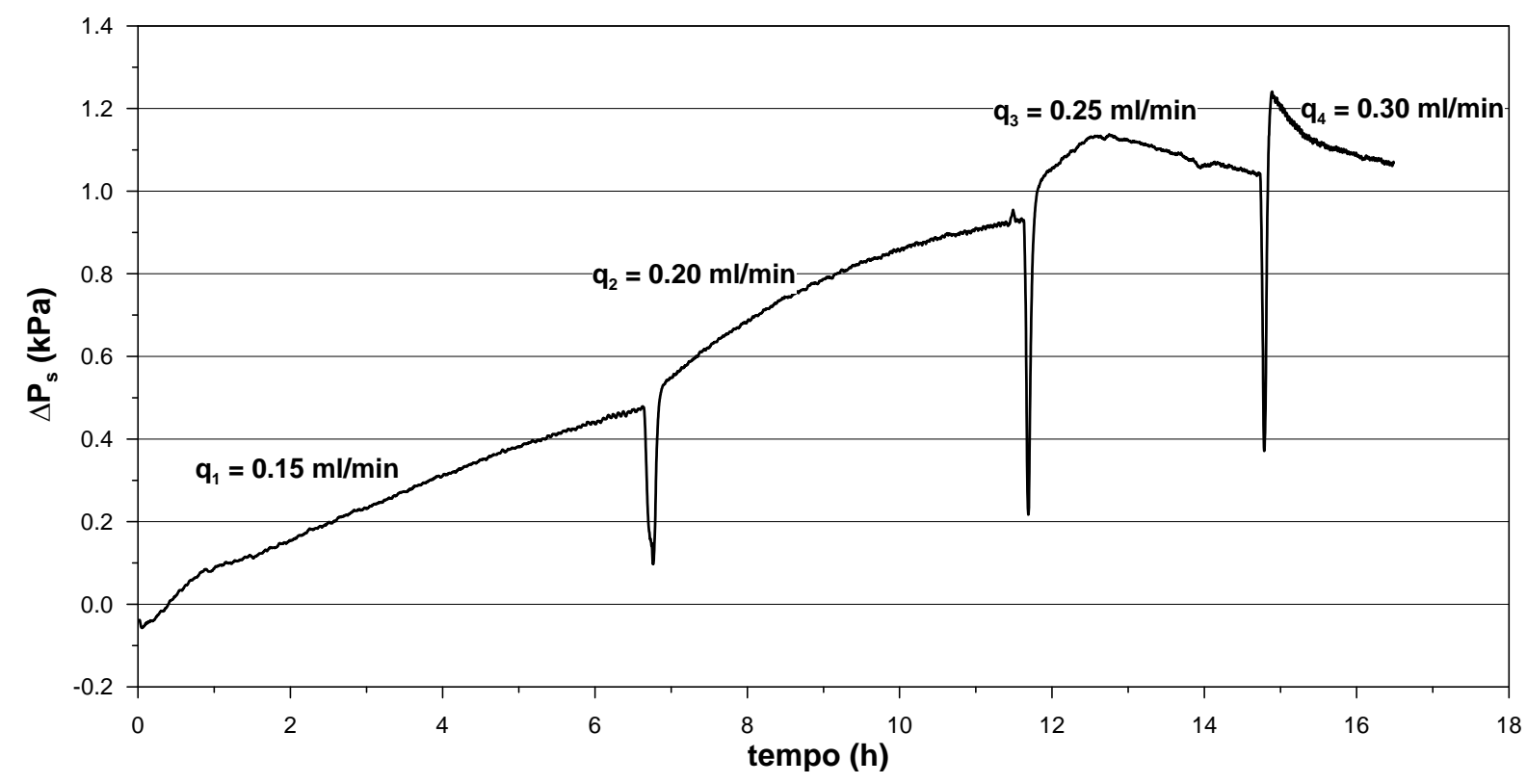

Figura 4.2 - Etapa de consolidação hidráulica (amostra vertedouro).

As quedas de pressão observadas nas Figura 4.2 e Figura 4.3 correspondem ao instante em que o fluxo foi interrompido para troca da seringa. As amostras do vertedouro realizaram aumento da vazão para cada troca da seringa, não sendo observado em alguns estágios $\left(q_{1} e q_{2}\right)$ uma diferença de pressão constante (estado transiente). 


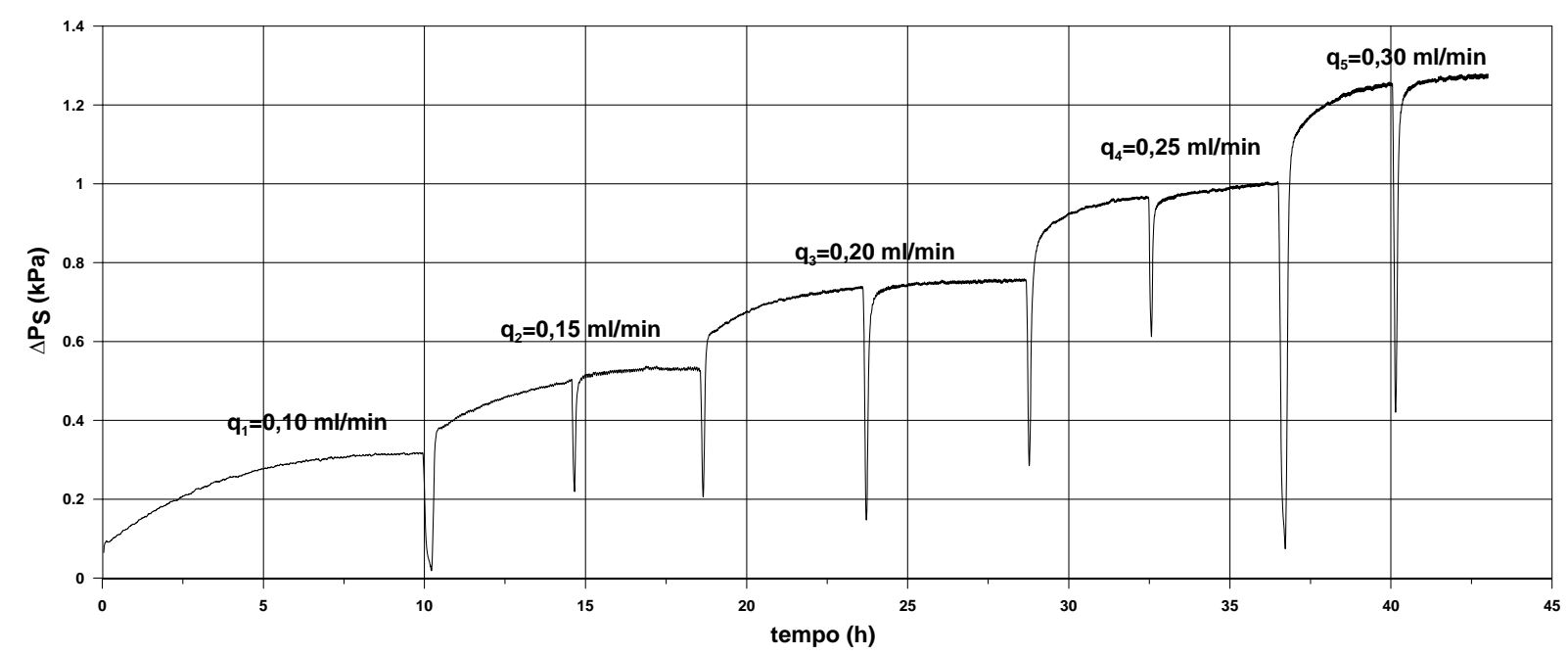

Figura 4.3 - Etapa de consolidação hidráulica (amostra espigotamento).

O ensaio com a amostra do espigotamento foi feita a opção de manter a vazão durante a primeira troca da seringa. Com isso foi observado que em todos os estágios foram obtidas a condição de estado estacionário, ou seja a diferença de pressão manteve-se constante constante para as vazões impostas.

A seguir é apresentada a Tabela 4.2 com o resumo dos resultados obtidos para a etapa de consolidação hidráulica de ambas as amostras..

Tabela 4.2 - Resultados experimentais da etapa de consolidação hidráulica (amostra vertedouro).

\begin{tabular}{|c|c|c|c|c|c|c|c|c|c|}
\hline Amostra & Estágio & Ho (m) & $e_{00}$ & $\sigma^{\prime}{ }_{0}(\mathbf{k P a})$ & $q(\mathrm{ml} / \mathrm{min})$ & $v(\mathrm{~m} / \mathrm{s})$ & $\boldsymbol{H}_{f}(\mathbf{m})$ & $\sigma_{b}^{\prime}(\mathbf{k P a})$ & $\Delta P_{S}(\mathrm{kPa})$ \\
\hline \multirow{4}{*}{$\begin{array}{l}0 \\
\stackrel{0}{3} \\
0 \\
\frac{0}{0} \\
\stackrel{ \pm}{0} \\
\stackrel{0}{>}\end{array}$} & A1 & 0,0492 & 15,81 & 0,088 & 0,15 & $3,73 \times 10^{-7}$ & 0,0352 & 0,649 & 0,50 \\
\hline & $\mathrm{A} 2$ & 0,0492 & 15,81 & 0,088 & 0,20 & $4,97 \times 10^{-7}$ & 0,0302 & 1,049 & 0,90 \\
\hline & $\mathrm{A} 3$ & 0,0492 & 15,81 & 0,088 & 0,25 & $6,21 \times 10^{-7}$ & 0,0302 & 1,249 & 1,10 \\
\hline & A4 & 0,0492 & 15,81 & 0,088 & 0,30 & $7,46 \times 10^{-7}$ & 0,0297 & 1,249 & 1,10 \\
\hline \multirow{5}{*}{ 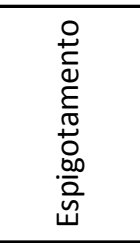 } & $\mathrm{A} 1$ & 0,0533 & 11,37 & 0,089 & 0,10 & $2,48 \times 10^{-7}$ & 0,0423 & 0,526 & 0,30 \\
\hline & $\mathrm{A} 2$ & 0,0533 & 11,37 & 0,089 & 0,15 & $3,73 \times 10^{-7}$ & 0,0412 & 0,736 & 0,56 \\
\hline & A3 & 0,0533 & 11,37 & 0,089 & 0,20 & $4,97 \times 10^{-7}$ & 0,0403 & 0,976 & 0,80 \\
\hline & A4 & 0,0533 & 11,37 & 0,089 & 0,25 & $6,21 \times 10^{-7}$ & 0,0393 & 1,226 & 1,05 \\
\hline & A5 & 0,0533 & 11,37 & 0,089 & 0,30 & $7,45 \times 10^{-7}$ & 0,039 & 1,496 & 1,32 \\
\hline \multicolumn{10}{|c|}{$\boldsymbol{H o}=$ Altura inicial do corpo de prova } \\
\hline \multicolumn{10}{|c|}{$\boldsymbol{e}_{\boldsymbol{\theta 0}}=$ índice de vazios correspondente à tensão efetiva nula } \\
\hline \multicolumn{10}{|c|}{$\sigma^{\prime}{ }_{0}=$ tensão efetiva no topo do corpo de prova } \\
\hline \multicolumn{10}{|c|}{$q=$ vazão na base do corpo de prova } \\
\hline \multicolumn{10}{|c|}{$\boldsymbol{v}=$ velocidade de Darcy na base do corpo de prova } \\
\hline \multicolumn{10}{|c|}{$\boldsymbol{H}_{f}=$ altura final do corpo de prova } \\
\hline \multicolumn{10}{|c|}{$\sigma^{\prime}{ }_{b}=$ tensão efetiva na base do corpo de prova } \\
\hline \multicolumn{10}{|c|}{$\Delta \boldsymbol{P}_{S}=$ pressão diferencial entre o topo e a base do corpo de prova } \\
\hline
\end{tabular}


A etapa com material do vertedouro apresentou como particularidade o estágio A1 que não apresentou estabilização da diferença de pressão. Entretanto foi considerada uma diferença de pressão igual a $0,5 \mathrm{kPa}$ para fins de avaliação deste resultado. Isso ocorreu devido à seringa ter chegado ao seu limite de volume que é de $60 \mathrm{ml}$.

É observada uma diferença de valores de $\mathrm{e}_{00}$ entre as amostras. Esta diferença pode ser atribuída a mudanças no processo de beneficiamento do material, a materiais de diferentes jazidas e ao tempo de beneficiamento sofrido por cada amostra.

Para ambas as amostras foi respeitada as recomendações de Znidarcic et al. (1992) de se ter diferença de pressão entre os limites de $0,3 \mathrm{kPa}$ e $10 \mathrm{kPa}$.

Ao término do quarto e último estágio de consolidação para ambas as amostras foi realizada a etapa seguinte de determinação da condutividade hidráulica com carregamentos incrementais.

Para o estágio de carregamento incremental, foram aplicadas cargas entre 10 e $100 \mathrm{kPa}$, consideradas apropriadas para a condutividade hidráulica, velocidades em torno de 10 vezes menores que as utilizadas na etapa de consolidação hidráulica são indicadas para evitar que a diferença de pressão ultrapasse o valor de $10 \mathrm{kPa}$. As etapas de carregamento e condutividade hidráulica podem ser realizados na mesma amostra, sob vários incrementos de cargas, porém, somente um estágio do teste de carga é requerido para a realização das análises.

Para ambas as amostras foram adotadas duas vazões de percolação para cada carregamento incremental, sendo posteriormente calculados os valores de condutividades hidráulicas. O momento da interrupção do ensaio se dava quando a diferença de pressão entre o topo e a base da amostra permanecia constante. Igualmente a etapa de consolidação hidráulica, todos os valores para calculo da condutividade hidráulica foram obtidos no 
momento em que a diferença de pressão entre o topo e a base da amostra permaneceu constante.

Os resultados desta etapa para o material do vertedouro são apresentados a seguir. A Figura 4.4 mostra a curva de diferença de pressão em função do tempo, para um carregamento de $36,58 \mathrm{kPa}$ e vazões de $0,05 \mathrm{ml} / \mathrm{min}$ e $0,10 \mathrm{ml} / \mathrm{min}$. A Figura 4.5 apresenta o mesmo gráfico da figura anterior para um carregamento de $88,33 \mathrm{kPa}$ e vazões de $0,05 \mathrm{ml} / \mathrm{min}$ e $0,10 \mathrm{ml} / \mathrm{min}$.

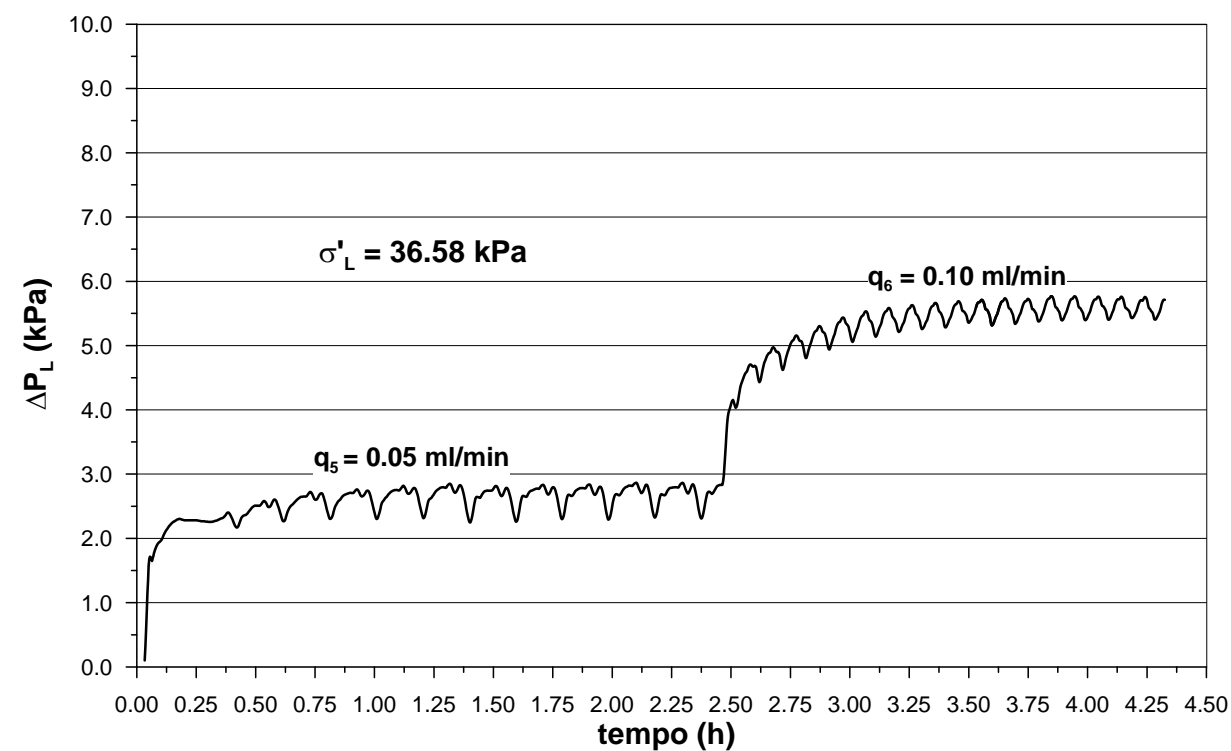

Figura 4.4 - Ensaio de condutividade hidráulica por carregamentos incrementais (carregamento vertical de $36,58 \mathrm{kPa})$ 


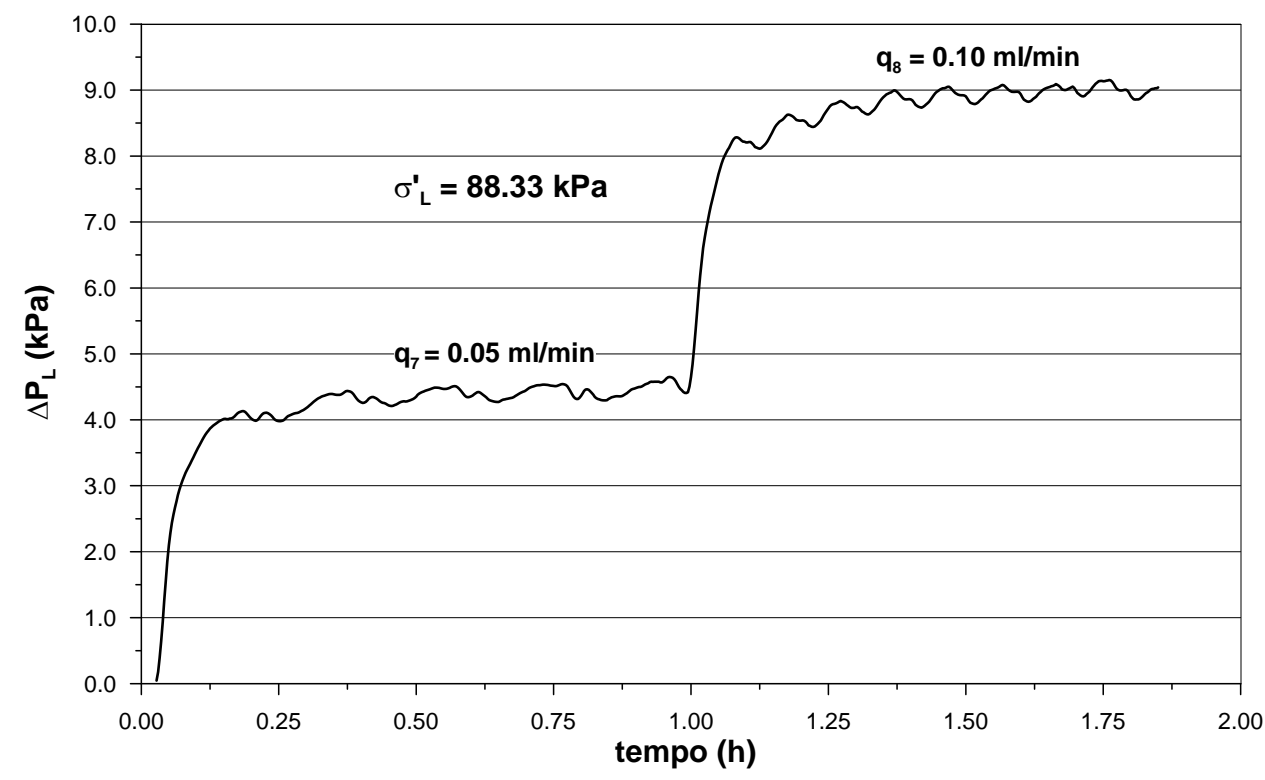

Figura 4.5 - Ensaio de condutividade hidráulica por carregamentos incrementais (carregamento vertical de $88,33 \mathrm{kPa})$.

O carregamento foi realizado em duas etapas, submetendo-se a amostra a uma tensão efetiva de 36,58 e $88,34 \mathrm{kPa}$. Ao atingir a condição estacionária sob estas condições, realizou-se o ensaio de condutividade hidráulica para cada carregamento de $(0,05 \mathrm{ml} / \mathrm{min}$ e 0,10 $\mathrm{ml} / \mathrm{min}$ ), até atingir, novamente, a estabilização da diferença de pressão. Observa-se para essa etapa do ensaio que a diferença de pressão é obtida em um menor período de tempo ao compara com a etapa de consolidação hidráulica.

Os resultados para o material do espigotamento são apresentados a seguir. A Figura 4.6 mostra a curva de diferença de pressão em função do tempo, para um carregamento de $18,05 \mathrm{kPa}$ e vazões de $0,01 \mathrm{ml} / \mathrm{min}$ e $0,05 \mathrm{ml} / \mathrm{min}$. A Figura 4.7 apresenta o mesmo gráfico da figura anterior para um carregamento de $52,68 \mathrm{kPa}$ e vazões de $0,01 \mathrm{ml} / \mathrm{min}$ e $0,05 \mathrm{ml} / \mathrm{min}$. 


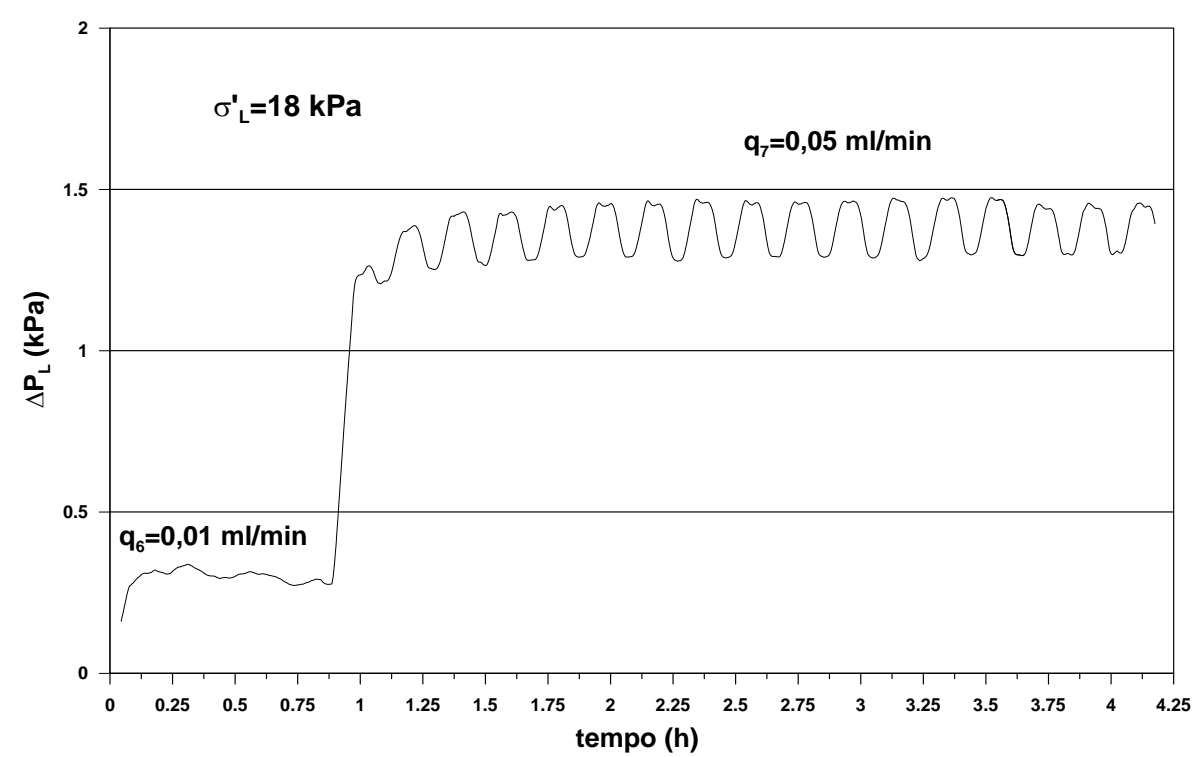

Figura 4.6 - Ensaio de condutividade hidráulica por carregamentos incrementais (carregamento vertical de $18,05 \mathrm{kPa})$.

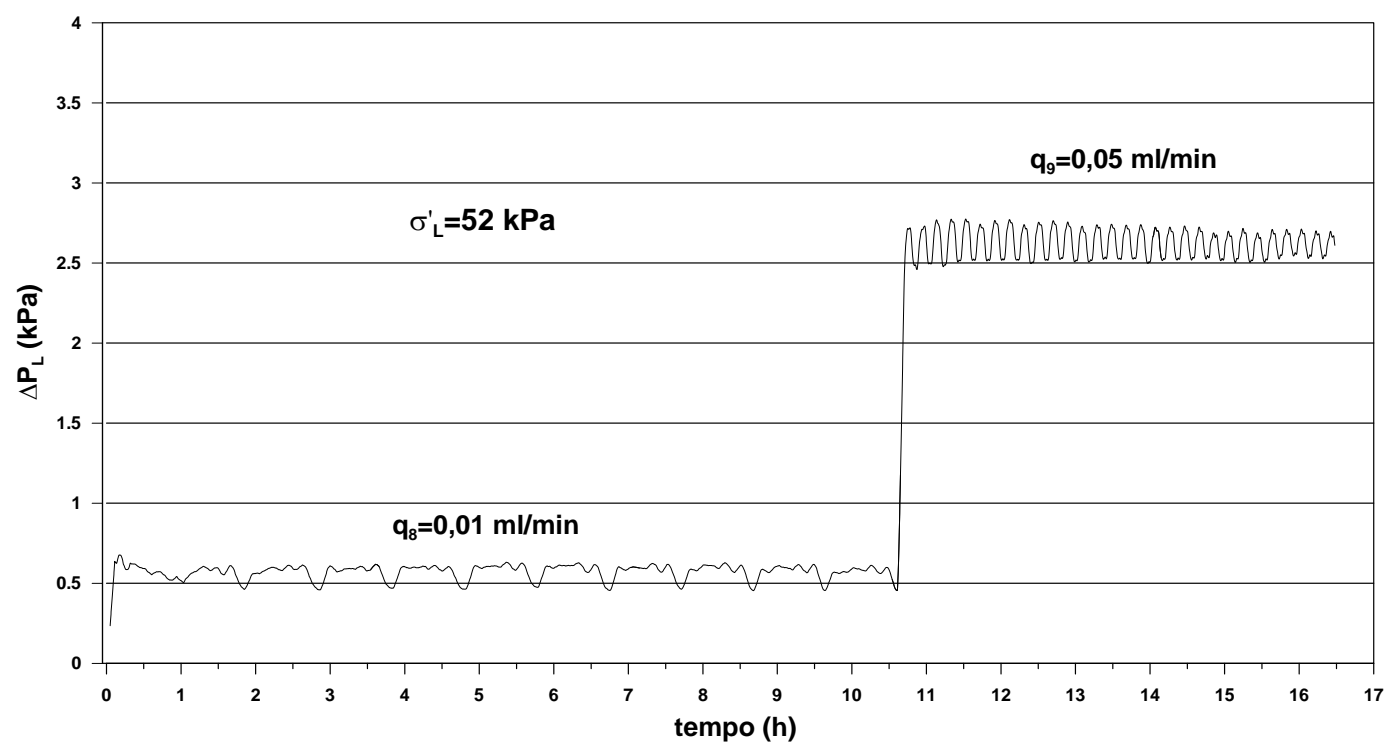

Figura 4.7 - Ensaio de condutividade hidráulica por carregamentos incrementais (carregamento vertical de $52,68 \mathrm{kPa}$ ).

A Tabela 4.3 apresenta os valores correspondentes aos dois estágios de carregamento realizados, para o cálculo de condutividade hidráulica de ambas as amostras. 
Tabela 4.3 - Resultados dos ensaios de condutividade hidráulica.

\begin{tabular}{|c|c|c|c|c|c|c|c|c|}
\hline Amostra & Estágio & $H_{L}(\mathbf{m})$ & $e_{L}$ & $\sigma^{\prime}{ }_{L}(\mathbf{k P a})$ & $\begin{array}{c}q_{L} \\
(\mathrm{ml} / \mathrm{min})\end{array}$ & $v_{L}(\mathrm{~m} / \mathrm{s})$ & $\begin{array}{l}\Delta P_{L} \\
(\mathrm{kPa})\end{array}$ & $k_{L}(\mathrm{~m} / \mathrm{s})$ \\
\hline \multirow{4}{*}{$\begin{array}{l}0 \\
\text { 일 } \\
\text { 응 } \\
\stackrel{0}{ \pm} \\
\stackrel{t}{0}\end{array}$} & $\mathrm{C} 1$ & 0,0142 & 2,92 & 36,58 & 0,05 & $1,24 \times 10^{-7}$ & 2,50 & $6,92 \times 10^{-9}$ \\
\hline & $\mathrm{C} 2$ & 0,0142 & 2,92 & 36,58 & 0,10 & $2,49 \times 10^{-7}$ & 5,60 & $6,18 \times 10^{-9}$ \\
\hline & $\mathrm{C} 3$ & 0,0122 & 2,36 & 88,33 & 0,05 & $1,24 \times 10^{-7}$ & 4,50 & $3,30 \times 10^{-9}$ \\
\hline & $\mathrm{C} 4$ & 0,0122 & 2,36 & 88,33 & 0,10 & $2,49 \times 10^{-7}$ & 9,00 & $3,30 \times 10^{-9}$ \\
\hline \multirow{4}{*}{ 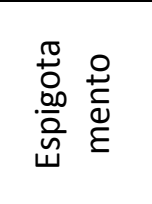 } & $\mathrm{C} 1$ & 0,0211 & 3,07 & 18,05 & 0,01 & $2,49 \times 10^{-8}$ & 0,30 & $1,71 \times 10^{-8}$ \\
\hline & $\mathrm{C} 2$ & 0,0210 & 3,05 & 18,05 & 0,05 & $1,24 \times 10^{-7}$ & 1,45 & $1,76 \times 10^{-8}$ \\
\hline & $\mathrm{C} 3$ & 0,0170 & 2,28 & 52,68 & 0,01 & $2,49 \times 10^{-7}$ & 0,65 & $6,38 \times 10^{-9}$ \\
\hline & $\mathrm{C} 4$ & 0,0170 & 2,28 & 52,68 & 0,05 & $1,24 \times 10^{-7}$ & 2,80 & $7,40 \times 10^{-9}$ \\
\hline
\end{tabular}

$\boldsymbol{H}_{\boldsymbol{L}}=$ altura do corpo de prova

$\boldsymbol{e}_{L}=$ índice de vazios médios do corpo de prova

$\sigma^{\prime}{ }_{L}=$ tensão efetiva no topo do corpo de prova

$\boldsymbol{q}_{\boldsymbol{L}}=$ vazão na base do corpo de prova

$v_{L}=$ velocidade de Darcy na base do corpo de prova

$\boldsymbol{\Delta} \boldsymbol{P}_{\boldsymbol{L}}=$ pressão diferencial entre o topo e a base do corpo de prova

$\boldsymbol{k}_{\boldsymbol{L}}=$ permeabilidade

Nota-se que, independentemente do valor de vazão ou do carregamento aplicado, os valores de condutividade hidráulica $\left(k_{L}\right)$ se apresentam bastante próximas, apresentando a mesma ordem de grandeza $\left(10^{-9} \mathrm{~m} / \mathrm{s}\right)$ para carregamentos incrementais iguais ou superiores a $36,58 \mathrm{kPa}$.

Para a determinação dos parâmetros de consolidação $(A, B, C, D e Z)$, bastaria um único par dos estágios de consolidação e condutividade hidráulica. Para realizar uma melhor avaliação dos ensaios foram feitas várias combinações para cada material gerando diversas análises. Finalmente foram determinadas as médias dos valores de cada parâmetro, e os respectivos desvios padrão e coeficientes de variação. 
Tabela 4.4 - Combinações para as análises de determinação dos parâmetros constitutivos.

\begin{tabular}{|c|c|c|c|}
\hline Amostra & Análise & $\begin{array}{c}\text { Estágio de } \\
\text { Consolidação }\end{array}$ & $\begin{array}{l}\text { Estágio de Cond. } \\
\text { Hidráulica }\end{array}$ \\
\hline \multirow{6}{*}{ 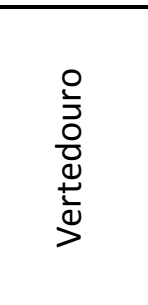 } & 1.1 & A1 & $\mathrm{C} 1$ \\
\hline & 1.2 & A3 & C3 \\
\hline & 1.3 & A4 & $\mathrm{C} 2$ \\
\hline & 1.4 & A2 & $\mathrm{C} 3$ \\
\hline & 1.5 & A3 & $\mathrm{C} 2$ \\
\hline & 1.6 & A4 & $\mathrm{C} 3$ \\
\hline \multirow{20}{*}{ 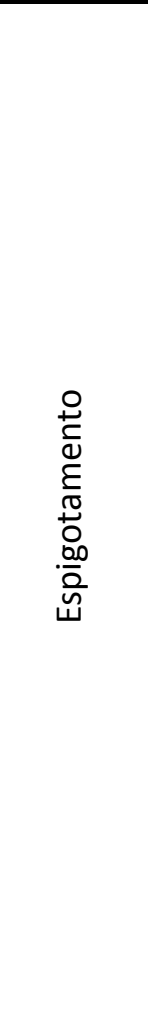 } & 2.1 & $\mathrm{~A} 1$ & $\mathrm{C} 1$ \\
\hline & 2.2 & A1 & $\mathrm{C} 2$ \\
\hline & 2.3 & A1 & $\mathrm{C} 3$ \\
\hline & 2.4 & A1 & $\mathrm{C} 4$ \\
\hline & 2.5 & $\mathrm{~A} 2$ & $\mathrm{C} 1$ \\
\hline & 2.6 & A2 & $\mathrm{C} 2$ \\
\hline & 2.7 & A2 & $\mathrm{C} 3$ \\
\hline & 2.8 & A2 & $\mathrm{C} 4$ \\
\hline & 2.9 & A3 & $\mathrm{C} 1$ \\
\hline & 2.10 & A3 & $\mathrm{C} 2$ \\
\hline & 2.11 & A3 & $\mathrm{C} 3$ \\
\hline & 2.12 & A3 & $\mathrm{C} 4$ \\
\hline & 2.13 & A4 & $\mathrm{C} 1$ \\
\hline & 2.14 & A4 & $\mathrm{C} 2$ \\
\hline & 2.15 & A4 & $\mathrm{C} 3$ \\
\hline & 2.16 & A4 & $\mathrm{C} 4$ \\
\hline & 2.17 & A5 & $\mathrm{C} 1$ \\
\hline & 2.18 & A5 & $\mathrm{C} 2$ \\
\hline & 2.19 & A5 & $\mathrm{C} 3$ \\
\hline & 2.20 & A5 & $\mathrm{C} 4$ \\
\hline
\end{tabular}

As combinações para a amostra do vertedouro foram realizadas de forma aleatória. O estágio A1 da amostra do vertedouro não pode ser considerado confiável, pois não chegou ao estado estacionário. A análise 1.1 foi realizada para demonstrar que o estágio que não atinge o estado estacionário fornece resultados incorretos.

Para a amostra do espigotamento foram realizadas todas as combinações possíveis. Verificou-se que os resultados correspondentes a uma análise são bastante próximos aos de outra análise, pois todos os estágios chegaram a condição estacionária.

A Tabela 4.5, apresenta os resultados dos ensaios que são dados de entrada para o programa SICTA. 
Tabela 4.5 - Dados de entrada para o programa SICTA.

\begin{tabular}{|c|c|c|c|c|c|c|c|c|c|c|c|c|}
\hline Amostra & Análise & $\begin{array}{c}\gamma_{w} \\
\left(\mathrm{kN} / \mathrm{m}^{3}\right)\end{array}$ & $\begin{array}{c}\gamma_{S} \\
\left(\mathbf{k N} / \mathbf{m}^{3}\right)\end{array}$ & $H_{0}(\mathrm{~m})$ & $e_{0}$ & $\begin{array}{c}\sigma^{\prime}{ }_{o} \\
(\mathbf{k P a})\end{array}$ & $v(\mathrm{~m} / \mathrm{s})$ & $\boldsymbol{H}_{f}(\mathbf{m})$ & $\begin{array}{c}\sigma^{\prime}{ }_{b} \\
(\mathbf{k P a})\end{array}$ & $e_{L}$ & $\begin{array}{c}\sigma^{\prime}{ }_{L} \\
(\mathbf{k P a})\end{array}$ & $k_{L}(\mathbf{m} / \mathbf{s})$ \\
\hline \multirow{6}{*}{ 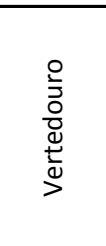 } & 1.1 & 9,81 & 27,10 & 0,049 & 15,81 & 0,088 & $4,97 \times 10^{-7}$ & 0,0352 & 0,649 & 2,920 & 36,58 & $6,92 \times 10^{-9}$ \\
\hline & 1.2 & 9,81 & 27,10 & 0,049 & 15,81 & 0,088 & $4,97 \times 10^{-7}$ & 0,0302 & 1,049 & 2,360 & 88,33 & $3,30 \times 10^{-9}$ \\
\hline & 1.3 & 9,81 & 27,10 & 0,049 & 15,81 & 0,088 & $6,21 \times 10^{-7}$ & 0,0302 & 1,250 & 2,920 & 36,58 & $6,18 \times 10^{-9}$ \\
\hline & 1.4 & 9,81 & 27,10 & 0,049 & 15,81 & 0,088 & $6,21 \times 10^{-7}$ & 0,0302 & 1,250 & 2,360 & 88,33 & $3,30 \times 10^{-9}$ \\
\hline & 1.5 & 9,81 & 27,10 & 0,049 & 15,81 & 0,088 & $7,46 \times 10^{-7}$ & 0,0297 & 1,250 & 2,920 & 36,58 & $6,18 \times 10^{-9}$ \\
\hline & 1.6 & 9,81 & 27,10 & 0,049 & 15,81 & 0,088 & $7,46 \times 10^{-7}$ & 0,0297 & 1,250 & 2,360 & 88,33 & $3,30 \times 10^{-9}$ \\
\hline \multirow{20}{*}{ 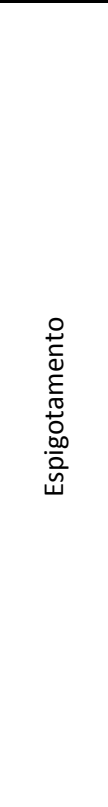 } & 2.1 & 9,81 & 26,58 & 0,0533 & 11,37 & 0,089 & $2,48 \times 10^{-7}$ & 0,0423 & 0,526 & 3,07 & 18,05 & $1,71 \times 10^{-8}$ \\
\hline & 2.2 & 9,81 & 26,58 & 0,0533 & 11,37 & 0,089 & $2,48 \times 10^{-7}$ & 0,0423 & 0,526 & 3,05 & 18,05 & $1,76 \times 10^{-8}$ \\
\hline & 2.3 & 9,81 & 26,58 & 0,0533 & 11,37 & 0,089 & $2,48 \times 10^{-7}$ & 0,0423 & 0,526 & 2,28 & 52,68 & $6,37 \times 10^{-9}$ \\
\hline & 2.4 & 9,81 & 26,58 & 0,0533 & 11,37 & 0,089 & $2,48 \times 10^{-7}$ & 0,0423 & 0,526 & 2,28 & 52,68 & $7,40 \times 10^{-9}$ \\
\hline & 2.5 & 9,81 & 26,58 & 0,0533 & 11,37 & 0,089 & $3,73 \times 10^{-7}$ & 0,0412 & 0,736 & 3,07 & 18,05 & $1,71 \times 10^{-8}$ \\
\hline & 2.6 & 9,81 & 26,58 & 0,0533 & 11,37 & 0,089 & $3,73 \times 10^{-7}$ & 0,0412 & 0,736 & 3,05 & 18,05 & $1,76 \times 10^{-8}$ \\
\hline & 2.7 & 9,81 & 26,58 & 0,0533 & 11,37 & 0,089 & $3,73 \times 10^{-7}$ & 0,0412 & 0,736 & 2,28 & 52,68 & $6,37 \times 10^{-9}$ \\
\hline & 2.8 & 9,81 & 26,58 & 0,0533 & 11,37 & 0,089 & $3,73 \times 10^{-7}$ & 0,0412 & 0,736 & 2,28 & 52,68 & $7,40 \times 10^{-9}$ \\
\hline & 2.9 & 9,81 & 26,58 & 0,0533 & 11,37 & 0,089 & $4,97 \times 10^{-7}$ & 0,0403 & 0,976 & 3,07 & 18,05 & $1,71 \times 10^{-8}$ \\
\hline & 2.10 & 9,81 & 26,58 & 0,0533 & 11,37 & 0,089 & $4,97 \times 10^{-7}$ & 0,0403 & 0,976 & 3,05 & 18,05 & $1,76 \times 10^{-8}$ \\
\hline & 2.11 & 9,81 & 26,58 & 0,0533 & 11,37 & 0,089 & $4,97 \times 10^{-7}$ & 0,0403 & 0,976 & 2,28 & 52,68 & $6,37 \times 10^{-9}$ \\
\hline & 2.12 & 9,81 & 26,58 & 0,0533 & 11,37 & 0,089 & $4,97 \times 10^{-7}$ & 0,0403 & 0,976 & 2,28 & 52,68 & $7,40 \times 10^{-9}$ \\
\hline & 2.13 & 9,81 & 26,58 & 0,0533 & 11,37 & 0,089 & $6,21 \times 10^{-7}$ & 0,0393 & 1,226 & 3,07 & 18,05 & $1,71 \times 10^{-8}$ \\
\hline & 2.14 & 9,81 & 26,58 & 0,0533 & 11,37 & 0,089 & $6,21 \times 10^{-7}$ & 0,0393 & 1,226 & 3,05 & 18,05 & $1,76 \times 10^{-8}$ \\
\hline & 2.15 & 9,81 & 26,58 & 0,0533 & 11,37 & 0,089 & $6,21 \times 10^{-7}$ & 0,0393 & 1,226 & 2,28 & 52,68 & $6,37 \times 10^{-9}$ \\
\hline & 2.16 & 9,81 & 26,58 & 0,0533 & 11,37 & 0,089 & $6,21 \times 10^{-7}$ & 0,0393 & 1,226 & 2,28 & 52,68 & $7,40 \times 10^{-9}$ \\
\hline & 2.17 & 9,81 & 26,58 & 0,0533 & 11,37 & 0,089 & $7,46 \times 10^{-7}$ & 0,0390 & 1,496 & 3,07 & 18,05 & $1,71 \times 10^{-8}$ \\
\hline & 2.18 & 9,81 & 26,58 & 0,0533 & 11,37 & 0,089 & $7,46 \times 10^{-7}$ & 0,0390 & 1,496 & 3,05 & 18,05 & $1,76 \times 10^{-8}$ \\
\hline & 2.19 & 9,81 & 26,58 & 0,0533 & 11,37 & 0,089 & $7,46 \times 10^{-7}$ & 0,0390 & 1,496 & 2,28 & 52,68 & $6,37 \times 10^{-9}$ \\
\hline & 2.20 & 9,81 & 26,58 & 0,0533 & 11,37 & 0,089 & $7,46 \times 10^{-7}$ & 0,0390 & 1,496 & 2,28 & 52,68 & $7,40 \times 10^{-9}$ \\
\hline
\end{tabular}

A Tabela 4.6 apresenta os resultados do programa SICTA para ambas as amostras.

Observa-se um significativa diferença na análise 1.1 com relação às outras análises realizadas para a amostra do vertedouro. Foram realizados cálculos da media, desvio padrão e coeficiente de variação para os resultados das amostras do vertedouro e espigotamento. Sendo desconsiderado para este cálculo os resultados da análise 1.1. Os resultados são apresentados na Tabela 4.7. 
Tabela 4.6 - Parâmetros constitutivos determinados a partir das análises.

\begin{tabular}{|c|c|c|c|c|c|c|}
\hline Amostra & Análise & $A$ & $\boldsymbol{B}$ & $Z$ (kPa) & $C(\mathrm{~m} / \mathrm{s})$ & $D$ \\
\hline \multirow{6}{*}{ 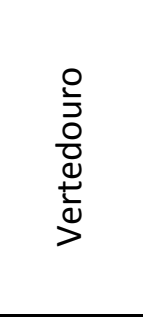 } & 1.1 & 8,551 & $-0,298$ & 0,128 & $2,94 \times 10^{-10}$ & 2,984 \\
\hline & 1.2 & 7,618 & $-0,261$ & 0,061 & $2,75 \times 10^{-10}$ & 2,884 \\
\hline & 1.3 & 7,828 & $-0,274$ & 0,077 & $2,78 \times 10^{-10}$ & 2,896 \\
\hline & 1.4 & 7,847 & $-0,268$ & 0,073 & $2,70 \times 10^{-10}$ & 2,908 \\
\hline & 1.5 & 7,624 & $-0,267$ & 0,065 & $2,23 \times 10^{-10}$ & 3,101 \\
\hline & 1.6 & 7,648 & $-0,262$ & 0,063 & $2,33 \times 10^{-10}$ & 3,080 \\
\hline \multirow{20}{*}{ 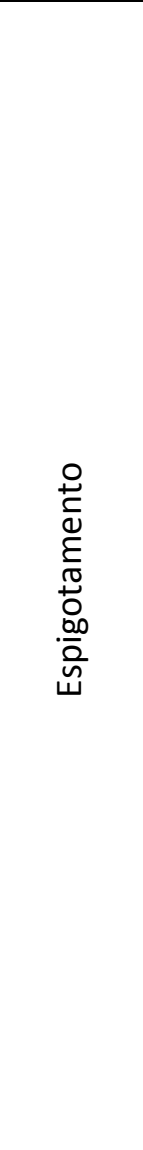 } & 2.1 & 7,066 & $-0,286$ & 0,190 & $8,50 \times 10^{-10}$ & 2,675 \\
\hline & 2.2 & 7,067 & $-0,289$ & 0,192 & $9,34 \times 10^{-10}$ & 2,631 \\
\hline & 2.3 & 7,059 & $-0,284$ & 0,187 & $6,22 \times 10^{-10}$ & 2,819 \\
\hline & 2.4 & 7,066 & $-0,285$ & 0,188 & $7,92 \times 10^{-10}$ & 2,708 \\
\hline & 2.5 & 7,213 & $-0,293$ & 0,212 & $8,39 \times 10^{-10}$ & 2,686 \\
\hline & 2.6 & 7,219 & $-0,296$ & 0,215 & $9,25 \times 10^{-10}$ & 2,641 \\
\hline & 2.7 & 7,198 & $-0,289$ & 0,206 & $6,16 \times 10^{-10}$ & 2,832 \\
\hline & 2.8 & 7,210 & $-0,290$ & 0,208 & $7,85 \times 10^{-10}$ & 2,717 \\
\hline & 2.9 & 7,383 & $-0,301$ & 0,239 & $8,47 \times 10^{-10}$ & 2,677 \\
\hline & 2.10 & 7,394 & $-0,304$ & 0,243 & $9,35 \times 10^{-10}$ & 2,630 \\
\hline & 2.11 & 7,353 & $-0,295$ & 0,228 & $6,17 \times 10^{-10}$ & 2,829 \\
\hline & 2.12 & 7,371 & $-0,295$ & 0,230 & $7,89 \times 10^{-10}$ & 2,711 \\
\hline & 2.13 & 7,436 & $-0,304$ & 0,247 & $8,32 \times 10^{-10}$ & 2,693 \\
\hline & 2.14 & 7,451 & $-0,307$ & 0,252 & $9,20 \times 10^{-10}$ & 2,645 \\
\hline & 2.15 & 7,393 & $-0,296$ & 0,234 & $6,09 \times 10^{-10}$ & 2,845 \\
\hline & 2.16 & 7,417 & $-0,297$ & 0,237 & $7,81 \times 10^{-10}$ & 2,724 \\
\hline & 2.17 & 7,747 & $-0,318$ & 0,299 & $8,54 \times 10^{-10}$ & 2,671 \\
\hline & 2.18 & 7,770 & $-0,321$ & 0,305 & $9,45 \times 10^{-10}$ & 2,621 \\
\hline & 2.19 & 7,670 & $-0,305$ & 0,275 & $6,17 \times 10^{-10}$ & 2,830 \\
\hline & 2.20 & 7,702 & $-0,306$ & 0,280 & $7,92 \times 10^{-10}$ & 2,707 \\
\hline
\end{tabular}

Tabela 4.7 - Parâmetros constitutivos determinados a partir das análises.

\begin{tabular}{|c|c|c|c|c|c|c|}
\hline Amostra & Cálculo Estatístico & $A$ & $\boldsymbol{B}$ & $Z$ (kPa) & $C(\mathrm{~m} / \mathrm{s})$ & $D$ \\
\hline \multirow{3}{*}{ 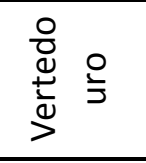 } & Média & 7,713 & $-0,266$ & 0,068 & $2,56 \times 10^{-10}$ & 2,974 \\
\hline & Desv. Padrão (\%) & $1,14 \mathrm{E}-01$ & $5,26 \mathrm{E}-03$ & $6,96 \mathrm{E}-03$ & $2,58 \mathrm{E}-11$ & 1,07E-01 \\
\hline & Coef. Variação (\%) & 1,48 & $-1,97$ & 10,28 & 10,08 & 3,60 \\
\hline \multirow{3}{*}{ 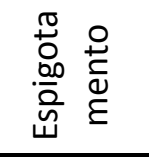 } & Média & 7,359 & $-0,298$ & 0,233 & $7,95 \times 10^{-10}$ & 2,715 \\
\hline & Desv. Padrão (\%) & $2,29 E-01$ & $1,01 E-02$ & $3,56 \mathrm{E}-02$ & $1,18 \mathrm{E}-10$ & $7,52 \mathrm{E}-02$ \\
\hline & Coef. Variação (\%) & 3,11 & $-3,39$ & 15,24 & 14,90 & 2,77 \\
\hline
\end{tabular}

Os maiores valores de coeficiente de variação foram obtidos pelo parâmetro $Z$. Apesar deste alto valor, são as curvas de compressibilidade e condutividade hidráulica que 
tornam o ensaio aceitável ou não. Para cada conjunto de parâmetros $(A, B, Z, C$ e $D)$ correspondentes a uma análise, utilizando a Equação 2.4, foram calculados os valores de índices de vazios em função de tensões efetivas. Da mesma forma, foram calculados os valores de condutividade hidráulica em função de índice de vazios. As curvas que representam as características de compressibilidade (índice de vazios versus tensão efetiva) e condutividade hidráulica (condutividade hidráulica versus índice de vazios) para o material do vertedouro estão mostradas na Figura 4.8 e Figura 4.9, respectivamente.

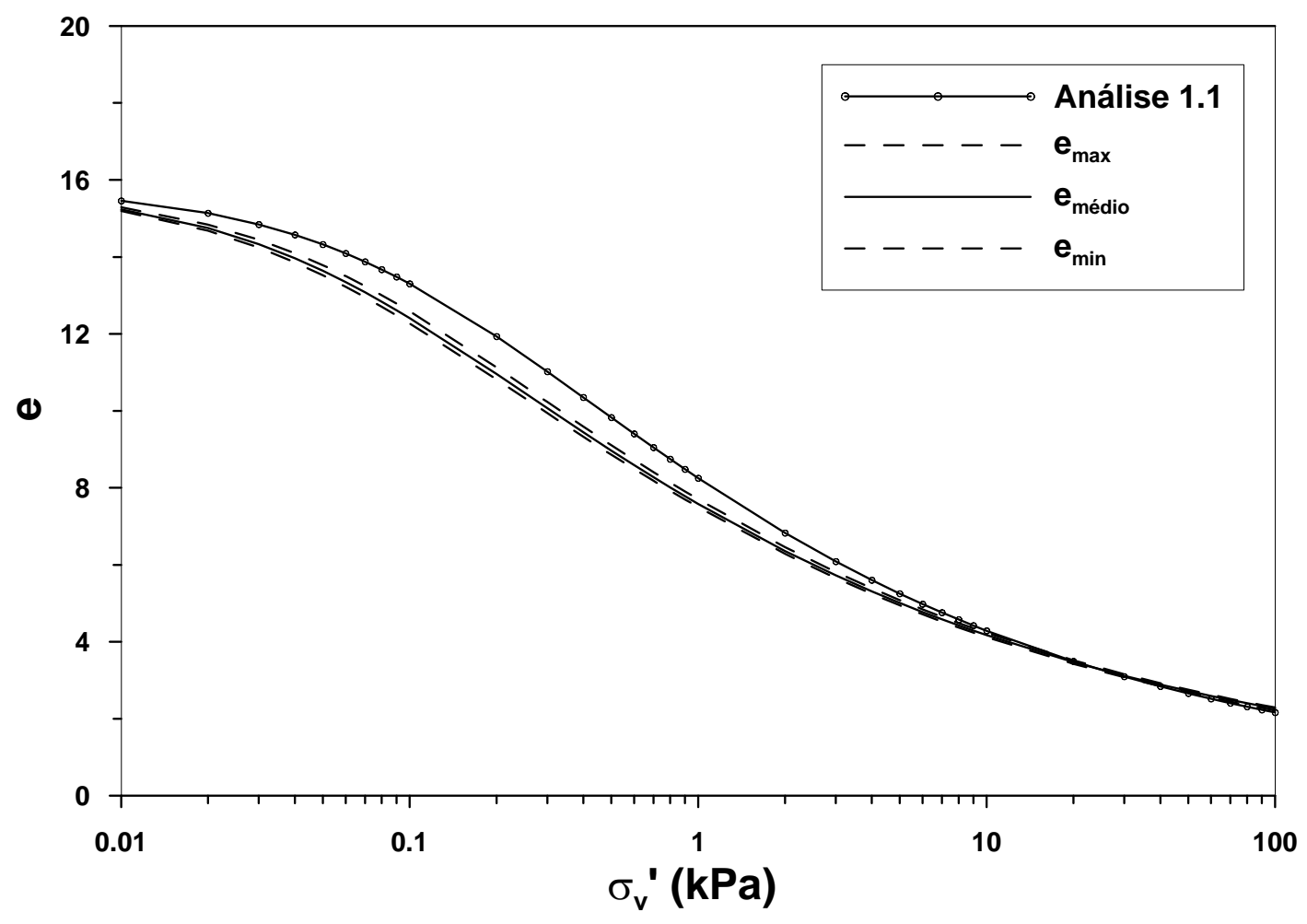

Figura 4.8 - Curvas de compressibilidade (amostra vertedouro) 


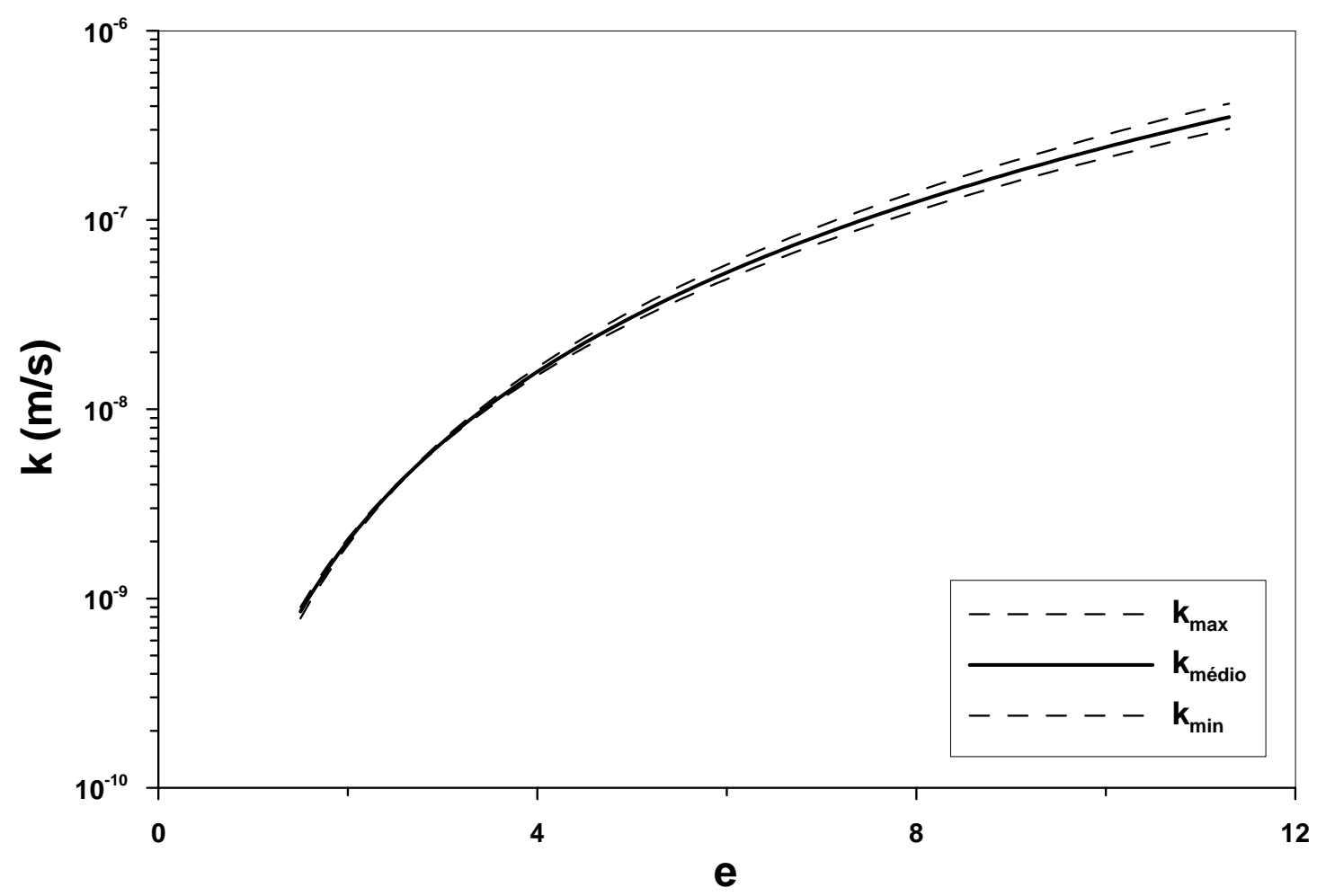

Figura 4.9 - Curvas de condutividade hidráulica (amostra vertedouro)

Analisando a Figura 4.8, observa-se uma boa concordância entre as análises, pois foi obtida uma faixa muito curta de valores máximos e mínimos para a mesma tensão efetiva vertical. Observa-se que conforme o esperado, uma única combinação de ensaios seria suficiente para se determinar as curvas de compressibilidade e condutividade hidráulica do material. Observa-se que a Análise 1.1 apresentou uma discordância acentuada para a faixa de índice de vazios entre 4 e 16. Esse resultado é justificado pela escolha do primeiro estagio de adensamento (A1) para a realização da análise. Durante a realização do ensaio A1 não foi obtida uma diferença de pressão constante. É importante que durante os ensaios seja atingida uma condição estacionária.

Ao analisar a Figura 4.9 observa-se uma boa concordância para os valores de condutividade hidráulica, que apresentam a mesma ordem de grandeza de coeficiente de condutividade hidráulica para os mesmos índices de vazios. Também é observada a formação 
de uma estreita faixa de valores entre os coeficientes de condutividade hidráulica máximos e mínimos para o mesmo índice de vazios.

A Figura 4.10 apresenta as curvas de compressibilidade e a Figura 4.11 apresenta as curvas de condutividade hidráulica para o material do espigotamento.

Para as amostras da região do espigotamento foram realizados os cálculo das faixas de valores para as 20 análises. Foram traçado os valores máximo, mínimo e médio para os ensaios de compressibilidade e condutividade hidráulica.

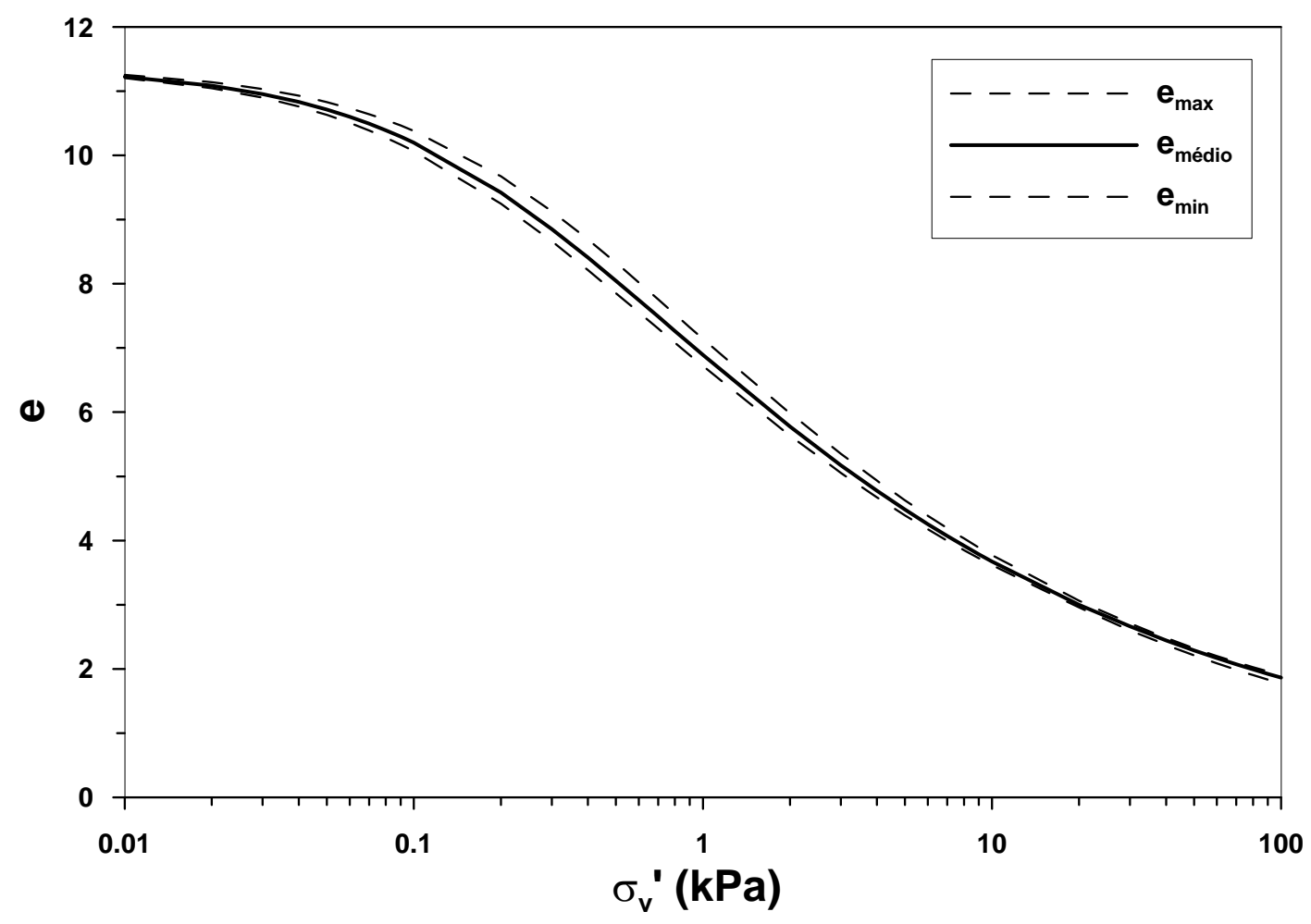

Figura 4.10 - Curvas de compressibilidade (amostra espigotamento) 


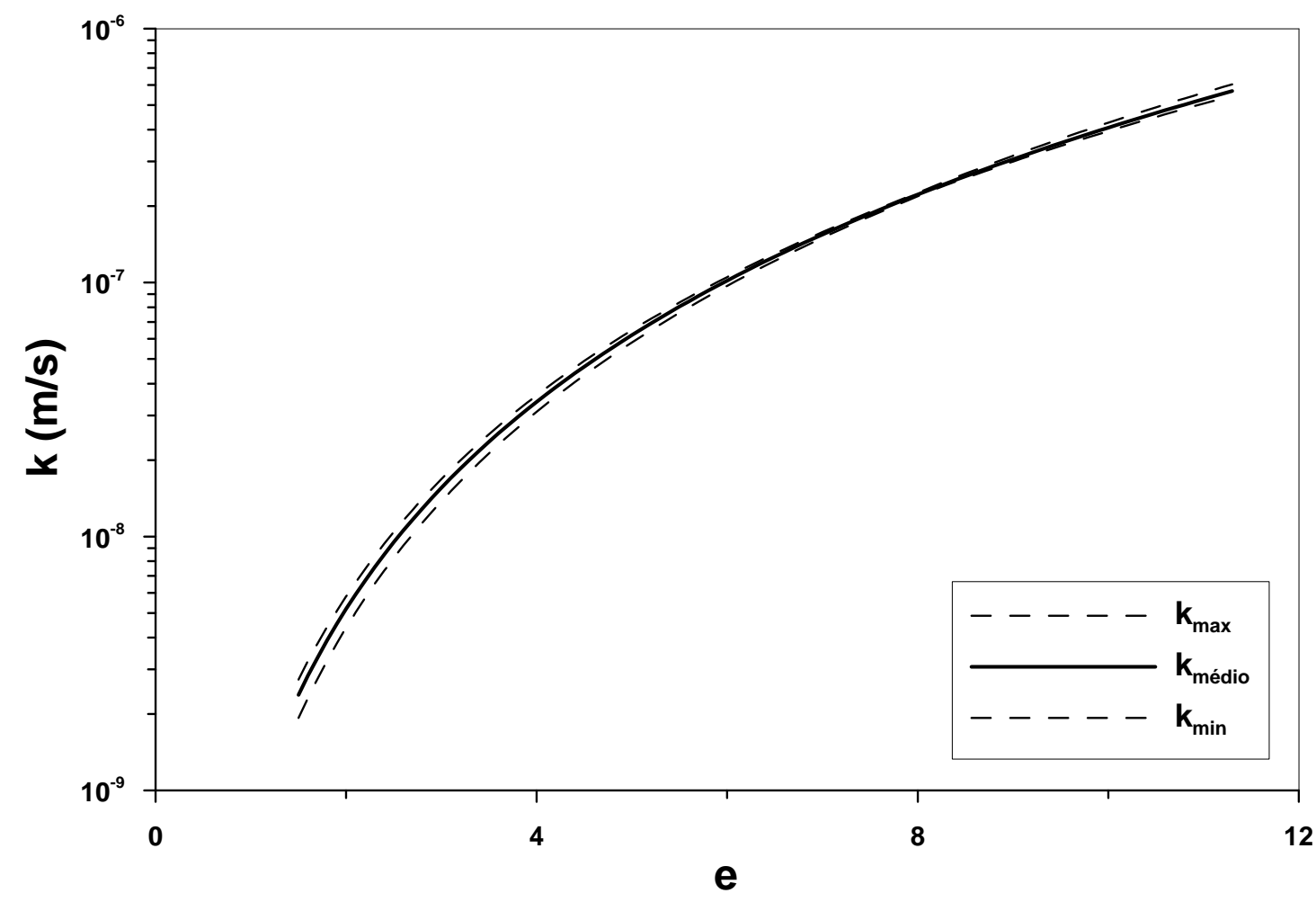

Figura 4.11 - Curvas de condutividade hidráulica (amostra espigotamento)

Os resultados de ambas as amostras foram bastante satisfatórios. Apesar de o material ser de uma mesma lagoa observa-se certa diferença no traçado das curvas de compressibilidade e condutividade hidráulica.

\subsection{ENSAIO DA REFLECTOMETRIA NO DOMÍNIO DO TEMPO (TDR)}

\subsubsection{Calibração da sonda TDR}

A calibração da sonda foi realizada numa faixa de teor de umidade entre $80 \%$ e 200\%, encontradas em campo. A Figura 4.12 apresenta a curva de calibração que é uma função polinomial de terceiro grau ajustada aos pontos experimentais. 


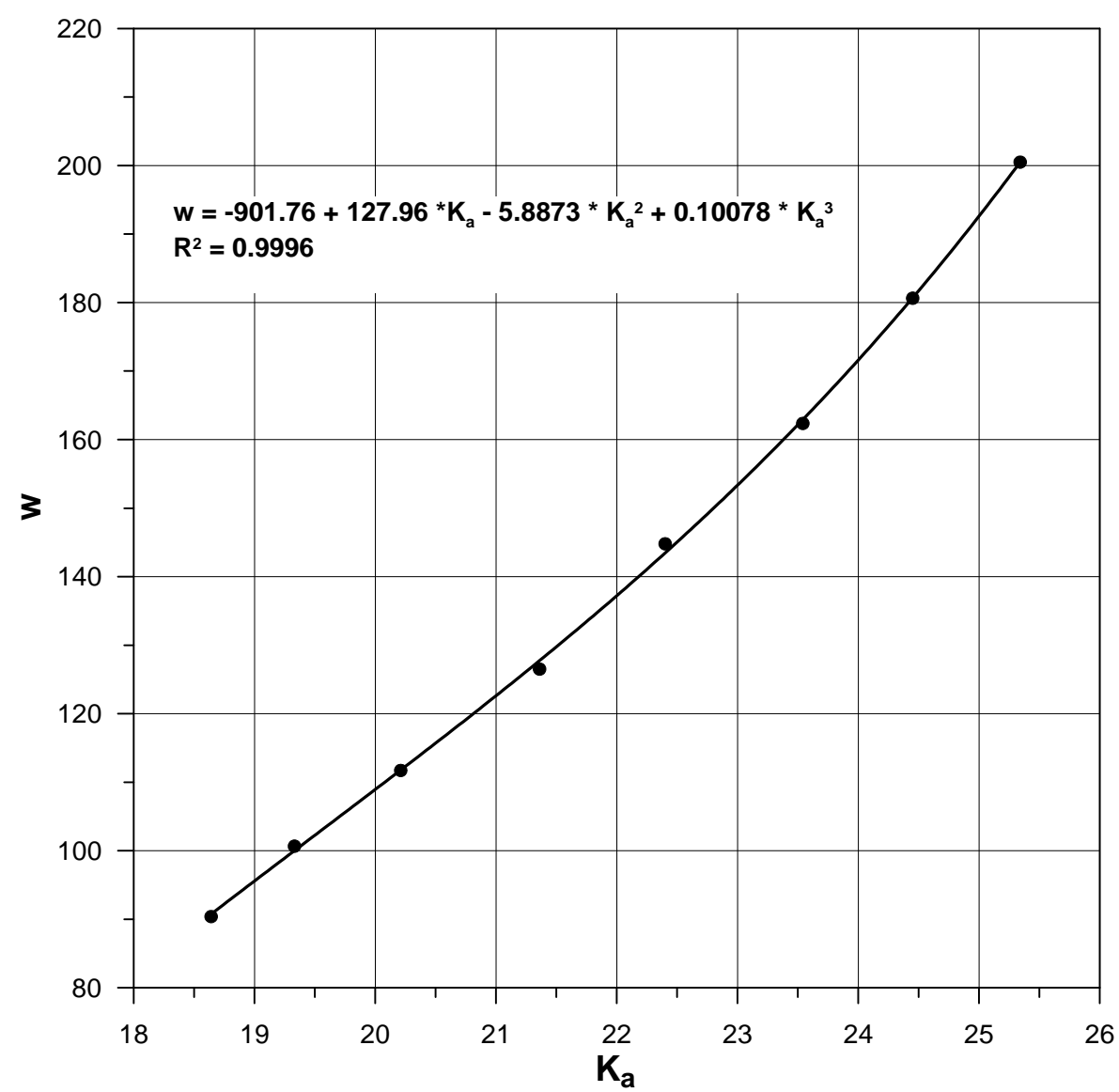

Figura 4.12 - Curva de Calibração da Sonda TDR com o rejeito.

Observa-se que a curva obteve um bom ajuste, com um coeficiente de determinação igual a 0.9996. Este resultado esta de acordo com os obtidos por Assis (2008).

\subsubsection{Ensaio de Campo}

Durante a realização das sondagens na lagoa de rejeitos observou-se a presença de uma lâmina de água de aproximadamente $0,2 \mathrm{~m}$, indicando a saturação do material. Está condição foi levada em consideração para o cálculo das tensões efetivas em função da profundidade.

As leituras foram realizadas entre as cotas 648,9 m (topo do rejeito) e 643,9 m, com um espaçamento de $0,5 \mathrm{~m}$ ao longo do eixo vertical, ou seja, foram realizadas dez 
leituras para cada uma das cinco sondagens. A origem do eixo da profundidade (z) está na cota 648,9 m. As profundidades (z) 0,5 m e 5 m correspondem às cotas 648,4 e 643,9.

Os valores com as estimativas dos teores de umidade, utilizando a técnica TDR, em todas as sondagens são apresentado na Tabela 4.8, assim como o cálculo da Média, Desvio Padrão e Coeficiente de Variação $\left(C_{v}\right)$ dos valores de umidade para cada profundidade.

Tabela 4.8 - Resultados das sondagens.

\begin{tabular}{|c|c|c|c|c|c|c|c|c|c|}
\hline \multirow{2}{*}{ Cota (m) } & \multirow{2}{*}{$\begin{array}{l}\text { Prof. (z) } \\
\text { (m) }\end{array}$} & \multicolumn{5}{|c|}{ Estimativa do Teor de Umidade (\%) nas sondagens } & \multirow{2}{*}{ Média } & \multirow{2}{*}{$\begin{array}{l}\text { Desvio } \\
\text { Padrão }\end{array}$} & \multirow{2}{*}{$\begin{array}{c}\text { Coef. } \\
\text { Variação }\end{array}$} \\
\hline & & S1 & $\mathrm{S} 2$ & S3 & $\mathrm{S} 4$ & S5 & & & \\
\hline 648,4 & 0,5 & 147,47 & 145,54 & 145,00 & 148,82 & 136,59 & 144,68 & 4,78 & 3,30 \\
\hline 647,9 & 1 & 160,63 & 166,00 & & 144,47 & 136,40 & 140,44 & 5,71 & 4,06 \\
\hline 647,4 & 1,5 & 134,06 & & & 138,14 & 125,65 & 132,62 & 6,37 & 4,80 \\
\hline 646,9 & 2 & 124,96 & 120,42 & 12 & 126,36 & 121,53 & 123,62 & 2,52 & 2,04 \\
\hline 646,4 & 2,5 & 127,98 & & & 124,21 & 129,83 & 127,34 & 2,86 & 2,25 \\
\hline 645,9 & 3 & 129,77 & 9,58 & 13620 & 130,45 & 116,78 & 131,52 & 3,20 & 2,43 \\
\hline 645,4 & 3,5 & 125,51 & & & 113,00 & 117,72 & 118,74 & 6,32 & 5,32 \\
\hline 644,9 & 4 & 119,23 & 115,55 & 111,04 & 120,04 & 122,11 & 117,59 & 4,36 & 3,71 \\
\hline 644,4 & 4,5 & 101,13 & & & 111,50 & 109,69 & 107,44 & 5,54 & 5,16 \\
\hline 643,9 & 5 & 101,00 & 101,06 & 123,12 & & & 101,03 & 0,04 & 0,04 \\
\hline
\end{tabular}

Estes valores de teores de umidade foram estimados através da curva de calibração obtida em laboratório. Observar que alguns pontos não possuem leitura, este fato deve-se a problemas com o equipamento durante a realização dos ensaios. Outro ponto que vale destacar é que foram desconsideradas as leituras em negrito por se apresentarem bastante longe de uma tendência de valores para a mesma profundidade.

Com os valores da Tabela 4.8 foi traçado um gráfico para melhor entendimento do comportamento do material ao longo da profundidade (Figura 4.13). 


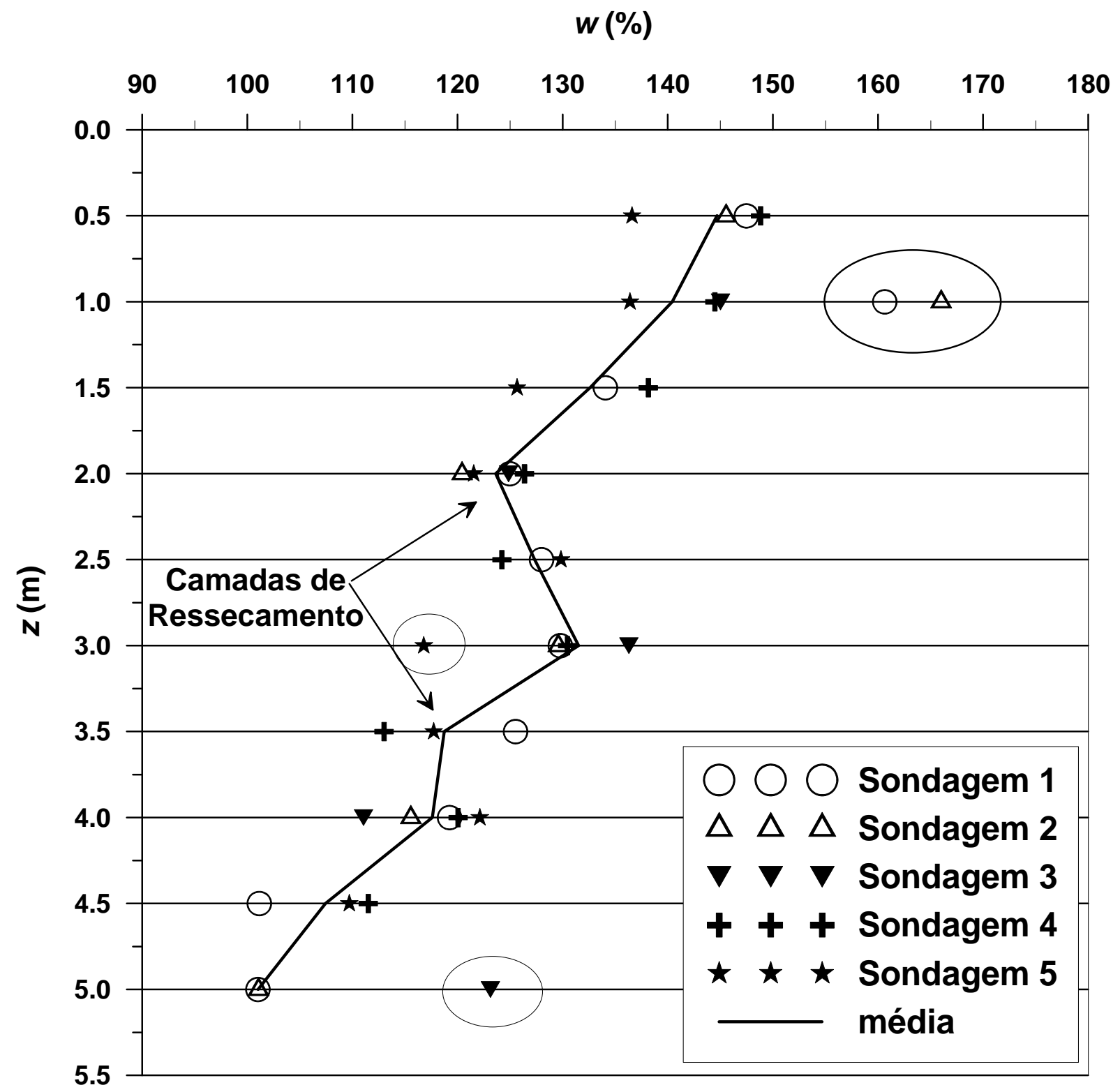

Figura 4.13 - Valores de teores de umidade estimados pela técnica TDR.

Observa-se na Figura 4.13 que alguns pontos estão visivelmente fora de uma curva de tendência. Estes pontos estão destacados por elipses. Estas anomalias são justificadas pela ocorrência de problemas com o equipamento durante a realização destas leituras. Foi então realizado um ajuste com a média dos valores de umidade obtidos nas sondagens. Com essa média foi ajustada uma linha de tendência

Outro fator que chama a atenção é a brusca redução do teor de umidade próximo a a profundidade de dois metros. O aparecimento desta anomalia pode ser justificado pela 
forma de deposição da lama. O rejeito é lançado no reservatório até a cota máxima do vertedouro. $\mathrm{O}$ material superficial além de sofrer com o processo de consolidação, também sofre com o processo de ressecamento pela ação do sol. Este processo promove a abertura de fissuras favorecendo ainda mais o ressecamento deste material superficial. O resultado deste processo é a formação de uma crosta de material ressecado, que mesmo após encoberto por outra camada de rejeito fluido, irá apresentar um menor teor de umidade.Um outra eventual explicação para esta anomalia seria o fato da distribuição de poropressões não ser hidrostática

Com os valores de teores de umidade estimados foram determinados para cada profundidade o índice de vazios $(e)$, massa especifica do solo $(\rho)$, massa especifica seca do solo $\left(\rho_{d}\right)$, peso específico saturado $\left(\gamma_{\text {Sat }}\right)$, poro pressão $(u)$, tensão total $(\sigma)$ e tensão efetiva $\left(\sigma^{\prime}\right)$. Estes valores que estão apresentados na Tabela 4.9 foram determinados com as equações mostradas no item 3.3.5.

Tabela 4.9 - Resultados das sondagens.

\begin{tabular}{ccccccccc}
\hline Cota & $\mathrm{w}_{\mathrm{TDR}}(\%)$ & $\mathrm{e}$ & $\rho_{d}\left(\mathrm{~g} / \mathrm{cm}^{3}\right)$ & $\rho\left(\mathrm{g} / \mathrm{cm}^{3}\right)$ & $\gamma_{S A T}\left(\mathrm{kN} / \mathrm{m}^{3}\right)$ & $u(\mathrm{kPa})$ & $\sigma(\mathrm{kPa})$ & $\sigma^{\prime}(\mathrm{kPa})$ \\
\hline 648,40 & 144,68 & 4,00 & 0,54 & 1,33 & 13,02 & 6,87 & 8,47 & 1,60 \\
647,90 & 140,44 & 3,88 & 0,56 & 1,34 & 13,10 & 11,77 & 15,02 & 3,25 \\
647,40 & 132,62 & 3,66 & 0,58 & 1,35 & 13,26 & 16,68 & 21,65 & 4,97 \\
646,90 & 123,62 & 3,42 & 0,61 & 1,37 & 13,47 & 21,58 & 28,38 & 6,80 \\
646,40 & 127,34 & 3,52 & 0,60 & 1,36 & 13,38 & 26,49 & 35,07 & 8,59 \\
645,90 & 131,52 & 3,63 & 0,58 & 1,35 & 13,28 & 31,39 & 41,72 & 10,32 \\
645,40 & 118,74 & 3,28 & 0,63 & 1,38 & 13,59 & 36,30 & 48,51 & 12,21 \\
644,90 & 117,59 & 3,25 & 0,64 & 1,39 & 13,62 & 41,20 & 55,32 & 14,11 \\
644,40 & 107,44 & 2,97 & 0,68 & 1,42 & 13,90 & 46,11 & 62,27 & 16,16 \\
643,90 & 101,03 & 2,79 & 0,71 & 1,44 & 14,10 & 51,01 & 69,31 & 18,30 \\
\hline
\end{tabular}




\subsubsection{Comparação dos resultados HCT e TDR}

Com os valores calculados e mostrados na Tabela 4.9 foram plotados os pontos $(e$ versus $\sigma^{\prime}$ ) correspondentes a cada profundidade em campo. Com esses valores pode-se comparar os resultados obtidos no ensaio HCT, mais especificamente com a curva de compressibilidade medida para cada amostra. Foram usadas as médias das curvas de compressibilidade das amostras do vertedouro e do espigotamento.

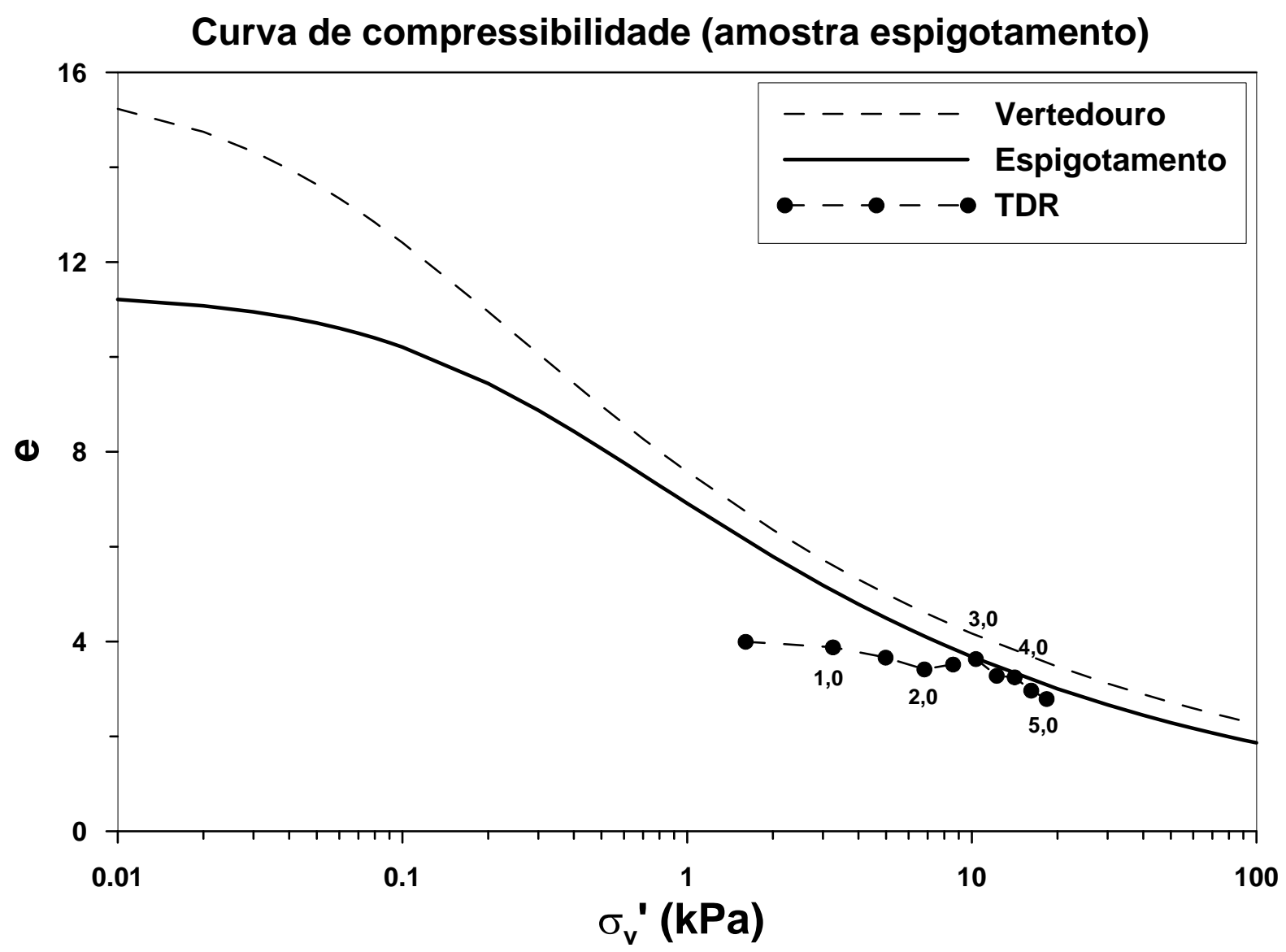

Figura 4.14 - Comparação dos resultados obtidos em laboratório e campo.

Observa-se que para tensões verticais efetivas superiores a $10 \mathrm{kPa}$ existe uma maior aproximação dos pontos determinados em campo com os obtidos em laboratório. As análises de laboratório que mais se aproximaram dos resultados de campo foram as das 
amostras do espigotamento, apesar das sondagens terem sido realizadas na região do vertedouro. Caso fossem consideradas as poropressões reais, ao invés das poropressões hidrostáticas adotada nos cálculos, os resultados poderiam ser mais próximos.

\subsubsection{Validação da técnica TDR em campo}

Com o intuito de validar a utilização da técnica TDR em campo foram coletadas amostras, em diferentes pontos da lagoa de contenção, limitando-se a uma profundidade de 0,5 m. Nesses pontos foram realizadas novas leituras e retiradas de amostras para determinação do teor de umidade pelo método gravimetrico. Os resultados estão apresentados na Tabela 4.10.

Tabela 4.10 - Verificação da técnica TDR em campo

\begin{tabular}{ccccc}
\hline Furo & $\mathbf{K}_{\mathbf{a}}$ & $\mathbf{w}_{\text {TDR }}$ & $\mathbf{w}_{\text {grav. (\%) }}$ & $\left(\mathbf{w}_{\text {grav }}-\mathbf{w}_{\mathbf{T D R}}\right)$ \\
\hline 1 & 15,79 & 66,34 & 58,13 & $-8,21$ \\
2 & 21,94 & 135,97 & 133,77 & $-2,19$ \\
3 & 14,86 & 60,98 & 63,36 & 2,38 \\
4 & 17,39 & 78,96 & 73,93 & $-5,03$ \\
5 & 19,66 & 103,31 & 96,77 & $-6,55$ \\
6 & 14,53 & 59,25 & 57,38 & $-1,87$ \\
7 & 17,04 & 75,87 & 73,80 & $-2,08$ \\
8 & 16,15 & 68,82 & 65,57 & $-3,25$ \\
9 & 18,41 & 88,88 & 82,45 & $-6,44$ \\
10 & 17,64 & 81,28 & 76,66 & $-4,61$ \\
11 & 19,16 & 97,32 & 90,56 & $-6,76$ \\
\hline & & $\sum\left(\mathrm{w}_{\text {grav }}-\mathrm{w}_{\text {TDR }}\right)^{2}$ & 272,62 \\
& & $\sum\left(\mathrm{w}_{\text {grav }}-\mathrm{w}_{\text {TDR }}\right)^{2} / \mathrm{n}$ & 24,78 \\
\cline { 3 - 5 } & & Erro Padrão $(\%)$ & 4,98 \\
\cline { 2 - 4 } & & \multicolumn{3}{c}{}
\end{tabular}

A Tabela 4.10 apresenta uma comparação entre os valores de teores de umidade obtidos pelo método gravimétrico e os valores de umidade estimados pela técnica TDR. Ao comparar os resultados foi obtido um erro padrão próximo a 5\%. Este valor de erro padrão é 
próximo à aquele encontrado por Assis (2008). A proximidade dos valores também pode ser mostrada na Figura 4.14.

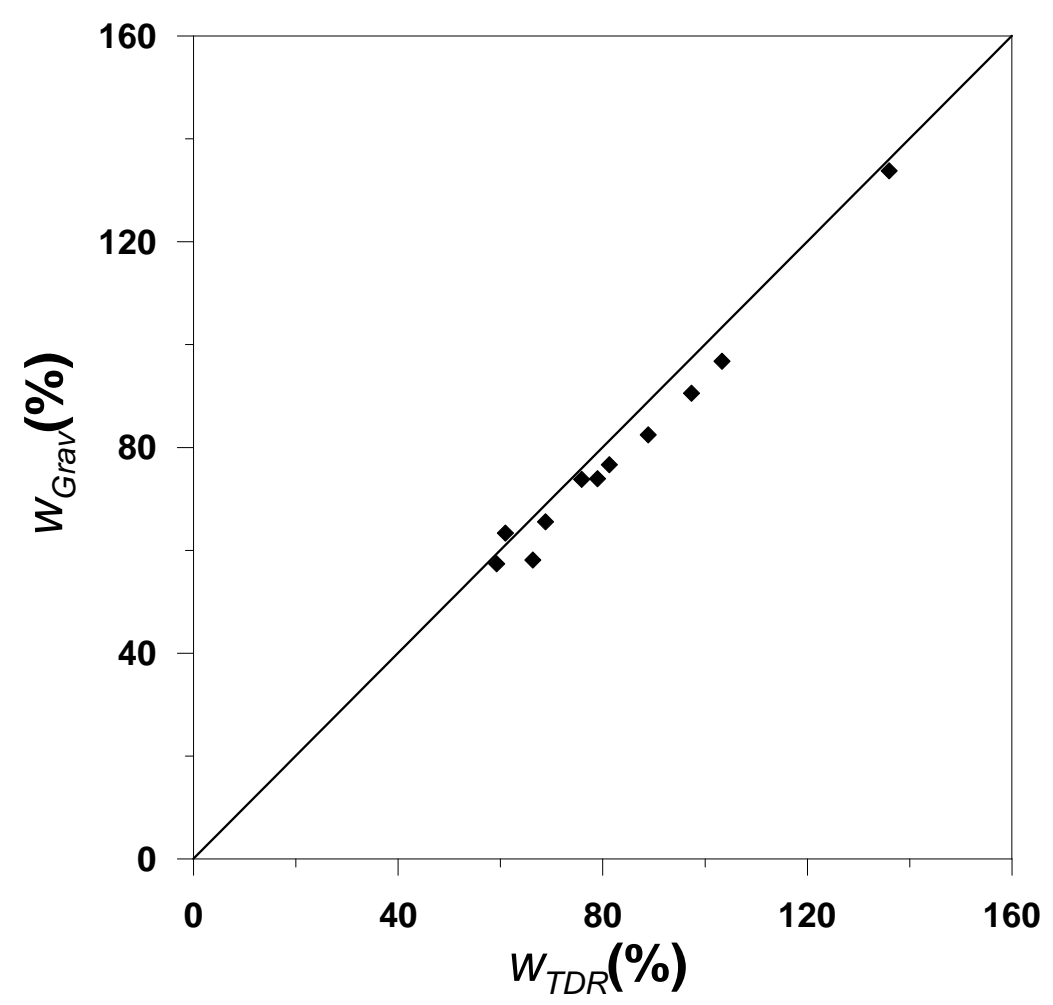

Figura 4.15 - Comparação entre os teores e umidade gravimétrico e estimado pela técnica TDR.

Cabe ressaltar que este procedimento foi realizado com uma cavadeira tipo concha. As amostras foram coletadas durante um período chuvoso, fator que pode ter influenciado a representatividade das amostras. Outro importante fator está associado à presença de água próxima a superfície dado o elevado nível do lençol freático, podendo haver contaminação das amostras, justificando ainda o erro padrão. 


\section{CONCLUSÕES E RECOMENDAÇÕES}

\subsection{CONSIDERAÇÕES FINAIS}

Em empreendimentos de mineração é muito importante o dimensionamento adequado dos reservatórios onde serão lançados os rejeitos oriundos do processo produtivo, em virtude dos grandes volumes envolvidos. As características de compressibilidade e condutividade hidráulica dos rejeitos podem ser obtidas através de relações empíricas baseadas no conhecimento anterior do comportamento de inúmeros rejeitos, através de dados coletados de campo; ou em ensaios de laboratório.

Nesta pesquisa foi utilizada a técnica de laboratório HCT para obter as características de compressibilidade e condutividade hidráulica de um rejeito fino. Os resultados de compressibilidade desta técnica foram comparados com a curva de compressibilidade calculada com as estimativas de umidade feita pela técnica TDR.

\subsection{CONCLUSÕES}

O resultado principal deste trabalho foi a implantação da técnica HCT no departamento de Geotecnia da EESC/USC. Foram comparados os resultados da técnicas HCT 
e TDR no monitoramento do processo de consolidação de um rejeito argiloso proveniente de uma mineração de areia localizada no município de Descalvado/SP:

- O ensaio HCT com bomba de fluxo realizado em materiais argilosos possui um tempo de execução menor quando comparado com os ensaios convencionais, porém requere um período de, no mínimo, três dias, conforme destacados nas metodologias apresentadas por Znidarcic et. al. (1992) e Botelho (2001).

- Devido à amostra utilizada nesta pesquisa já se encontrar saturada em campo, não foi utilizada o sistema de contrapessão para saturar a amostra.

- Observou-se uma melhor determinação do estado estacionário, adotando o seguinte critério: ao chegar num estagio inicial de diferença de pressão constante para um determinada vazão deve ser mantida este fluxo por um período de no mínimo mais duas horas. Este procedimento irá confirmar que este ensaio chegou ao estado estacionário para a vazão estudada.

- O ensaio HCT apresentou melhores resultados para as amostras do espigotamento com relação às amostras do vertedouro, fator que se deve ao uso do procedimento citado no item anterior;

- A presente pesquisa obteve bons resultados para diferença de pressão de até $1,5 \mathrm{kPa}$ durante a etapa de consolidação hidráulica. Este valor está dentro do intervalo recomendado por Znidarcic et. al. (1992) sendo entre 0,3 e $10 \mathrm{kPa}$,

- Os resultados com o ensaio HCT se mostraram bastante confiáveis, pois foram repetidos exaustivamente e realizadas todas as combinações possíveis. Estas combinações obtiveram resultados (parâmetros das equações que governam o processo de consolidação) bastante próximos; 
- A técnica TDR utilizada em campo mostrou-se promissora para a finalidade de monitoramento do processo de consolidação em reservatórios de materiais finos e de elevada compressibilidade. Esta técnica além de apresentar bons resultados obteve resultados em tempo real avaliando a condição de consolidação do material in sittu;

- A validação da sonda TDR em campo apresentou valores de erro padrão próximo a 5\%, que é considerado aceitável ao comparar com o trabalho realizado por Assis (2008), que utilizou a mesma sonda para estudar os solos da região de São Carlos/SP;

- As curvas de compressibilidade obtidas pelo ensaio HCT mostraram-se bastante próximas das curvas de compressibilidade obtidas em campo com o auxílio da técnica TDR;

\subsection{RECOMENDAÇÕES PARA TRABALHOS FUTUROS}

Recomendam-se para trabalhos futuros, melhorias no equipamento HCT como:

- Instalação de um transdutor de deslocamento submersível, no interior da célula triaxial, tornado possível a leitura da altura do corpo de prova de uma maneira precisa e direta, mesmo durante a fase de consolidação hidráulica.

- $\mathrm{Na}$ impossibilidade de realização do item anterior uma alternativa seria realizar as leituras utilizando um sistema a laser;

- É recomendado também a instalação de uma célula de carga submersível, no interior da célula triaxial, tornando mais precisa a determinação das tensões verticais atuantes na superfície superior do corpo de prova; 
- Como medida de cautela é recomendada o uso de uma fonte de energia auxiliar (no-break) para o caso de interrupções momentâneas de energia. Esta medida evitará perda de dados, pois o ensaio durante as fases mais importantes de aquisição de dados (etapa de consolidação e condutividade hidráulica) tem duração de no mínimo 2 dias;

- Compra de uma seringa metálica para uso da contrapressão ao se estudar amostras secas que necessitem ser saturadas;

Para futuras pesquisas também é recomendado

- Acoplar a sonda TDR um sensor de poropressão, de modo que seja possível efetuar leituras das poropressões, simultaneamente com as estimativas de teor de umidade;

- Realizar uma campanha de ensaios laboratorial mais extensa, para verificar a influência de alguns fatores, tais como: índice de vazios inicial, altura inicial da amostra e a influência da vazão imposta pela bomba de fluxo na formação das curvas de compressibilidade, permeabilidade e na formação de canais de fluxo no interior da amostra;

- Utilização de outros ensaios laboratoriais como o ensaio de consolidação com taxa de deslocamento constante (CRD) para a comparação com os resultados obtidos pelo HCT;

- Realização de novas campanhas de sondagens em diferentes pontos da lagoa, assim como em diferentes épocas do ano para se ter uma idéia do processo de consolidação da lagoa;

- Usar os dados obtidos no item anterior para gerar um modelo tridimensional do processo de consolidação no reservatório; 
- Durante o processo de enchimento do reservatório, ensaios de sondagem piezométrica são mais recomendados para a obtenção das leis de compressibilidade e de permeabilidade dos rejeitos in situ.

- Fazer uma cava experimental instrumentada para realização de um maior controle da amostra realizando também o estudo das propriedades de ressecamento seguindo os detalhes do trabalho de Silva D. R. (2003); 


\section{REFERÊNCIAS}

ABU-HEJLEH, A. N. E ZNIDARCIC, D. (1992). User manual for computer program SICTA. Department of Civil, Environmental and Architectural Engineering, University of Colorado, 101 p., Boulder, Colorado.

ABU-HEJLEH, A. N., ZNIDARCIC, D. E BARNES, B. L. (1996). Consolidation characteristics of phosphatics clays. Journal of Geotechnical Engineering, ASCE, v. 122, no 4, p. 295-301.

AIBAN, S.A E ZNIDARCIC, D. (1989). "Evaluation of the flow pump and constant head techniques for permeability measurements." Geotechnique, 39 (i4), p 655-666.

ASSIS, A. E ESPÓSITO, T. (1995). Construção de barragens de rejeitos sob uma visão geotécnica. In: simpósio sobre barragens de rejeitos e disposição de resíduos REGEO'95, 3., Ouro Preto, MG. Anais. Ouro Preto, MG: ABMS/ABGE/CBGB, 1995. p. 259-273. v.1.

ASSIS, C. D., (2008). Avaliação de uma Sonda TDR Helicoidal para a Estimativa do Teor de Umidade dos Solos em Campo e Laboratório. 2008. 178 f. Dissertação (Mestrado) Escola de Engenharia de São Carlos, Universidade de São Paulo, São Carlos.

ASSOCIAÇÃO BRASILEIRA DE NORMAS TÉCNICAS. NBR 6459 - Solo: Determinação do Limite de Liquidez. Rio de Janeiro, ABNT, 1984.

ASSOCIAÇÃO BRASILEIRA DE NORMAS TÉCNICAS. NBR 6508 - Grãos de Solos que Passam na Peneira de 4,9mm: Determinação da Massa Específica. Rio de Janeiro, ABNT, 1984.

ASSOCIAÇÃO BRASILEIRA DE NORMAS TÉCNICAS. NBR 7180 - Solo: Determinação do Limite de Plasticidade. Rio de Janeiro, ABNT, 1984. 
ASSOCIAÇÃO BRASILEIRA DE NORMAS TÉCNICAS. NBR 7181 - Solo: Análise Granulométrica. Rio de Janeiro, ABNT, 1984.

ÁVILA, J.P. E SOARES, R. (1995). A simulação numérica do adensamento de rejeitos finos por métodos numéricos: aplicação aos rejeitos de bauxita da Mineração Rio do Norte em Porto Trombetas. III Simpósio Sobre Barragens de Rejeitos e Disposição de Resíduos REGEO’95, Ouro Preto, Minas Gerais.

BEEN, K. E SILLS, G. C. (1981). Self-weight consolidation of soft soils: an experimental and theoretical study. Géotechnique, v. 31, nº 4, p. 519-535.

BOTELHO, A. P. D., (2001). Implementação de metodologias de ensaios para determinação de relações constitutivas de processos de fluxo em solos com a utilização da bomba de fluxo. Dissertação de Mestrado, Departamento de Engenharia Civil, Universidade Federal de Ouro Preto, 242p., Ouro Preto, Minas Gerais, 2001.

BURKE, H. H., (1973). Structural characteristics resulting from construction methods: tailing disposal today. In: INTERNATIONAL TAILING SYMPOSIUM, 1., Tucson, Arizona, 1973. Proceedings...Tucson, Arizona: Miller Freeman Publications, 1973. p. 211-223.

CAETANO-CHANG, M. R. \& WU, F. T. (2006). Arenitos flúvio-eólicos da porção superior da formação pirambóia no centro-leste paulista. Revista Brasileira de Geociências, V. 36, p. 296-304.

CONCIANI W., HERRMANN JR. P.S.P, MACHADO S.L. E SOARES M.M., (1996). Uso da técnica de reflectometria no domínio do tempo (TDR) para a determinação da umidade do solo in situ. Solos e Rochas, São Paulo, 19 (3), 189 -199, Dez., 1996.

DASBER, S. AND HOPMANS,J.W., (1992) Time Domain Reflectometry calibration for uniformly na nonuniformly wetted sandy and clayey loam soils. Soil Science Society of America Journal, v.56, p. 1341 -1345.

DAVIS, J.L. AND CHUDOBIAK,W.J., (1975). In situ meter for measuring relative permittivity of soils. Geology Survey of Canadá, Part A, Paper 75 -1, p.75 -79. 
DOBSON, M. C.,; UlABY F. T.; HALliKAINEN, M. T.; EL -RAYES, M. A., (1985). Microwave dieletric behavior of wet soil II. Dieletric mixing models. IEEE. Transactions Geoscience Remote Sensors, v.23, p. 35 -46.

DOWDING D.G. E HUANG F.C., (1994). Early detection of rock movement with time domain reflectometry. ASCE, Journal of Geotechnical Engineering, v. 120, n.8, p. 1413 1427.

ESQUIVEL, E.R., (2001). Desenvolvimento de técnica para determinação das propriedades de adensamento de materiais argilosos moles. Relatório FAPESP 96/10608-9 e 9702847-6. Fundação Amparo à Pesquisa do Estado de Estado o São Paulo, 2001.

ESQUIVEL, E.R., (2006). Desenvolvimento de uma sonda baseada na reflectometria no domínio de tempo (TDR) para a determinação in situ do teor de umidade e condutividade elétrica dos solos. Relatório FAPESP 04/13273-6. Fundação Amparo à Pesquisa do Estado de Estado o São Paulo, 2006.

GERSEVANOV, N. M. (1934). Dinamika Mekhaniki Gruntov (Foundation of Doil Mechanics), 2, Gros- stroiisdat.

GIBSON, R. E., ENGLAND, G. L. E HUSSEY, M. J. L. (1967). The theory of onedimensional consolidation of saturated clays: I. finite non-linear consolidation of thin homogeneous layers. Géotechnique, v. 17, nº 3, p. 261-273.

GIBSON, R. E., SCHIFFMAN, R. L. E CARGILL, K. W. (1981). The theory of onedimensional consolidation of saturated clays: II. Finite nonlinear consolidation of thick homogeneous layers. Canadian Geotechnical Journal, v.18, p. 280-293.

GOBARA, W., PINTO, C. S. E DE SÍLVIO, E. (1995). Obtenção de parâmetros para dimensionamento de reservatórios para disposição de rejeitos pelo ensaio HCT. $3^{\text {o }}$ Simpósio sobre Barragens de Rejeitos e Disposição de Resíduos, REGEO’95, v. 1, p. 1 14, Ouro Preto, MG.

GORDON, R. P., (1998). A Guide to the Management of Tailings Facilities. The Mining Association of Canada. 
HALLIKAINEN, M. T.; ULABY F. T.; DOBSON, M.; EL -RAYES, M. A. WU, L., (1985). Microwave dieletric behavior of wet soil, Part I. Empirical models and experimental observations. . IEEE. Transactions Geoscience Remote Sensors, v.23, n.1, p.25 -34.

HERKELRATH, W. N.; HAMBURG, S. P.; MURTHY, F., (1991). Automatic, real-time monitoring of soil moisture in a remote field area with time domain reflectometry. Water Resources Research. V. 27, nº. 5, p. 857-864.

IMAI, G. (1979). Development of a new consolidation test procedure using seepage force. Soils and Foundations, Jap. Soc. SMFE, 19 (3), p 45-60.

JONES, S.B., WRAITH J.M. AND OR, D., (2002). Time domain reflectometry measurement principles and applications. Hydrological Processes. 16, 141 -153.

KLEMUNES JR., J., (1998). Determining soil volumetric moisture content using time domain reflectometry. Report No. FHWA -RD -97 -139, Ofice of Engineering R\&D, Federal Highway Administration, McLean, 1998.

KUJALA K. AND RAVASKA O., (1994). Soil water content measurement with time domain reflectometer. ICSMFE, 13, New Delhi, v. 1, p. 219 -224.

LIU, J. C. (1990). Determination of soft soil characteristics. PhD. Thesis, Department of Civil, Environmental and Architectural Engineering, University of Colorado, 297 p, Boulder, Colorado.

LIU, J. C. AND ZNIDARCIC, D. (1991). Modeling one-dimensional compression characteristics of soils. Journal of Geotechnical Engineering, 117 (i1), p 162-169.

LOOK, B. AND REEVES, I.,(1982). The application of time domain reflectometry of measurement on unfrozen water content in frozen soils. Cold Region Science Technology, v.3, p.205 -210.

MANSUKHANI, S. AND SELIG, E. T., (1975). Relationship of soil moisture to the dieletric property. Journal of the Geotechnical Engineering Division, v.101, n.8, p.755 -770.

MIKASA, M. (1963). The Consolidation of Soft Clay- A New Consolidation Theory and Its Application Kajima Shuppankai, Tokyo ( in Japanese, with summary in English). 
NIEBLE, C. M E ROCHA, R. S.,(1976). Método construtivo usa rejeitos para construir barragem de deposição. Construção Pesada, São Paulo, v. 6, n. 70, p 90-96.

NISSEN, H. H.; MOLDRUP, P.; HENRIKSEN, K., (1998). High-Resolution time domain reflectometry coil probe for measuring soil water content. Soil Science Society America Journal. V. 62, p. 1203-1211.

OLSEN, H. W. (1966). Darcy’s law saturated kaolinite. Water Resources Research, v. 2, nº 2, p. $287-295$.

OR, D.; JONES, S. B.; VANSHAAR, J. R.; HUMPHRIES, S.; KOBERSTEIN, L., (2003). WintTDR Soil Analysis Software - Users Guide. Utah State University, Plants, Soils \& Biometeorology, Logan.

PANE, V. (1985). Sedimentation and consolidation clays. PhD. Thesis, Universtity of Colorado, Department of Civil, Environmental and Architectural Engineering, Boulder, 302 p, Colorado, USA.

PANE, V. AND SCHIFFMAN, R.L., (1981). A comparison between two theories of finite strain consolidation. Soil and Foundations, 21 (4), p 81-84.

PERSSON, M.; WRAITH, J. M., (2002). Shaft-mounted time domain reflectometry probe for water content and electrical conductivity measurements.Vadose Zone Journal. V.1, p. 316-319.

RADA, G. R., ELKINS, G. E., HENDERSON, B., VAN SAMBEEK, B., LOPEZ JR., A.,(1994). LTTP seasonal monitoring program: instrumentation, installation and data collection inêselines, Mc Lean: U S Department of Transportation, 70p.

ROTH, K.; SCHULIN, R.; FLULER, H.; ATTINGER, W., (1990). Calibration of time domain reflecometry for water content measurement using a composite dieletric approach. Water Resouces Research, v.26, n.10, p.2267 -2273.

SANCHEZ, L. E. (2000) Manejo de residuos sólidos en mineria. In: CURSO INTERNACIONAL DE ASPECTOS GEOLÓGICOS DE PROTECCIÓN AMBIENTAL, 2., 2000, Campinas. Notas de classes Montevideo. Montevideo: UNESCO, p 249-250. 
SCHIFFMAN, R. L., VICK, S. G. AND GIBSON, R. E. (1988). Behavior and properties of hydraulic fills. Hydraulic Fill Structures, D. J. A . Zyl e S. G. Vick, Eds., Geotechnical Special Publication, ASCE, v. 21, p. 166-202.

SCOTT, M. G.; PHANG, W. A.; PATTERSON, D. E., (1983). Developments in situ monitoring os moisture in pavement structures by time domais reflectometry (TDR). Ontário: The Transportation Technology and Energy Branch, 85p.

SILVA, D. R.,(2003). Estudo do processo de ressecamento de um rejeito fino de minério de ferro em uma área teste. Dissertação de Mestrado, Departamento de Engenharia Civil, Universidade Federal de Ouro Preto, 141p., Ouro Preto, Minas Gerais, 2003.

SOMOGYI, F. (1979). Analysis and prediction of phosphatic clay consolidation: implementation package", Technical Report, Florida Phosphatic Clay Research Project, Lakeland, Florida, USA.

TOMMASELLI, J. T. G., (1997). Influência de algumas características do solo sobre a calibração de um aparelho TDR. Piracicaba, 1997. 109p. Tese (Doutorado) - Centro de Energia Nuclear na Agricultura, Universidade de São Paulo.

TOPP, G.C. ; LAPEN, D. R. ; EDWARDS, M . J. ; YOUNG, G. D., (2003). Laboratory calibration, in field validation and use of a soil penetrometer measuring cone resistance and water content. Soil Science Society of America Journal. P. 633-641.

TOPP, G.C., DAVIS J.L. E ARMAN A.N, (1980). Electromagnetic determination of soil water content: measurements in coaxial transmission line. Water Resource Research, v.16, n.3, p. $574-582$.

TOPP, G.C., E DAVIS J.L., (1985). Time -domain reflectometry (TDR) and its application to irrigation scheduling.. In D. Hillel (ed.) Advances in irrigation. Vol. 3. Academic Press, London. p. $107-127$.

TRONCOSO, J.H., (1997). Geotechnics of Tailings dams and sediments. International Congress of Environmental Geotechnics. ICEG pp.1405-1423 
VAZ, C. M. P. AND HOPMANS, J. W, (2001). Simultaneous measurements of soil penetration resistance and water content with a combined penetrometer-TDR moisture probe. Soil Science Society of America Journal. Madison: V. 65, nº.1, p. 4-12.

VICK, S. G., (1981). Siting and desing of tailings impoundments. Mining Engineering, New York, v.33, n. 6, p. 653-657.

VICK, S. G., (1983). Planning, design and analysis of tailing dams. New York: John Wiley \& Sons, $369 \mathrm{p}$.

YU, X. AND DRNEVICH, P., (2004). Soil water content and dry density by time domain reflectometry. Journal of Geotechnical and Geoenvironmental Engineering, Vol.130, No. 9, p. 922 -934.

ZNIDARCIC, D., ABU-HEJLEH, A. N., FAIRBANKS, T. E ROBERTSON, A. (1992). Seepage induced consolidation test, equipment description and users manual. Reported Prepared for Florida Institute of Phosphate Research, Department of Civil, Environmental and Architectural Engineering, University of Colorado, 63 p, Boulder, Colorado. 